\title{
APPLYING A MODIFIED VERSION OF THE THEORY OF PLANNED BEHAVIOUR TO PREDICT REACTIVE PHYSICAL AGGRESSION BETWEEN UNDERGRADUATE STUDENTS
}

\author{
by \\ Jennifer E. Newman \\ Master of Arts in Psychology, Ryerson University, 2012 \\ Bachelor of Arts in Psychology and Sociology, Wilfrid Laurier University, 2010 \\ A dissertation presented to Ryerson University \\ In partial fulfillment of the requirements for the degree of \\ Doctor of Philosophy in the Program of Psychology \\ Toronto, Ontario, Canada, 2016 \\ (C) Jennifer E. Newman 2016
}




\section{Author's Declaration Page}

I hereby declare that I am the sole author of this dissertation. This is a true copy of the dissertation, including any required final revisions, as accepted by my examiners.

I authorize Ryerson University to lend this dissertation to other institutions or individuals for the purpose of scholarly research

I further authorize Ryerson University to reproduce this dissertation by photocopying or by other means, in total or in part, at the request of other institutions or individuals for the purpose of scholarly research.

I understand that my dissertation may be made electronically available to the public. 


\begin{abstract}
Applying a modified version of the theory of planned behaviour to predict reactive physical aggression between undergraduate students

Jennifer E. Newman

Doctor of Philosophy in the Program of Psychology, 2016

Ryerson University

The current dissertation applied a modified version of the Theory of Planned Behaviour (TPB) to predict reactive physical aggression between university students. In addition to examining the primary constructs of the traditional TPB model (attitudes, subjective norms, perceived behavioural control and intentions), this dissertation extended the traditional model by also examining the impact of implicit attitudes toward aggression as well as executive functioning in the prediction of reactive physical aggression. Results provided support for the application of the traditional TPB model in the prediction of reactive physical aggression, although implicit attitudes and executive functioning did not significantly contribute to the prediction of aggressive behaviour in this sample. Gaining a better understanding of the predictors of reactive physical aggression between university students may lead to the identification of early intervention strategies for individual aggressors. This may in turn help to prevent the possible escalation of aggressive behaviour and create a safer and less threatening campus environment for all students.
\end{abstract}




\section{Acknowledgements}

I would like to thank my supervisor, Dr. David Day, for your support and mentorship throughout my training as a graduate student. I am so grateful for the countless hours you have spent helping me to develop the skills required to become a competent and autonomous

researcher. In addition to your tutelage in preparing other professional research documents, you have been exceptionally helpful in all stages of the dissertation process. I have learned so much under your guidance and feel very fortunate to have worked under your supervision. I look forward to our continued work together.

I would also like to thank the members of my dissertation committee, Dr. Becky Choma and Dr. Karl Hennig, who have each been so helpful throughout this process. I am grateful for the many hours you spent reviewing my dissertation document as well as time spent discussing conceptual and statistical issues. I believe your thoughtful feedback has significantly improved the quality of my dissertation. I would also like to thank my dissertation examination committee: Dr. John Turtle, Dr. Christopher Powell, and Dr. Jennifer Connolly, who served as the external examiner for my defense. Thank you for your thought provoking comments and questions during my examination.

Thank you to my wonderful family and friends who have supported me throughout my graduate career and played a major role in both my professional and personal development. Thank you for believing in me and always being there for me. Finally, I would like to thank the provincial and federal government who has each provided me with financial support throughout my doctoral degree. More specifically, I am grateful for funding I have received through the Ontario Graduate Scholarship as well as the Social Science and Humanities Research Council who awarded me a three-year, Joseph-Armand Bombardier Canada Graduate Scholarship. 


\section{Dedication}

I dedicate this dissertation to my mother for her constant love, support, and encouragement. You are a wonderful role model and I learn so much from you each and every day. You inspire me to reach for my dreams and have taught me that anything is possible. 


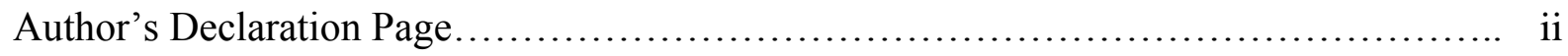

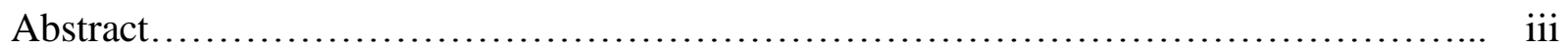

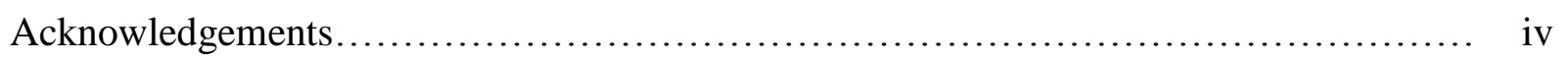

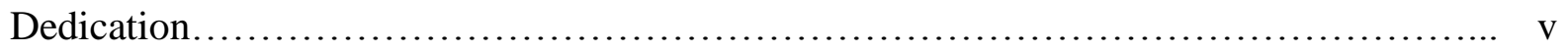

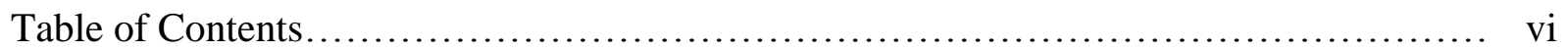

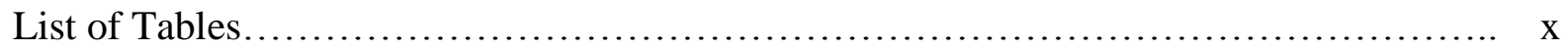

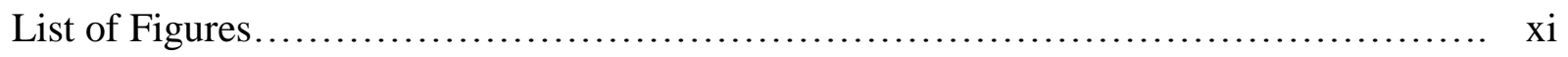

List of Appendices...................................................... xii

Chapter 1: Introduction................................................... 1

1.1 Proactive versus Reactive Physical Aggression......................... 4

1.2 Measuring Physical Aggression in the Laboratory.................... 6

1.3 Social Cognitive Theory and Physical Aggression........................ 11

1.4 The Theory of Reasoned Action (TRA) ............................ 12

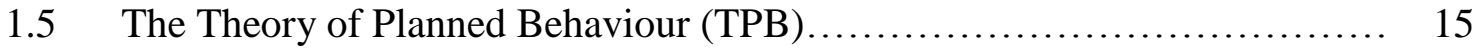

1.6 TPB and Aggressive Behaviour................................... 18

1.7 Explicit versus Implicit Measures of Attitudes in Predicting Aggressive Behaviour.................................................. 26

$1.8 \quad$ The Implicit Association Test (IAT) ................................ 29

$1.9 \quad$ IAT and Aggressive Behaviour.................................... 30

1.10 Executive Functioning as a Measure of Actual Behavioural Control......... 36

1.11 The Present Research............................................ 39

Chapter 2: Study 1: TPB Questionnaire Development............................ 43 
2.1 Method............................................................. 44

2.1.1 Participants............................................ 44

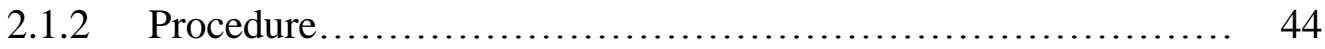

2.1.3 Data Analytic Strategy.................................... 44

$2.2 \quad$ Results............................................................ 45

2.2.1 Reliability Analysis....................................... 45

2.2.2 Principal Components Analysis ............................. 45

Chapter 3: Study 2: Test of the Modified TPB Model.................................. 49

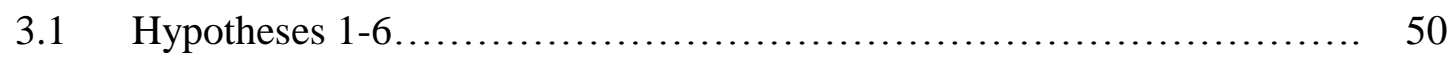

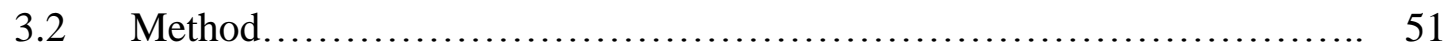

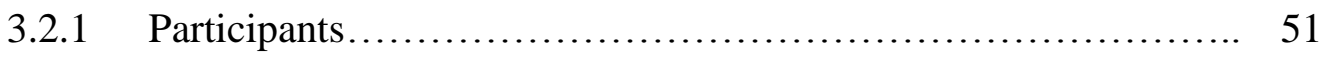

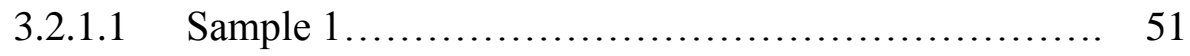

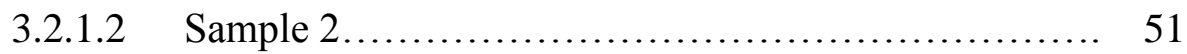

3.2.2 Measures............................................... 51

3.2.2.1 Reactive Physical Aggression........................ 51

3.2.2.2 Demographics................................... 52

3.2.2.3 Explicit Attitudes, Subjective Norms, PBC, and Intentions...................................... 52

3.2.2.4 Implicitly Measured Attitudes...................... 52

3.2.2.5 Actual Behavioural Control......................... 55

3.2.2.6 Debriefing Questions............................... 55

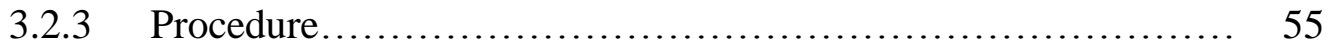

3.2.4 Data Analytic Strategy..................................... 57 
$3.3 \quad$ Results............................................................ 58

3.3.1 Preliminary Analyses..................................... 58

3.3.2 Descriptive Statistics and Correlations......................... 59

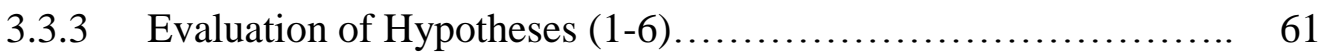

Chapter 4: Discussion.................................................................. 68

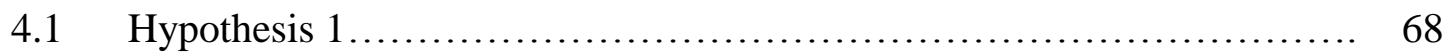

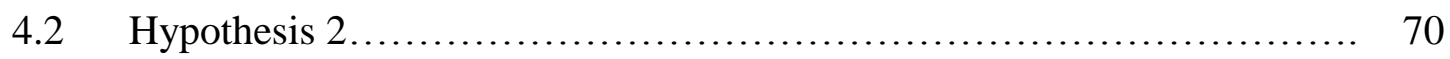

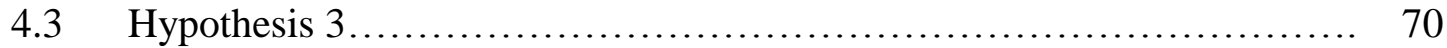

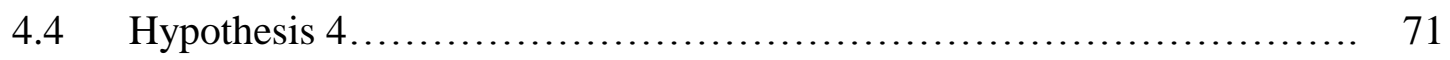

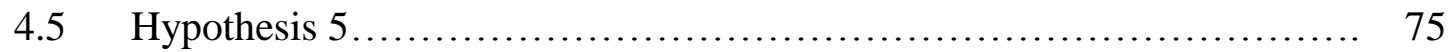

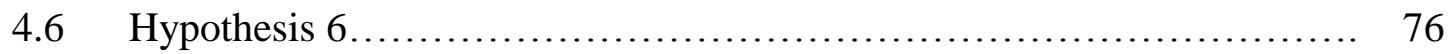

$4.7 \quad$ Limitations................................................................ 78

$4.8 \quad$ Future Directions.................................................. 81

4.9 Conclusions........................................................ 84

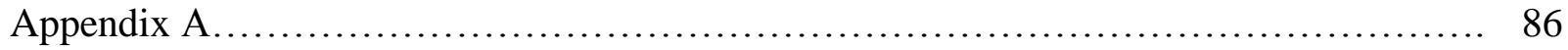

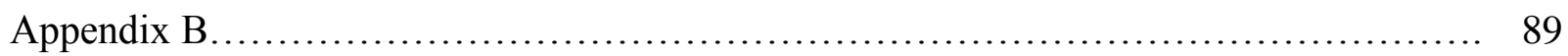

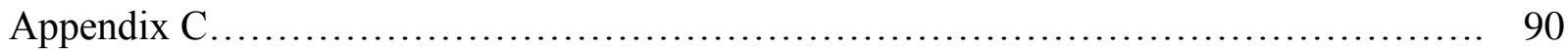

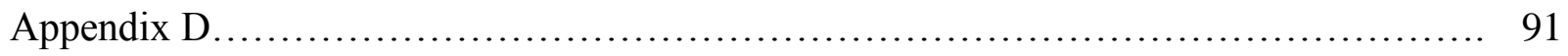

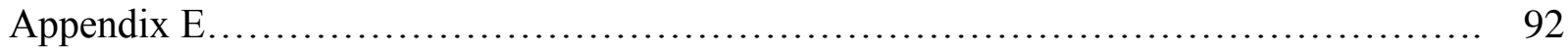

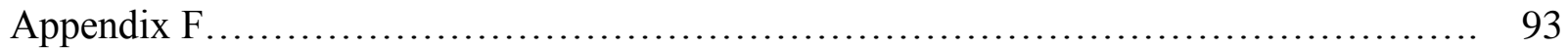

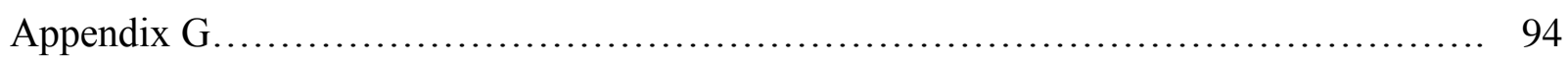

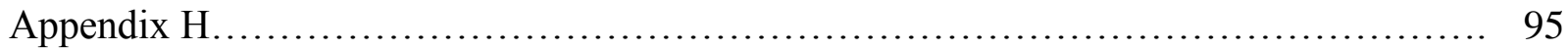

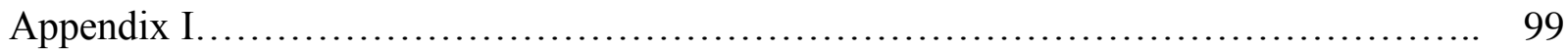




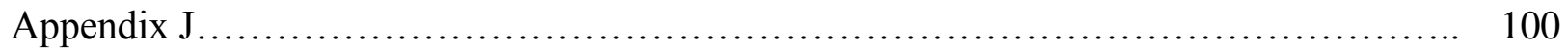

References............................................................ 101 


\section{List of Tables}

Table 1 Summary of Factor Loadings after Rotation for TPB Questionnaire.......... 48

Table 2 Reactive Aggression IAT Stimulus Items.......................... 54

Table 3 Descriptive Statistics and Pearson Correlation Matrix for Path Variables....... 60

Table 4 Standardized Direct and Indirect Effects of Predictors on Reactive Physical

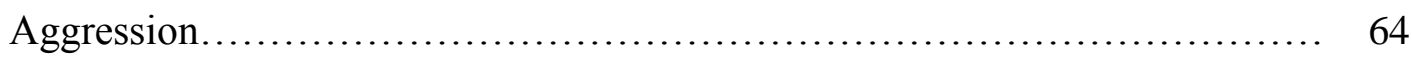

Table 5 Standardized Direct and Indirect Effects of Predictors on Reactive Physical Aggression as Moderated by Condition................................ 67 


\section{List of Figures}

Figure 1 Model of the Theory of Planned Behaviour ................................ 16

Figure 2 Modified Version of the Theory of Planned Behaviour Model.................. 40

Figure 3 Principal Components Analysis: Scree Plot................................ 47

Figure 4 Modified Version of the TPB Model Including Pathway Regression Weights... 62 


\section{List of Appendices}

Appendix A Questionnaire Development.................................... 86

Appendix B Explicit Attitudes Items...................................... 89

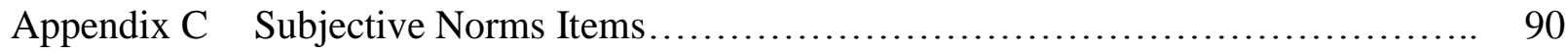

Appendix D PBC Items................................................ 91

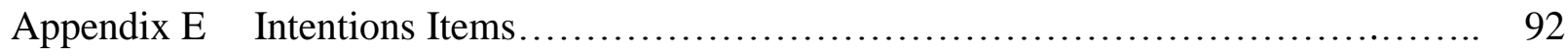

Appendix F Scenarios....................................................... 93

Appendix G Pearson Correlation Matrix for Path Variables by Condition (No

Delay/Short Delay)......................................... 94

Appendix H Manipulation Check Study...................................... 95

Appendix I Standardized Direct and Indirect Effects of Predictors on Reactive Physical Aggression as Moderated by Gender................................. 99

Appendix J Pearson Correlation Matrix for Path Variables by Gender (Male/Female)... 100 


\section{CHAPTER ONE}

\section{$\underline{\text { INTRODUCTION }}$}

Devastating acts of student violence such as the massacre at École Polytechnique, and the school shootings at Virginia Tech, the University of California, and Umpqua Community College have resulted in elevated concerns about student safety on university and college campuses in North America (Kaminski, Koons-Witt, Stewart Thompson, \& Weiss, 2010). Although these tragic events have drawn widespread attention to the problem of student violence, less serious and often unacknowledged forms of aggression are a significant concern for many university students (Tremblay et al., 2008b). This dissertation highlights the problem of aggressive behaviour in the university student population and proposes a theoretical framework for predicting reactive physical aggression between undergraduate students. Gaining a better understanding of the predictors of aggression between university students may lead to early intervention strategies and may also prevent the escalation of more serious forms of violent behaviour (De Wall, Anderson, \& Bushman, 2011).

Previous research has demonstrated that aggressive behaviour is a relatively common experience for many university students. Luckey (1999) found that 30\% of a large sample of university students attending a mid-sized university in the United States had been victims of at least one incident of violence or aggressive behaviour over the previous academic year. In that study, possible forms of violence or aggression included robbery, assault, sexual victimization, verbal aggression, domestic violence, dating violence, and hazing behaviours. More recent research on student violence and aggressive behaviour suggests that many university and college students in Canada and the United States continue to be victims of various forms of verbal, physical, and sexual violence (Tremblay, Graham, \& Wells, 2008a). 
It is important to note that the terms "aggression" and "violence" are conceptually different and exist along a continuum. Aggression is defined as "behavior directed toward another individual carried out with the proximate (immediate) intent to cause harm" (Anderson \& Huesmann, 2003, p. 298). In order for behaviour to be characterized as aggressive, the perpetrator must assume that their behaviour will harm the target (although actual harm is not required) and that the target is motivated to avoid the behaviour (Anderson \& Huesmann, 2003). In contrast, violence is understood as physical aggression that exists at the extremely high end of the aggression continuum, such as murder or serious forms of assault (Anderson \& Huesmann, 2003). Furthermore, it should be noted that all violence is aggression but not all aggression is violence. For example, delivering a blast of white noise to a partner in a social psychology experiment may be characterized as aggressive but is not thought of as violent. However, a campus shooting would be understood as both an aggressive and violent behaviour.

Much of the available research on aggressive and violent behaviours between university students has focused on sexual harassment or sexual violence perpetrated by students in stranger, acquaintance, or dating relationships (e.g., Aosved \& Long, 2005; Humphrey \& White, 2000). In a study investigating the prevalence of sexual assault at an American university, Gross, Winslett, Roberts and Gohm, (2006) found that $36 \%$ of female African American undergraduate students and $26 \%$ of White female students in the sample had experienced unwanted sexual contact since their university enrolment. The perpetrators of these acts were known to the women in all but $2 \%$ of the reported incidents.

Less explored in the research literature is the issue of physical aggression between university students. The lack of research on factors related to physical aggression between university students is problematic, given the high incidence of behaviours. A 2010 report 
released by the American College Health Association (ACHA) revealed that up to $21 \%$ of college students had experienced some form of verbal or physical aggression in the past 12 months. Furthermore, a survey of physical aggression across six Canadian universities indicated that $30 \%$ of males and $22 \%$ of female students were victims of at least one act of physical aggression in the past year or academic year (Tremblay et al., 2008a).

It appears that much of the research on physically aggressive behaviour has concentrated on non-university student populations, such as employee workplace violence (e.g., Campbell et al., 2011; Leeper Piquero, Piquero, Craig, \& Clipper, 2013), bullying in children and adolescents (e.g., Juvonen, Wang, \& Espinoza, 2013; Wei \& Jonson-Reid, 2011), or violence among correctional or forensic populations (e.g., Papadopoulos et al., 2012; Wooldredge \& Steiner, 2013). Indeed, only a small number of studies have examined factors related to physical aggression between university students, with many of these studies investigating risk factors and prevention strategies for campus shootings (Fox \& Savage, 2009) and physical aggression or violence in university students' dating relationships (Hines \& Straus, 2007; Kaukinen, 2014).

In a study examining the incidence of physical aggression in student dating relationships, Shorey et al. (2008) found that approximately $20-30 \%$ of college students confirmed using physically coercive behaviours against their partner over the previous academic year. Straus (2004) conducted a study examining prevalence rates of physical aggression in student dating relationships across 31 universities around the world. He reported that an average of $29 \%$ of respondents had used some form of physical aggression against their partner, with rates of aggression ranging from $17 \%$ to $45 \%$ across universities. Straus reported that although the majority of incidents could be characterized as "minor" assaults (e.g., slapping), approximately $10 \%$ of reported incidents were more severe in nature (e.g., choking). These statistics may 
underestimate the problem of student perpetrated physical aggression, as more recent research suggests that $8-16 \%$ of individuals in college dating relationships have experienced at least one incident of severe physical aggression (e.g., punching, choking, or kicking) in their relationship (Shorey, Stuart, \& Cornelius, 2011).

There appears to be a significant lack of research investigating less serious forms of physically aggressive behaviour between university students in non-romantic relationships. Research investigating less serious forms of physical aggression between university students is important for a number of reasons. First, it is possible that relatively mild aggressive interactions between university students may be precursors to engagement in more serious physically aggressive behaviour (De Wall, Anderson, \& Bushman, 2011; Leonard, Quigley, \& Collins, 2002; Storch, Bagner, Geffken, \& Baumeister, 2004). Second, gaining a better understanding of predictors of less serious forms of physical aggression may inform intervention strategies at a systemic level that can be used to create a safer and less threatening campus for all students. Third, empirical research demonstrates that even less serious forms of physically aggressive behaviour are associated with a host of physical health and psychological consequences for victims and perpetrators (Storch et al., 2004).

\section{Proactive versus Reactive Physical Aggression}

Physical aggression is a complex phenomenon that comprises a range of actions that have different functions (Barker, Tremblay, Nagin, Vitaro, \& Lacourse, 2006). Brown (2007) notes that there is a consensus in the literature that the two main functions of aggression are instrumental or proactive aggression and hostile or reactive aggression (Barker et al., 2006; Brown, 2007; Feshbach, 1964; Poulin \& Boivin, 2000). On one hand, instrumental (proactive) aggression refers to an injurious act that is motivated by the desire for an outcome that does not 
involve physical injury of the other person; that is, a means to an end. For example, a boy may physically attack a peer, not for the sole purpose of harming him, but because by harming him he will gain something like social status. On the other hand, hostile (reactive) aggression refers to an injurious act where the primary intention is to cause harm to another person. This type of aggression is understood as a retaliatory response to previous harm or threat of harm inflicted upon the aggressor, real or perceived (Dodge, Lochman, Harnish, Bates, \& Pettit, 1997), and is a response to difficult feelings, such as anger (Berkowitz, 1990). For example, a boy may respond with physical aggression when teased by a peer at school. For the purpose of maintaining consistency throughout this discussion, the terms "proactive" and "reactive" aggression will be used.

It appears that the majority of studies on proactive versus reactive aggression have been conducted on children and adolescents (Barker et al., 2006; Card \& Little, 2006; Smithmyer, Hubbard, \& Simons, 2000). This is perhaps unsurprising as physical aggression is a more common response to conflict among children and adolescents in comparison to adults (Barker et al., 2006). The higher frequency of physical aggression in childhood and adolescence as compared to adulthood may be due to a number of developmental factors. These factors may include underdeveloped social competency skills (broadly defined as effectiveness in social interaction; Rose-Krasnor, 1997), as well as difficulties with emotion regulation (i.e., ability to self-soothe to control negative emotions; Kochanska, Murray, \& Harlan, 2000) that come with brain maturation (Barker et al., 2006; Robinson, Fetterman, Hopkins, \& Krishnakumar, 2013). Research indicates that adults generally have a wider repertoire of responses for managing social conflicts and higher levels of cognitive sophistication compared to youth, which may inhibit them from engaging in forms of proactive aggression (Barker et al., 2006). However, research on 
likelihood of engaging in forms of reactive physical aggression in adulthood is less clear (Baumeister \& Boden, 1998).

Some scholars have argued that reactive aggression is an impulsive and automatic process that is triggered by anger and driven by a need to retaliate, regardless of its consequences (Ramirez, 2009). However, other scholars suggest that impulsive urges to retaliate can be overridden when one decides it is unwise to act aggressively and inhibits their behaviour to avoid problematic consequences (Metcalfe \& Mischel, 1999). In support of this argument, aggression researchers have found significant individual differences in how people respond to provocation, with some engaging in aggressive behaviour, whereas others are able to inhibit aggressive responses (Baumeister \& Boden, 1998; Robinson et al., 2013; Wilkowski \& Robinson, 2010). As it is not ethically possible to recreate incidents of aggression that occur in real life, researchers have developed safe and reliable methods in which to assess physical aggression within the laboratory (Anderson \& Bushman, 1997). The following section provides an overview of the history of the assessment of physical aggression within psychological laboratories.

\section{Measuring Physical Aggression in the Laboratory}

The Buss Aggression Machine (BAM; Buss, 1961) has been the primary laboratory procedure used to measure direct physical aggression, and is generally credited for paving the way for alternative measures of laboratory aggression (Anderson \& Bushman, 1997). In this task, the participant and their "partner" (actually a confederate) are told that the study is concerned with the effects of punishment on learning. The participant is asked to play the role of teacher, while the confederate who is sitting in another room plays the role of the learner. The participant is asked to either reward or punish the learner's response to various arithmetic problems. More

specifically, the participant provides positive reinforcement when the learner's answer is correct 
by illuminating a light on a console. In contrast, the participant administers an electric shock to the learner as a form of punishment when the learner provides an incorrect response. The participant can control the intensity of the shock given to the learner with shock intensity ranging from just perceptible to excruciatingly painful (Anderson \& Bushman, 1997). Physical aggression on this task is operationalized as the intensity of electric shocks administered to the learner (Buss, 1961). Throughout the task, however, the learner's responses to the teacher's questions are predetermined and the learner never receives any shock. Although this procedure may seem quite similar to techniques used in Milgram's (1963) classic study on obedience, an important contrast between studies is noted. In contrast to Milgram's technique, Buss' (1961) procedure allows participants to voluntarily select the level of shock to be administered to the learner, whereas participants in Milgram's study were commanded by an experimenter to deliver increasingly more intense shocks to the learner. In this way, it is suggested that Buss' procedure may provide a more accurate measure of voluntary physical aggression (Korn, 1997).

Although the BAM became a relatively common device of measuring aggression in the laboratory, critics of this technique argue that participants' responses may have been influenced by altruistic intentions, as they were instructed to "help" one's partner solve the arithmetic problems (Baron \& Eggleston, 1972; Phillips, 2011). Furthermore, as participants did not receive any electric shocks during the task, they were never provoked to behave aggressively against their partner. In order to address these criticisms, Taylor (1967) developed the Taylor Aggression Paradigm (TAP) as a measure of direct physical aggression in response to provocation. The TAP is disguised as a competitive reaction time task where participants compete against an ostensive opponent who is supposedly seated in a nearby room. Prior to each reaction time trial, the participant is asked to select the shock intensity they wish to administer to their opponent with 
intensities ranging from 1 (low) to 10 (high). In contrast to the BAM, participants in the trial receive shocks from their partner, which function as a means of provocation. The frequency of wins and losses are predetermined with the participant winning 50 percent of the trials. However, the intensity of the shocks received by the participant slowly increase throughout the task in order to assess the effect of provocation on aggressive responding. In the TAP, direct physical aggression is operationalized as the average shock intensity selected over the trials (Taylor, 1967). Since the development of the TAP, numerous modifications of the aggression task have emerged. For example, Zeichner and Pihl (1979) created a version of the TAP that allows participants to vary the duration of the shocks selected. Giancola and Zeichner (1995) further altered the paradigm to allow participants to select the intensity of the shock to be administered after winning a reaction time trial, rather than prior to winning or losing. Additional modifications have allowed the participant to refrain from retaliation all together (Zeichner, Frey, Parrott, \& Butryn, 1999) or provide a "no shock" option (McCloskey \& Berman, 2003).

In yet another version of the TAP, Bushman and Baumeister (1998) substituted the use of electric shocks with aversive white noise blasts in their competitive reaction time task. Bushman and Baumeister further modified the context of the experiment by administering an "ego threat" (i.e., receiving insulting essay feedback) as an additional means of provocation. More specifically, the authors asked the participants to write a short pro-choice or pro-life essay on abortion that would later be evaluated by their partner (who was in fact, nonexistent). Participants were told that they would be matched up with a partner who had similar views on abortion and that their partner would be sitting in a nearby room. A short time later, the experimenter returned the participant's essay with comments ostensibly made by the other participant. These comments served as an experimental manipulation of ego threat as participants 
were assigned to receive either negative feedback from their partner (e.g., "This is one of the worst essays I have read!’) or positive feedback (e.g., "No suggestions, great essay!”)

After receiving this feedback, the participant began the reaction time task against their partner and had the option to set the noise intensity (including a nonaggressive "no noise" setting) as well as the duration of the white noise blasts at the beginning of each trial. Similar to previous versions of this task, the frequency of winning and losing trials, as well as the intensity and duration of white noise received were predetermined. In this task, the participant's level of aggression was operationalized as the mean sum of the standardized score for the duration and intensity of all white noise blasts.

Although the validity of laboratory physical aggression measures has long been debated (Giancola \& Parrott, 2008), a number of studies have found support for the validity of the TAP, (as well as its modified versions) as a measure of direct physical aggression for men and women (e.g., Anderson \& Bushman, 1997; Giancola \& Parrott, 2008; Giancola \& Zeichner, 1995; Hammock \& Richardson, 1992). More recent studies of reactive physical aggression appear to use white noise blasts as opposed to electric shocks as a means of punishment and provocation. Furthermore, a number of studies have examined the impact of social exclusion or ego threat on aggressive behaviour between university students, in addition to provocation associated with white noise blasts (e.g., Bushman \& Baumeister, 1998; Twenge, Baumeister, Tice, \& Stucke, 2001).

For example, Twenge et al. (2001) conducted a series of studies to examine the impact of social exclusion on physical aggression between university students. Prior to engaging in the experimental task, a group of 4-6 participants were introduced to one another and asked to speak together for 15 minutes. Following their discussion, participants were asked to write down the 
names of two individuals that they would be most interested in working with on a collaborative task. The researchers then randomly provided each of the participants with feedback that either everyone or no one in the larger group of participants had chosen them as a partner for the task. Upon receiving this feedback, participants were asked to engage in the modified version of the TAP by Bushman and Baumeister (1998). Results of the study indicated that those who had experienced social rejection were more likely to blast their partner with aversive white noise than when they had received positive feedback from their partner.

Jones and Paulhus (2010) aimed to examine the types of provocation that triggered physical aggression between university students who received high scores on measures of narcissism and/or psychopathy. Participants were first asked to fill out a questionnaire package that included personality measures. The authors then followed the study procedure outlined by Bushman and Baumeister (1998) and used a modified version of the TAP. Participants were first asked to write a pro-life or pro-choice essay on abortion that would be evaluated by their ostensive partner. After receiving either positive or negative evaluations of their essay, participants were asked to compete in the reaction time trial where they had the opportunity to blast their partner with white noise at the beginning of each trial.

Results of the study indicated that students who received higher scores on the narcissism personality measure responded with a greater frequency of white noise blasts than those with lower scores on this measure when in the "ego threat" condition (i.e., were provoked by negative feedback on their essay) than when in the "no provocation", control condition. As noted by Bushman and Baumeister (1998), negative feedback serves as an ego threat because participants' personal opinions and attitudes as well as their essay writing ability are being assailed. It may be argued that an ego threat may be particularly provoking for individuals who score higher on a 
measure of narcissism. Furthermore, results indicated that students who received higher scores on the measure of psychopathy were likely to respond with physical aggression, regardless of whether they received positive or negative feedback from their partner.

In summary, a number of studies have found support for various types of provocation in eliciting reactive physical aggression in the laboratory. These findings have led to the development of social-cognitive theoretical frameworks for understanding why some individuals may be more likely than others to respond with aggression, such as the "cognitive neoassociationist" theory of aggression (Berkowitz, 1990); variations of the "information processing model" (Anderson \& Bushman, 2002; Anderson, Deuser, \& DeNeve, 1995; Dodge, 1980; Huesmann, 1988) as well as the "ego-threat" theory of aggression (Bushman \& Baumeister, 1998). The following section outlines social cognitive theory as it applies to the prediction of physically aggressive behaviour.

\section{Social Cognitive Theory and Physical Aggression}

Social cognitive theory operates under the assumption that one's behaviour is under the influence of internal, self-regulating cognitive processes (Anderson \& Huesmann, 2003). With regard to aggressive behaviour, social cognitive theory posits that the expression of aggression and the level of the aggression depend on a number of factors, including one's attitudes toward the appropriateness of aggression in a particular situation or whether they believe an aggressive response is justified (Anderson \& Huesmann, 2003). In addition, social cognitive theory takes into consideration an individual's level of social competence or cognitive sophistication to foresee negative consequences associated with an aggressive response, as well as the level of personal significance attached to the provoking situation (e.g., one's relationship with the aggressor) (Anderson \& Huesmann, 2003; Dodge \& Coie, 1987). 
Although social cognitive models of behaviour are arguably the most dominant theoretical framework in the field of social psychology (Fiske, 2009), scholars, such as Wicker (1969), have argued that a measure of one's attitude toward a given behaviour alone is unlikely to predict behaviour. As a result, social psychology researchers have created more complex models to examine the impact of additional social cognitive variables in predicting behaviour (Olson \& Zanna, 1993). The Theory of Planned Behaviour (TPB; Ajzen, 1985, 1991) is one of the most widely researched social cognitive models of behaviour (Armitage \& Conner, 2001). This model considers the predictive influence of three factors: 1) attitudes, 2) subjective norms, and 3) perceived behavioural control (PBC) of a given behaviour, all mediated by one's intention to engage in the behaviour. The TPB is an extension of an earlier theory, the Theory of Reasoned Action (TRA) proposed by Ajzen and Fishbein (1980). According to the TRA and TPB, people are in control of their own behaviour and make conscious decisions as to whether they will take action or not (Ajzen \& Fishbein, 1980). Hence, both the TRA and the TPB operate on the underlying assumption that humans make systematic use of available information and are aware of actions or behaviours required to obtain certain goals (Ajzen, 1985). It is suggested that this model may be particularly well suited for understanding the more nuanced beliefs that people hold toward engaging in aggressive behaviour, and may therefore extend previous social cognitive theories of aggression. The following section will describe the TRA followed by a discussion of the TPB.

\section{The Theory of Reasoned Action (TRA)}

The TRA was developed under the assumption that "people's behavior follows reasonably from their beliefs about performing that behavior" (Fishbein, 2008, p. 2). Fishbein (2008) was careful to explain that one's beliefs toward the behaviour are subjective and that 
others may consider these beliefs to be illogical. Indeed, Ajzen and Fishbein (1980) noted that the theory does not require beliefs to be "rational" and, instead, suggested that one's behaviour follows reasonably from the beliefs held by the actor, even if the actor's beliefs are perceived by others to be quite irrational.

Ajzen and Fishbein (1980) stated that the immediate antecedent of behaviour is the intention to perform the behaviour. In other words, Ajzen and Fishbein suggested that the best predictor of an individual's behaviour is to ask them whether they intend to engage in the behaviour. For example, in the context of reactive physical aggression, one may ask "How likely are you to use physical aggression against someone who has provoked you?" or "Do you intend to use physical aggression against someone who has provoked you?" Several meta-analytic reviews have found that between 19\% (McEachan, Conner, Taylor, \& Lawton, 2011) and 36\% (Trafimow, Sheeran, Conner, \& Finlay, 2002) of the variance in behaviour can be explained by one's intentions. Ajzen and Fishbein (1980) explained that the relation between intentions and actual behaviour can be strengthened if the following suggestions are taken into account when designing a TRA model.

First, the authors suggested that the target behaviour must be explicitly described. Second, the individual must be aware of the context or situation in which the target behaviour may occur in order to improve the predictive association between intentions and behaviour. For example, when asking about the likelihood of engaging in physically aggressive behaviour, it is not enough to ask the respondent whether they intend to engage in physically aggressive behaviour in a more general sense, but rather if they intend to engage in physically aggressive behaviour against a peer who has provoked them at school. Third, the time frame for which the behaviour is likely to occur must be specified. For example, the respondent is asked, "Do you 
plan to engage in physically aggressive behaviour against a peer who has provoked you within the next few days?" The authors argued that intentions are most accurate in predicting behaviour when they are assessed close in time to the actual behaviour (Ajzen, 1985; Ajzen \& Fishbein, 1980).

Although measuring intentions is often useful in making predictions about behaviour, it does not provide insight into why the individual intends to engage in a particular behaviour. Ajzen and Fishbein proposed that intentions are a function of an individual's attitude toward the behaviour, as well as subjective norms surrounding the performance of the behaviour. The "attitude toward the behaviour" predictor of intentions (hereafter referred to as "attitudes") is composed of a positive or negative evaluation of the behaviour (e.g., "Using physical aggression against someone who has provoked me is bad"), as well as beliefs regarding the consequences of performing the behaviour (e.g., "Using physical aggression against someone who has provoked me will lead me to get in trouble") (Ajzen, 1991). The "subjective norms" predictor is related to an individual's perception of social pressure to perform or not perform the behaviour (Ajzen \& Fishbein, 1980). For example, “My friends think it's cool to use physical aggression against someone if they provoke you." The TRA treats these determinants as related but conceptually distinct predictors of intentions.

In summary, the TRA comprises two levels of analysis. First, one's intention to behave is the most direct determinant of their behaviour. Second, intentions are determined by attitudes as well as subjective norms toward the behaviour. Although the TRA has been successfully employed to predict a range of human behaviours, it has been criticized for its assumption that behaviour is under the volitional control of the individual (Armitage, \& Conner, 2001). In other words, the theory assumes that people have complete control over whether they will perform or 
not perform a given behaviour (Ajzen \& Madden 1986). Scholars argue that this is not always the case as other factors, such as a lack of resources or opportunities to behave, for example, may prevent an individual from engaging in a given behaviour, despite their positive attitude toward the behaviour. For example, one may intend to visit a relative across the country but may lack the resources, that is, the money to afford a plane ticket to follow through with the behaviour.

\section{The Theory of Planned Behaviour (TPB)}

In order to address the issue of volitional control, Ajzen (1985) extended the TRA into the Theory of Planned Behaviour (TPB). In addition to attitudes and subjective norms, the revised theory considers the influence of perceived behavioural control $(P B C)$ on intentions and actual behaviour (see Figure 1). PBC refers to an individual's perceived evaluation of how easy or difficult it would be to perform a given behaviour, based on beliefs about the presence of factors that would facilitate or impede performance of the behaviour (Ajzen, 1991). For example, "I think it would be difficult to visit South America as I cannot afford a plane ticket."

Furthermore, Ajzen (1985) suggested that PBC may affect behaviour directly or indirectly. PBC may affect one's behaviour indirectly through intentions, similar to the attitudes and subjective norms variables. In contrast, PBC can directly affect behaviour in situations where the behaviour is not under the total control of the person. For example, a lack of resources (money) may directly affect one's behaviour (staying at home) as they are financially unable to buy a place ticket. In summary, the TPB consists of three levels of analysis. First, and similar to the TRA, the TPB assumes that one's intention to behave is the direct antecedent of behaviour. Second, PBC may directly affect behaviour in situations where the behaviour is not under one's total control. Third, one's intention to behave is determined by the following three predictors: attitudes, subjective norms, and PBC. When all three determinants of intentions are "congruent" 


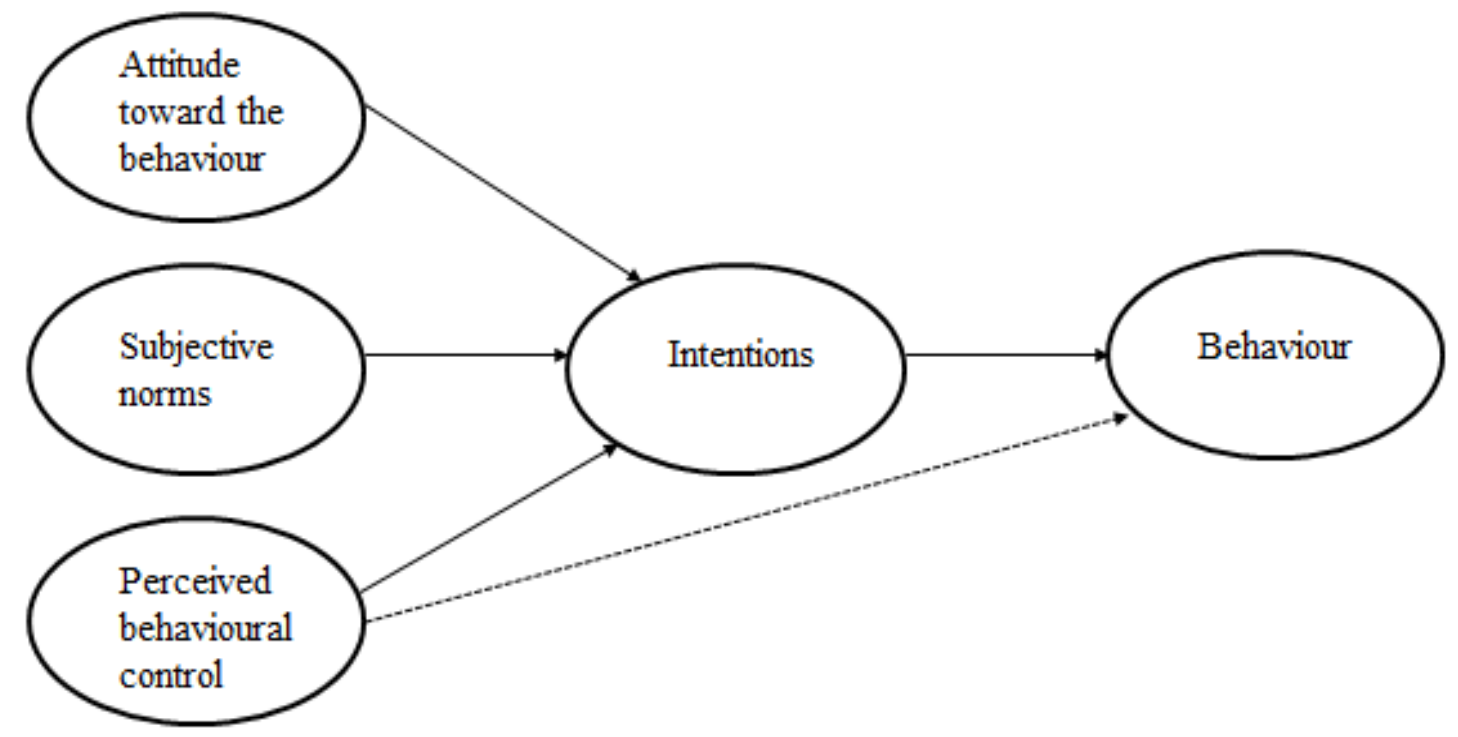

Figure 1. Model of the theory of planned behaviour (TPB; Ajzen, 1985, 1991). 
(i.e., supportive or unsupportive of engaging in a particular behaviour), and the behaviour is under one's volitional control, the individual is expected to engage in the behaviour.

The TPB, as well as its earlier version, the TRA, have been successfully applied to predict a wide range of behaviours, such as increasing one's level of education (Casper, 2007; Davis, Ajzen, Saunders, \& Williams, 2002); voting (Hansen \& Jensen, 2007); and recycling (Tonglet, Phillips, \& Read, 2004). In addition, the TPB has been applied to a number of health behaviours, such as exercise (Gordon, 2008), self-examinations for cancer (Norman \& Cooper, 2011), smoking cessation (Bledsoe, 2006; Norman, Conner, \& Bell, 1999), condom use (Albarracin, Johnson, Fishbein \& Muellerleile, 2001; Morrison, Rogers-Gillmore, \& Baker, 1995), and healthy eating habits (Conner, Norman, \& Bell, 2002; Fila \& Smith, 2006).

Furthermore, the TPB has been applied to more "controversial" health-related behaviours, such as binge-drinking (Norman \& Conner, 2006), and high-risk sexual behaviours (Basen-Engquist, \& Parcel, 1992; Turchik, 2010). According to Armitage and Conner (2001), the TPB is regarded as the dominant model in the field of health psychology. It is also broadly applied to a number of other disciplines, including information technology, social policy, sociology, and psychology more generally.

In the most frequently cited meta-analysis on the efficacy of the TPB in predicting social behaviours, Armitage and Conner (2001) indicated that, on average, the TPB accounted for $39 \%$ of the variance in intentions and $27 \%$ of the variance in actual behaviour. In addition, the metaanalysis provided strong evidence for each of the main constructs in the TPB model. Intentions $(r=.47)$ and PBC ( $r=.37)$ were found to have significant moderate correlations with behaviour. Furthermore, attitudes ( $r=.49)$, subjective norms ( $r=.34)$ and PBC ( $r=.43)$ were significantly correlated with intentions. 
More recently, McEachan and colleagues (2011) conducted a meta-analysis of studies using the TPB to predict a range of health-related behaviours. The analysis indicated that the TPB model explained approximately $19 \%$ of the variance in behaviour and $44 \%$ of the variance in intentions across studies. Correlations between predictors of intentions (i.e., attitudes, subjective norms, and $\mathrm{PBC}$ ) and intentions were stronger in this study compared to those reported by Armitage and Conner (2001). Indeed, the correlation between attitudes and intentions was 0.57, whereas the subjective norms-intentions and PBC-intentions correlations were 0.40 and 0.54 , respectively. McEachan and colleagues suggested that the stronger correlations found in their review may be the result of a number of factors, such as their focus on prospective studies rather than cross-sectional studies, inclusion of random effects meta-analyses (rather than fixed effects meta-analyses), as well as tighter control for both sampling and measurement error. Overall, findings of previous and more recent meta-analyses of the TPB provide strong evidence for the utility of this model in predicting social behaviours.

\section{TPB and Aggressive Behaviour}

Although the TPB is a widely researched model of intentions and actual behaviour, there appears to be a significant lack of research applying the TPB to predict engagement in aggressive or violent behaviour. The TPB may be particularly helpful in gaining a better understanding of the predictors of physical aggression, which may inform early intervention strategies to prevent the possible escalation of violent behaviour. A review of the literature revealed that the majority of studies using the TPB to predict aggressive or violent behaviours has focused on youth (e.g., Finigan-Carr et al., 2015) and adult offender populations (e.g., Kernsmith, 2005), while fewer studies (e.g., Betts et al., 2011) have used the TPB to predict physically aggressive behaviour between university students. 
Evans and Taylor (1995) applied the earlier version of the TPB, the TRA, to predict violent behaviour in previous and current gang members. The authors interviewed 18 core members of earlier gangs (i.e., gang members between the years of 1930-1960) and 30 members of contemporary gangs (i.e., gang members between the years of 1960-1990) to find out more about their personal experiences and perceptions of gang life. Violent behaviour was assessed using a self-report format and included involvement in fighting, robbery, scouting for additional gang members, dealing drugs, or shooting rival gang members. Results indicated that members of contemporary gangs demonstrated more positive attitudes toward violence than members of earlier gangs. Furthermore, contemporary gang members were found to experience more pressure to conform to role expectations than did respondents of earlier gangs.

Due to a number of methodological limitations, it is difficult to draw conclusions from this study regarding the TRA's ability to predict aggressive behaviour. First, the authors noted that they did not conduct any formal statistical analyses to examine the impact of attitudes or subjective norms on intention to engage in violent behaviour, and explained that their results are more exploratory in nature and should be further examined in future studies. Second, although the authors reported using the TRA model to predict violent behaviour, the methods used in this study were not in line with Ajzen and Fishbein's (1980) recommendations. For example, when measuring the subjective norms variable, the authors examined frequencies of engaging in violent behaviours, rather than asking the gang members about social pressures to perform or not perform violent behaviours. Overall, the study focused more on comparing frequencies of violent behaviour between current and earlier gang members, rather than examining the ability of the main constructs of the TRA model to predict violent behaviour. 
Tolman, Edleson, and Fendrich (1996) used the TPB model to predict men's abusive behaviour against a female partner. More specifically, the authors used transcripts from interviews that were initially conducted by Harrell (1991) in her study examining abusive men's experiences in treatment programs. Tolman et al. used information in these transcripts to generate the four primary constructs of the TPB model (i.e., attitudes, subjective norms, PBC, and intentions). The attitudes construct was developed by examining men's reported consequences of engaging in abusive behaviour (e.g., "I might go to jail"). The subjective norms construct was developed by asking whether their family or friends were critical of them when they became aware of their abusive behaviour. PBC was assessed by asking men to rate their confidence in their ability to remain nonviolent in 13 different situations (e.g., "If she starts yelling at you"). Finally, intentions were assessed by asking about expectations about future violence. The authors found that, of the TPB constructs, $\mathrm{PBC}$ was the strongest predictor of men's intentions to abuse their partner in the future.

In a follow-up to the study conducted by Tolman and colleagues, Kernsmith (2005) applied the TPB model to predict male- and female-perpetrated incidents of intimate partner violence to examine potential gender differences in the model. Kernsmith used the same items and methods as Tolman et al. to develop TPB constructs. Interestingly, Kernsmith found that the TPB accurately predicted abusive behaviour for male perpetrators but not for female perpetrators. Kernsmith hypothesized that the lack of prediction for women may be due to differences in motivations underlying their aggressive behaviour. The author noted that the sample was divided in terms of women reporting violence as a means of self-defense and those who engaged in violence as a means of revenge. Kernsmith found that women who engaged in violence as a means of self-defense reported higher rates of approval of their behaviour by 
family and friends, whereas women who used violence as a means of revenge reported significantly lower approval rates. These differences in motivation and acceptability of behaviour may have contributed to the overall lack of prediction of the TPB model for female- perpetrated incidents of intimate partner violence.

Roberto, Meyer, Boster, and Roberto (2003) used the TRA to predict young adolescents' (i.e., Grade 7 students) decisions to engage in physically aggressive behaviour against a peer at school. The authors examined physical aggression using a self-report format by asking participants, "During the past 30 days, how many times were you involved in a fight?" The authors defined "fighting" as "a physical fight where two or more people hit, punch, slap, push, or kick each other in anger" (p. 137). Intentions were assessed by asking participants, "How many times do you think you will fight in the next 30 days?" Attitudes were assessed by asking participants to provide an evaluation of whether performing the behaviour was good or bad, while subjective norms was evaluated by asking whether members of their peer group would support their aggressive behaviour. Consistent with the TRA, attitudes significantly predicted intentions, and intentions predicted actual aggressive behaviour. However, in contrast to predictions made by the TRA, subjective norms were not found to be a significant predictor of behavioural intent.

Critics of the TRA and TPB models, more generally (e.g., Godin \& Kok, 1996) argue against the influence of the subjective norms construct and suggest that it is a relatively weak predictor of intentions in comparison to the attitudes and PBC constructs. Although results of meta-analytic reviews indicate that the subjective norms construct is generally the weakest predictor of intentions (e.g., Armitage \& Conner, 2001; McEachan et al., 2011), the authors of these reviews suggest that this finding may be a result of a poor operational definition of this 
construct. For example, Armitage and Conner found that subjective norms was found to be a consistent predictor of intentions when measured using multi-item scales (i.e., through asking about the influence of multiple referents, for example, friends, family, teachers, etc.), as opposed to single item measures (e.g., only asking about social pressure to perform or not perform from friends).

In order to expand the findings of Roberto and colleagues (2003), Brown (2007) examined aggressive intentions as well as actual reactive and proactive aggressive behaviour among a slightly older age group (i.e., Grade 10 to 12 students). As was previously mentioned, reactive aggression is a direct response to provocation where the primary intention is to cause harm to another person. In contrast, proactive aggression is defined as aggressive behaviour that is motivated by the desire for an outcome that does not involve physical injury of the other person. The author conducted an elicitation study (Fishbein \& Ajzen, 1980) to develop each of the primary constructs in the TPB model (attitudes, subjective norms, $\mathrm{PBC}$, and intentions). In an elicitation study, open-ended questions are designed to uncover a range of beliefs underlying an individual's attitude toward a specific behaviour. For example, the researcher may ask, "What do you think would be the advantages of using physical aggression against someone who has provoked you?" In addition, Brown modified the TPB model by adding self-efficacy (i.e., one's "belief in their own capability to perform a specific behaviour and have control over the events in their lives" p. 26) as an additional predictor of intentions.

Results of the study indicated that the TPB model significantly predicted both proactive and reactive aggression among participants. However, Brown found that self-efficacy only enhanced the prediction of proactive intentions, but did not significantly contribute to the prediction of reactive intentions. Attitudes were found to have the largest influence on reactive 
aggression intentions, although subjective norms and PBC were also significant predictors of intentions. In contrast, the self-efficacy variable was found to be the strongest predictor of instrumental aggression intentions, and attitudes, subjective norms, and PBC were also significant predictors of intentions. Brown suggested that it is perhaps not surprising that selfefficacy contributed to a model predicting instrumental intentions and not for reactive aggression intentions. Brown explained that the ability to perform a behaviour successfully would be a highly motivating factor for instrumental aggression which involves using aggressive behaviour to obtain rewards (Feshbach, 1964). However, self-efficacy may not be as important in the reactive context when individuals are responding to a situation in which they have been provoked. In this case, the primary goal is to react to the aggression and whether they are successful or not may be less important than simply retaliating (Brown, 2007).

More recently, Finigan-Carr, Cheng, Gielen, Haynie, and Simons-Morton (2015) explored whether the TPB model significantly predicted aggressive behaviour and weapons carrying behaviours among a sample of urban African American adolescents. In contrast to the previously reviewed studies, intentions were not included in the model and attitudes, subjective norms and $\mathrm{PBC}$ were examined as direct predictors of aggressive or weapons carrying behaviours. In order to measure the frequency of aggressive behaviours, participants were asked about how many times in the last 30 days they had exhibited the following aggressive behaviours at school: encouraging others to fight, spreading rumours/gossip, making someone mad on purpose, pushing or shoving another person, and hurting someone on purpose. Weapons carrying behaviour was measured by asking participants how many times over the last 30 days they carried a gun, a knife, or a weapon other than a gun or a knife. 
Furthermore, the attitudes construct was measured by the "Acceptance of Deviant Peer Behaviours" scale (Simons-Morton et al., 1999); and subjective norms were assessed using both the "Friend Behaviour Influence" scale (Simons-Morton et al., 1999) as well as the "Perception of Parental Attitudes about Fighting” scale (Orpinas, Murray, \& Kelder, 1999). PBC was assessed using two scales representing decision making (e.g., "I think about possible consequences of different choices for what to do", p. 222) adapted from the National Longitudinal Study of Adolescent Health (Harris et al., 2009) as well as "self-control" over behaviour (e.g., "I calm myself down when I get excited or wound up", p. 223), adapted from the Self-Control Rating Scale (SCRS; Kendall \& Wilcox, 1979). Contrary to the results of previous studies, the authors found that attitudes toward aggression did not significantly predict aggressive behaviour in the current sample. However, perceived social pressure from both peer and parental relationships were found to be significant predictors of aggressive behaviour. Interestingly, neither attitudes toward aggressive behaviour nor the subjective norms constructs were found to be significant predictors of weapons carrying behaviour. With regard to PBC, only the self-control dimension was found to predict the outcome variables, such that greater control was related to lower odds of engaging in aggressive behaviour or carrying a weapon.

To this writer's knowledge, only two studies have used the TPB to predict aggressive behaviours in an undergraduate sample. Thompson, Koss, Kingree, Goree, and Rice (2011) applied the TPB to predict sexual aggression perpetration among male college students. Sexual aggression was assessed using the revised "Sexual Experiences Survey" (SES; Koss et al., 2007) at one year follow up. Attitudes, subjective norms, and $\mathrm{PBC}$ were also assessed using preexisting measures. More specifically, attitudes were assessed using the "Rape Supportive Beliefs Scale" (Lonsway \& Fitzgerald, 1995), subjective norms were assessed using a measure of peer 
approval of forced sex (Abbey \& McAuslan, 2004), and PBC was assessed using the "Sexual Compulsivity Scale” (Kalichman \& Rompa, 2001). Similar to Finigan-Carr and colleagues (2015), behavioural intentions were not assessed in this study. Results indicated that attitudes as well as subjective norms significantly predicted engaging in sexually aggressive behaviour at one year follow up.

Betts, Hinsz, and Heimerdinger (2011) used the TPB to predict intention to engage in romantic partner abuse (i.e., verbal, physical or sexual abuse) among male and female undergraduate students. In this study, the authors assessed self-reported attitudes, subjective norms, $\mathrm{PBC}$, and intention to engage in each of the three forms of romantic partner abuse. In contrast to the other reviewed studies, the authors included three different measures of intentions for each type of romantic partner abuse (i.e., "I plan to...", "I intend to..." and "How likely is that you will...”).

Results indicated that the TPB accounted for a significant portion of the variance in intention to engage in romantic partner abuse. More specifically, the TPB accounted for $74 \%$ of the variance in verbal abuse intentions, with attitudes as well as PBC significant predictors of intentions. Similar to the verbal abuse analyses, the TPB model accounted for approximately $72 \%$ of the variance in sexual abuse intentions, with attitudes and PBC emerging as significant predictors of intentions. The subjective norms construct was not a significant predictor for either verbal or sexual abuse intentions. Finally, the authors found that the TPB model predicting physical abuse intentions was the strongest model compared to the models predicting verbal and sexual abuse intentions. Indeed, the TPB model predicting physical abuse intentions accounted for $72 \%$ of the variance in intentions with attitudes, subjective norms, and PBC significantly predicting intention to engage in physical abuse. 


\section{Explicit versus Implicit Measures of Attitudes in Predicting Aggressive Behaviour}

It is noted that the TPB relies solely on "explicit" attitudes toward a given behaviour (e.g., Ogden, 2003), which are typically assessed using self-report questionnaires. According to Nosek (2007), explicit attitudes are attitudes that are "controllable, intended, made with awareness, and require cognitive resources" (p. 65). Furthermore, explicit attitudes typically involve the use of thoughtful, deliberate mental processes that aim to organize available information to form a coherent evaluative judgment (Gawronski \& Bodenhausen, 2011). A potential disadvantage of the TPB is that it does not jointly consider individuals' "implicit" attitudes which may also be important in predicting a range of behaviours, especially those that are relatively fast and effortless (Ajzen \& Dasgupta, 2015).

Fazio and Olson (2003) explain that implicit attitudes are automatic (e.g., spontaneous), do not require introspection, and typically exist outside of one's conscious awareness. Researchers suggest that implicit attitudes are activated by mental representations in memory that instantaneously elicit evaluative responses (Gawronski \& Bodenhausen, 2011). In order to provide further insight into the mental processes underlying implicit and explicit attitudes, Gawronski and Bodenhausen (2006) developed the Associative-Propositional Evaluation (APE) model. According to this model, implicit and explicit attitudes are the behavioural outcomes of two distinct mental processes. Implicit attitudes are the behavioural outcome of associative processes, whereas explicit attitudes are the behavioural outcome of validation processes.

Gawronski and Bodenhausen (2006) note that the primary difference between the association and validation processes is that activation of associations occurs independently of whether an individual considers the associations to be accurate or inaccurate. In this way, the associative process can be thought of as a "gut response" to an object/stimulus (Gawronski \& 
Bodenhausen, 2011). In contrast, validation processes generally allow the individual to consciously assess the subjective truth or falsity of information that has been activated. This, in turn, allows the individual to determine whether the automatic association is consistent with their beliefs and other available information (Gawronski, LeBel, \& Peters, 2007).

In many situations, people may use their spontaneous gut reaction to an object or situation as the basis for an evaluative judgment, such that they may report the evaluative quality of their gut response on an explicit, self-report measure. For example, if an individual experiences a negative, spontaneous reaction toward a member of a stigmatized group (associative process underlying implicit attitudes), they may report that they dislike members of that particular group on a self-report measure (explicit attitude/evaluation). However, in other situations, the two kinds of responses may be in conflict (Gawronski \& Bodenhausen, 2011). For example, one may experience a spontaneous negative reaction toward a member of a stigmatized group even though that individual may have a strong desire to be unprejudiced. In this case, an individual may experience contrasting implicit and explicit attitudes toward the same issue and must make efforts to resolve this inconsistency to avoid feelings of cognitive dissonance (Gawronski \& Bodenhausen, 2011).

If one were to consider underlying mental processes proposed by the APE model when evaluating explicit attitudes under the TPB model, three possible interpretations of self-reported attitudes can be made. First, it is possible that an individual may consciously agree with their affective gut reaction to a particular stimulus/object and verbally responds in a manner that is consistent with their implicit beliefs (i.e., individual experiences a negative affective gut reaction toward a certain group of people and explicitly reports that they do not like members of that group). Second, it may be possible that an individual may first experience a negative affective 
gut reaction (negative implicit evaluation) to a certain stimulus/object and rejected this gut reaction as it was inconsistent with their conscious beliefs (i.e., individual experiences a negative affective gut reaction to a certain group and explicitly reports that they are tolerant/unprejudiced towards members of this group). Third, it is possible that an individual may experience an affective gut reaction that is congruent with their explicit evaluation but responds in a socially desirable manner on self-report measures in order to appear more favourable to an examiner.

A host of research suggests that explicit attitudes are particularly vulnerable to social desirability biases (Jong, Halberstadt, \& Bluemke, 2012). Although discrepancies between implicit and explicit measures of attitudes may be related to social desirability issues (Fazio \& Olson, 2003), weak or no correlation between implicit and explicit measures are typical, even on topics that are not socially sensitive (Hofmann, Gawronski, Gschwendner, Le, \& Schmitt, 2005). In their meta-analysis on the correlation between the Implicit Association Test (IAT; Greenwald, McGhee, \& Schwartz,1998) and explicit self-report measures, Hofmann et al. (2005) suggest that, in addition to issues associated with social desirability, low correlations between implicit and explicit measures may be due to: a) differences in people's awareness of implicit representations, b) factors influencing the retrieval of information from memory, such as motivation or cognitive capacity, c) method-related characteristics between the two measures, for example, differences in the influence of systematic error variance or conceptual correspondence between measures, or d) complete independence of the underlying constructs.

As implicit attitudes may provide "raw" insight into evaluative mental associations, and may also help to inform explicit, self-reported judgments (Gawronski \& Bodenhausen, 2006), a burgeoning amount of research has begun to examine the role of implicit attitudes in predicting a range of behaviours (e.g., Nosek \& Smyth, 2007). Unlike the use of self-report questionnaires 
typically used in the measurement of explicit attitudes, implicit attitudes are measured using “indirect”, nonreactive procedures. These measures rely on speed or accuracy of participants' responses to different categories of information, with the goal of capturing underlying mental associations indirectly (Gawronski \& Payne, 2010). Although several examples of indirect measures of attitudes currently exist (see Fazio \& Olson, 2003 for a review of measures), the IAT is the most prominent experimental paradigm to measure individuals' implicit attitudes.

\section{The Implicit Association Test (IAT)}

The IAT comprises five blocks and indirectly measures the strength of an association between two contrasted targets (e.g., Self versus Others) and two contrasted attribute categories (e.g., Pleasant versus Unpleasant) via a classification task (i.e., using two response keys to classify the four categories of stimuli). For example, in the first block of the Self-Esteem IAT (Greenwald \& Farnham, 2000), participants are asked to classify stimulus items into the "Self" and "Others" target categories (e.g., "Me" into "Self" and "Not Me" into "Others". In the second block, participants are asked to classify stimulus items into the "Pleasant" and "Unpleasant" attribution categories (e.g., "Joy" into "Pleasant" and "Vomit" into "Unpleasant"). In the third block, the four categories that were originally presented separately now appear together and participants are asked to classify all stimulus items into the proper combined categories (e.g., "Self and Pleasant" versus “Others and Unpleasant". In the fourth block, participants are again required to classify stimulus items into the target category dimensions ("Self" and "Others"), however, the position of these categories have reversed so that they now appear on opposite sides of the computer screen. In the final block, the four categories appear together in a new configuration (e.g., "Self and Unpleasant" and "Others and Pleasant") and participants are required to accurately classify all stimulus words into the proper target or attribute dimension 
categories. The assumption underlying the IAT is that if a respondent closely associates two concepts (e.g., "Self" and "Pleasant"), the classification task will be easier and the respondent will be more quickly to respond. However, when the concepts are not highly associated (e.g., "Self" and "Unpleasant"), the classification task will be harder and the respondent will be slower to respond.

Numerous studies have established the reliability of the IAT (e.g., Greenwald, Poehlman, Uhlmann, \& Banaji, 2009) and have used it to assess implicit attitudes toward a range of behaviours, including voting behaviour (Arcuri, Castelli, Galdi, Zogmaister, \& Amadori, 2008), political ideology (Choma \& Hafer, 2009), smoking (Dal Cin, Gibson, Zanna, Shumate, \& Fong, 2007; Robinson, Meier, Zetocha, \& McCaul, 2005); and body image and related levels of body satisfaction (Ahern \& Hetherington, 2006; Hoffmeister, Teige-Mocigemba, Blechert, Klauer, \& Tuschen-Caffier, 2010). The IAT has also been used to examine implicit attitudes toward personality variables, such as shyness and anxiety (Asendorpf, Banse, \& Mücke, 2002) as well as self-esteem and self-concept beliefs (Greenwald \& Farnham, 2000).

\section{IAT and Aggressive Behaviour}

Although recent years have seen a dramatic increase in the number of studies using the IAT to assess attitudes toward a range of behaviours, relatively few studies have examined the predictive validity of implicit attitudes as they apply to physically aggressive behaviours (Richetin, Richardson, \& Mason, 2010). A number of scholars highlight the parallel that may be drawn within models of aggressive behaviour that distinguish the role played by automatic processes (i.e., implicit attitudes) and the role played by deliberate or reflective processes (i.e., explicit attitudes) in the execution of aggressive behaviour (e.g., Fazio, 1990; Gawronski \& Bodenhausen, 2006; Strack \& Deutsch, 2004). Strack and Deutsch (2004) refer to this as the 
"Reflective-Impulsive System" and suggest that there may be both a reflective system in which a behaviour occurs as a result of a careful decision making process, as well as an impulsive system, in which behaviour occurs as a result of automatic, subconscious processing of stimuli that are closely associated in one's memory. Perhaps not surprisingly then, explicit attitudes would likely tap more into the reflective processes than implicit measures would, whereas implicit measures would tap more into impulsive processes than explicit measures would (Richetin et al., 2010; Spence \& Townsend, 2007). It is noted that the Reflective-Impulsive System is consistent with Gawronski and Bodenhausen's (2006) APE model of implicit and explicit attitudes that was described earlier in this chapter.

Research on the validity of implicit attitudes as a predictor of aggressive behaviour has produced mixed findings (McCormick, 2013). Indeed, some authors have found support for the use of implicit measures as they apply to the prediction of aggressive behaviours (e.g., Banse \& Fischer, 2002), whereas others have found that explicit, self-report measures of attitudes are stronger predictors of aggression than implicit attitudes (e.g., Maimone, 2014). Banse and Fischer (2002) developed a modified version of the IAT, the "Aggressiveness-IAT" to examine the predictive validity of implicit measures of aggressiveness as they applied to physically aggressive behaviours of hockey and volleyball players. Results of the study revealed that the IAT successfully predicted aggressiveness among both types of athletes with more aggressive athletes having stronger associations between the "me and fight" category than the "not me and talk" category. These results were more recently supported by Teubel, Asendorpf, Banse, and Schnabel (2011) in their study examining the predictive validity of the IAT as it applies to physically aggressive behaviour among basketball players. 
Richetin and colleagues (2010) examined the extent to which implicit measures of aggressiveness predicted aggressive behaviour in response to provocation (i.e., being insulted by the examiner). Although the relevant behaviour was not physical aggression, the researchers sought to determine whether respondents who had been provoked by a rude examiner would provide aggressive evaluations of the examiner's performance compared to those who had not been provoked. Results indicated that the IAT significantly predicted aggressively worded evaluations when provoked but it was not predictive when there was no provocation. Interestingly, none of the explicit measures was associated with aggressive behaviour. The Richetin et al. study provides important evidence of the potential usefulness of implicit measures in predicting aggressive behaviour that is expressed as a means of retaliation.

McCormick (2013) examined the mediating role of both implicit and explicit attitudes in the relationship between exposure to interparental violence and dating violence among a sample of undergraduate students. Results revealed that only explicit attitudes mediated the relationship between interparental violence and dating violence for female participants. In contrast, both implicit and explicit attitudes were found to mediate the relationship between interparental violence and dating violence for male participants. The author hypothesized that gender differences in the predictive validity of the IAT may be partially accounted for by implicit beliefs about gender roles in dating relationships. More specifically, the author suggested that male participants may have interpreted the task from the perspective of the perpetrator, while female participants may have approached the task from the perspective of the victim.

Nunes, Hermann, and Ratcliffe (2013) examined implicit and explicit attitudes toward rape, past sexual coercion, and future likelihood of rape in a sample of male heterosexual undergraduate students. Findings revealed that those who reported the most past sexual coercion 
or likelihood to rape in the future had significantly more positive implicit and explicit attitudes toward rape than those who did not report past sexual coercion or likelihood of rape in the future. These results suggest that implicit and explicit attitudes toward sexual violence provide complimentary information and that assessing both may be particularly beneficial in the assessment of perpetrators of sexual violence in an undergraduate population.

Additional research has focused on the role of the IAT in uncovering implicit attitudes toward violence among offender populations as well as those requiring treatment for violent behaviour. Robertson and Murachver (2007) examined implicit attitudes toward violence among a sample of offenders incarcerated for intimate partner violence, compared to a sample of nonincarcerated participants. The authors found that the incarcerated sample had significantly more positive implicit attitudes toward violence than members of the non-incarcerated sample. However, no significant differences were found between groups on explicit, self-report attitudes toward violence. These findings may suggest possible biased responding on the explicit measures of attitudes among the offender population.

In a related study, Eckhardt, Samper, Suhr, and Holtzworth-Munroe (2012) used the IAT to assess attitudes toward gender, violence, and the association between gender and violence among men enrolled in an intimate partner violence treatment program and a comparison sample of nonviolent men. Although no significant differences were noted on explicit attitudinal measures, men in the intimate partner violence group showed a more positive and rapid association between women and violence than those in the non-violent group. In addition, among men in the treatment group, attitudes toward violence on the IAT were significantly correlated with self or partner reported violence frequency. 
More recently, Nunes, Ennis, Hermann, Maimone, and Choy (2014) used both implicit and explicit measures of attitudes to assess the relationship between attitudes toward violence, risk of violent recidivism, and psychopathy. The sample consisted of 30 male forensic psychiatric patients with a history of violent behaviour. Findings indicated that neither the implicit nor explicit measures of attitudes were significantly predictive of the outcome variables; however, the self-report measures had stronger correlations than the implicit attitude measure with risk of violent recidivism. The authors suggested that this finding may be a result of the setting in which the tests were administered. More specifically, it was hypothesized that participants in the sample (i.e., forensic psychiatric patients) may have been less likely to respond in a socially desirable manner as potential release from the hospital was not contingent on their responses. The authors postulated that if participants had been anticipating discharge or had perceived their stay in the hospital to be short, they may be more likely to engage in socially desirable responding for fear of delaying their discharge. Indeed, a study by Gudjonsson and Moore (2001) found that forensic patients in medium security hospitals were more likely than maximum security patients to be deceptive on a self-report questionnaire measuring attitudes toward a range of undesirable behaviours.

Lastly, Maimone (2014) conducted three studies examining implicit and explicit attitudes toward violent behaviour among two samples of male undergraduate students and one sample of adult offenders. The first study examining attitudes toward violence among male university students found that only explicit (and not implicit) attitudes toward violence differentiated students who reported engaging in violence from those who had not. Similar to the first study, the second study sought to determine whether implicit and explicit, self-reported, attitudes toward violence differentiated violent offenders from non-violent offenders. In addition, this 
study examined whether implicit and explicit attitudes toward violence were associated with future risk for violence. Findings indicated that neither implicit nor explicit attitudes significantly differentiated violent from non-violent offenders. Furthermore, the results revealed that implicit attitudes toward violence were not significantly related to future risk of violent behaviour. However, more positive self-reported attitudes toward violence were found to be associated with a greater future risk of violent behaviour.

In order to expand the findings of the previous two studies, the third study examined whether a sample of university students' implicit and explicit attitudes toward violence varied as a result of engaging in, or observing another person engage in, a violent task (a boxing videogame) or peaceful task (a tennis videogame). More specifically, the author investigated whether engaging in and/or observing someone engage in violence increased the positive relationship between implicit and explicit attitudes toward violence and furthermore, one's risk for future violent behaviour. To detect potential changes in implicit or explicit attitudes, both types of attitudes were measured before and after the study manipulation. Findings showed that participants demonstrated more violent implicit attitudes at post-test, regardless of whether they engaged in or observed someone playing either the violent or peaceful task. Interestingly, significantly more positive (supportive) explicit attitudes toward violence were found postmanipulation for those engaged in the violent task, as well as those who watched someone engage in the violent task. Moreover, explicit attitudes toward violence were not significantly different post-manipulation for participants who either played the peaceful task or watched someone playing the peaceful task.

In summary, the reviewed studies suggest that support for the relation between implicit attitudes toward aggression and violence is mixed in both undergraduate and clinical samples 
(Eckhardt, Samper, Suhr, \& Holtzworth-Munroe, 2012; McCormick, 2013). It is evident that further research examining implicit and explicit aspects of cognitive processing as they apply to the prediction of aggressive behaviour is required in order to clarify their utility in this domain.

\section{Executive Functioning as a Measure of Actual Behavioural Control}

Similar to attitudes and subjective norms, the PBC construct in the TPB model has traditionally been assessed using explicit, self-report measures. To recap, the PBC construct measures an individual's evaluation of the ease or difficulty associated with performing a given behaviour, based on their knowledge of factors that may facilitate or impede their performance (Ajzen, 1991). For example, an individual might report that it would be easy for them to walk away from provocation as they believe they would be able to control angry impulses to retaliate. The PBC construct assumes that individuals are aware of the factors (both internal and external) that may facilitate or impede their performance of a given behaviour (e.g., aggressive behaviour). This assumption may be problematic for at least two reasons. First, it is possible that people are not fully aware of the internal and external factors that may facilitate or impede their performance of a given behaviour. For example, an individual may report that they would be able to walk away from a provoking situation, but may not be aware of their own deficits in regulating their own behaviour, which may lead to an aggressive response. Second, it is possible that individuals may provide socially desirable responses on a self-report questionnaire (e.g., "It would be easy for me to walk away from a fight because I can control angry impulses"), rather than admitting to difficulties related to their ability to control angry impulses.

In light of the problems with the explicit measurement of $\mathrm{PBC}$, it is suggested here that including a measure of "actual" behavioural control (ABC) in the TPB model may improve the prediction of aggressive behaviour. It is suggested that $\mathrm{ABC}$ may be measured by examining 
one's ability to self-regulate behaviour, commonly referred to as executive functioning (Baumeister \& Vohs, 2003). According to Alvarez and Emory (2006), executive functioning can be defined as "higher-level cognitive functions involved in the control and regulation of lowerlevel cognitive processes and goal-directed, future oriented behaviour" (p. 17). Deficits in executive functioning can manifest as behavioural inhibition difficulties, such as aggression or impulsivity (Anderson, Anderson, Northam, Jocobs, \& Catroppa, 2001). Control over executive functioning is located in the prefrontal cortex (Goldberg, 2001) and deficits in limbic regions of this area have been found to be associated with difficulties controlling aggressive impulses (Banfield, Wyland, Macrae, Munte, \& Heatherton, 2004; Denson, Pederson, Ronquillo, \& Nandy, 2009). Indeed, researchers have found deficits in executive functioning among a number of aggression-prone clinical populations, such as conduct disordered adolescents (Giancola \& Mezzich, 2000) and adult violent offenders (Valliant, Gristey, Pottier, \& Kosmyna, 1999).

As executive functioning involves the ability to regulate impulsive behaviour, deficits in this area may play a central role in explaining reactive aggression. In order to investigate this assumption, MacTavish (2011) examined the effect of executive functioning as a moderator of the relation between provocation and physical aggression between university students. MacTavish dichotomized executive functioning as consisting of either "cool" cognitive processes, such as cognitive flexibility [(measured via the Wisconsin Card Sorting Test (WCST; Grant \& Berg, 1948) and Part B of the Trails Making Test (Reitan, 1958)], or "hot" emotional processes, such as decision-making [(measured via the Iowa Gambling Task (Bechara, Damasio, Damasio, \& Anderson, 1994)]. McTavish measured physical aggression using the modified version of the TAP by Bushman and Baumeister (1998) mentioned earlier in this chapter. To recap, reactive physical aggression is measured via the administration of white noise blasts after 
receiving positive or negative feedback from an ostensive partner. Results of the study revealed that individuals with lower levels of executive functioning were more physically aggressive than individuals with higher levels of executive functioning. Interestingly, this pattern was found for "cool" and "hot" executive functioning processes.

More recently, Foti, Hennig and Hoaken (2014) jointly examined narcissism and executive functioning [measured via the WCST, the Self Ordered Pointing task (SOP; Milner \& Petrides, 1984), as well as the Go/No-Go task (Helmers, Young, \& Pihl, 1995)] as predictors of reactive physical aggression in a sample of undergraduate students. Similar to MacTavish (2011), the authors used the modified version of the TAP to measure reactive physical aggression, following positive or negative (i.e., ego threatening) essay feedback from an ostensive partner. Results indicated that deficits in executive functioning were predictive of aggressive responding. More specifically, a modified version of the Wisconsin Card Sorting Test (WCST; Grant \& Berg, 1948) was found to be the strongest executive functioning measure to predict aggression. Contrary to Vazire and Funder's (2006) hypothesis that suggests that narcissists engage in aggression due to difficulties inhibiting behavioural responses, Foti and colleagues failed to find a relation between narcissism and any of the measures of executive functioning in their study.

Results of the aforementioned studies provide convincing evidence that deficits in executive functioning may be an important predictor of reactive physical aggression. Furthermore, these results suggest that $\mathrm{ABC}$, measured via an executive functioning task, may be a particularly novel means of measuring behavioural control that is less vulnerable to issues associated with the measurement of the $\mathrm{PBC}$ construct. 


\section{The Present Research}

This dissertation aimed to extend current research on reactive physical aggression in undergraduate students and consisted of two studies. Study 1 aimed to develop a valid and reliable questionnaire to measure the primary constructs of the TPB model (i.e., attitudes, subjective norms, $\mathrm{PBC}$, and intentions) as they apply to reactive physical aggression. Study 2 aimed to test a modified version of the TPB model that included the traditional constructs of the TPB model (measured via the TPB questionnaire developed in Study 1), as well as three additional constructs that served to expand the original model (see Figure 2). First, an implicit measure of attitudes was added to the model as an additional predictor of reactive physical aggression. In addition to overcoming limitations associated with explicit-self report measures (e.g., social desirability biases), the inclusion of an implicit measure of attitudes may help to determine whether reactive physical aggression is an automatic or controlled behaviour. Implicit attitudes were measured through the use of a modified version of the Implicit Association Test (IAT), that combined two existing versions of the IAT that have previously been used to examine general implicit attitudes toward aggression (Banse \& Fisher, 2002) and specific implicit attitudes toward dating violence (McCormick, 2013).

Second, executive functioning measured using the Wisconsin Card Sorting Test: Computer Version 4 Research Edition (WCST: CV4; Heaton, PAR Staff, \& Goldin, 2003) was added to the model and served as a measure of ABC. As previous research has established an association between deficits in executive functioning and behavioural inhibition difficulties, such as impulsivity and aggression (e.g., Anderson et al., 2001), it is possible that individuals with low levels of executive functioning may experience a lack of awareness regarding their ability to control their behaviour. For this reason, the inclusion of a measure of $\mathrm{ABC}$ may be particularly 


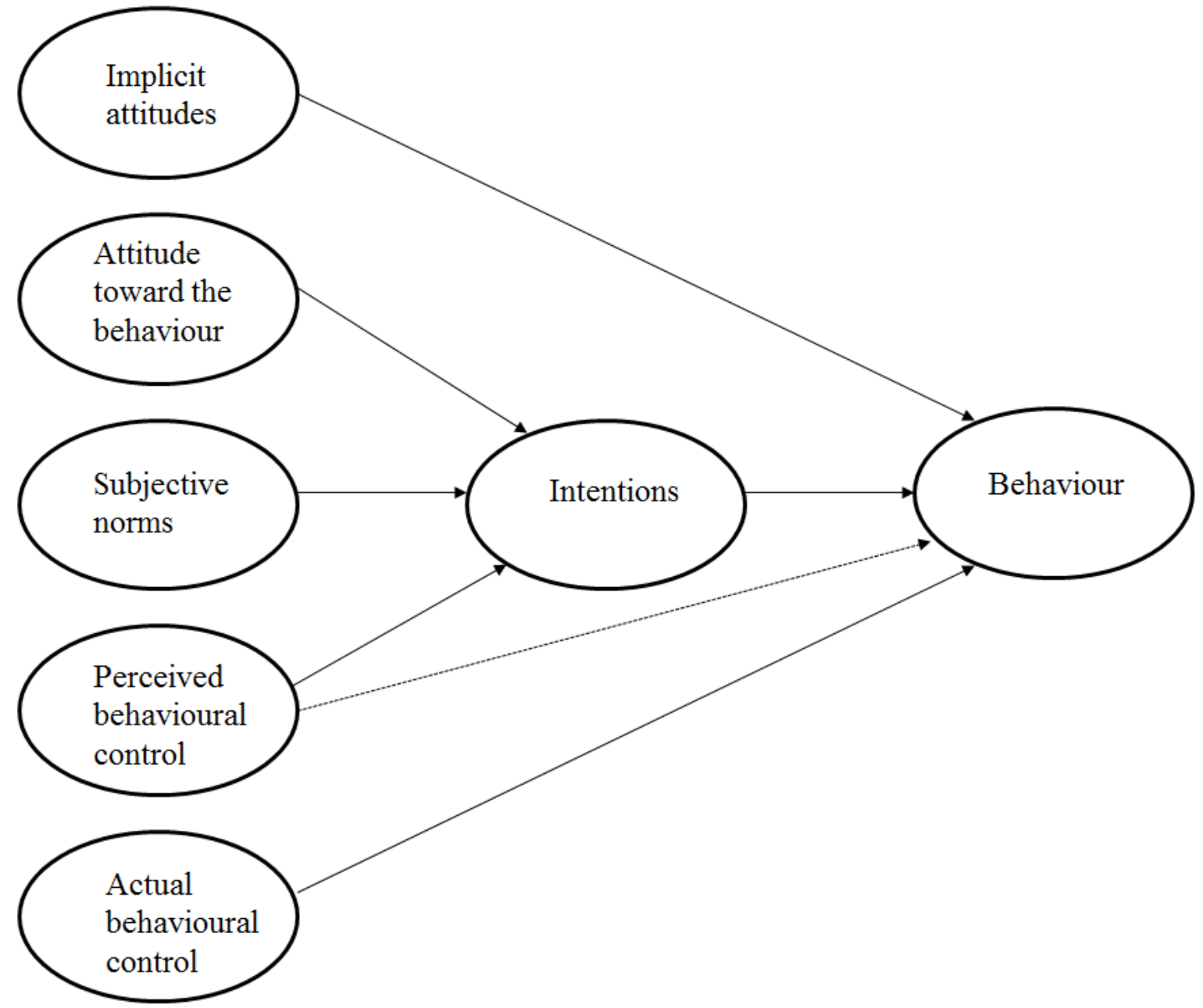

Figure 2. Modified version of the theory of planned behaviour model. 
useful in predicting reactive physical aggression. It should be noted that the subjective norms construct was only measured explicitly through the use of a self-report questionnaire, as it was not plausible to measure this construct in an implicit fashion.

Third, the traditional TPB model was modified by applying an objective assessment of reactive physical aggression (i.e., the modified version of the Taylor Aggression Paradigm (TAP) developed by Bushman and Baumeister, 1998). Similar to criticism regarding the sole use of explicit measures of cognitions toward behaviours in the TPB model, the TPB has additionally been criticized for using self-report questionnaires to measure behaviour (Ogden, 2003). Although self-reporting of behaviour appears to be the norm in the TPB literature, it is possible that respondents may provide untruthful reports of their behaviour in order to present themselves in a more positive light to the experimenter. This may be especially relevant when the behaviour in question is socially sensitive in nature (e.g., physically aggressive behaviour). The addition of an objective measure of physical aggression in the TPB model provided a novel method of measuring physically aggressive behaviour that avoided problems associated with self-report measures of aggression.

Finally, the modified model was then used to predict reactive physical aggression under the following two study conditions: a) a "no delay" condition, where participants were provoked and then immediately provided with an opportunity to retaliate against a partner, and b) a "short delay" condition, where participants were provoked and were then made to wait 10 seconds before they were provided with an opportunity to retaliate. By including condition as a moderator, the researcher was able to examine whether a brief delay impacted participants' level of reactive physical aggression. 
It is noted that this "cool down" approach has been adopted by other well-established treatment programs, such as the "STOP” program (Nay, 2014), which encourages clients to take a deep breath and count down from 10 before acting on angry impulses. This strategy is in line with the "Reflective-Impulsive System" (Strack \& Deutsch, 2004) described earlier in this chapter. As was previously mentioned, this system suggests that there may be both a reflective system in which behaviour occurs as a result of a careful decision making process, as well as an impulsive system, in which behaviour occurs as a result of automatic, subconscious processing. In this way, it is suggested that the addition of a 10 second delay may provide participants with additional time to inhibit urges to retaliate and/or decide whether they wish to respond aggressively. 


\section{CHAPTER TWO}

\section{STUDY 1: TPB QUESTIONNAIRE DEVELOPMENT}

The purpose of Study 1 was to develop a questionnaire that measured the four constructs of the TPB: 1) attitudes; 2) subjective norms; 3) perceived behavioural control (PBC); and 4) intentions, as they apply to reactive physical aggression. According to Ajzen (1985), one's intention to engage in a particular behaviour is guided by the following three factors: a) whether the person is in favour of performing the behaviour (i.e., their attitude toward the specific behaviour), b) how much social pressure the person feels to perform or not perform the behaviour (i.e., subjective norms), and c) whether the person feels that they are in control of performing the behaviour (i.e., PBC). Generally, the more favourable the attitude and subjective norm, and the greater the PBC, the more likely the person is to intend to perform the behaviour in question (Francis et al., 2004) ${ }^{1}$. It is noted that the TPB is an indirect model whereby the relations between attitudes, subjective norms, PBC and behaviour are mediated by intentions. In this way, intentions are assumed to be the most proximate predictor of behaviour. The questionnaire developed in this study was used in the test of the modified version of the TPB model (i.e., Study 2) described in the following chapter. Details related to questionnaire development, including scoring for each of the TPB constructs, can be found in Appendix A. Additionally, individual questionnaire items related to the attitudes, subjective norms, PBC, and intentions constructs can be found in Appendices B, C, D, and E, respectively.

\footnotetext{
${ }^{1}$ In contrast to how the relation between PBC and intentions has been conceptualized by Ajzen (1985) (i.e., the greater the PBC, the greater the intention to engage in the behaviour), higher scores on PBC items in the current study were thought to indicate lower intention to engage in physically aggressive behaviour. The researcher chose to conceptualize the PBC-intentions association in this way as reactive physical aggression is a direct response to provocation and may occur as a result of a lack of control over angry impulses to retaliate. See Appendix A for further details.
} 


\section{Method}

\section{Participants}

Two hundred and eighty five participants from Ryerson University in southern Ontario were recruited through SONA, the undergraduate participant pool, in exchange for 0.5 course credits. Participants were required to be enrolled in a first year undergraduate psychology course in order to participate. Participants were not required to disclose additional demographic information.

\section{Procedure}

Research Ethics Board (REB) approval was obtained prior to beginning the study. Participants were informed that the aim of the study was to develop a valid and reliable questionnaire that effectively characterized university students' attitudes toward engaging in reactive physical aggression. Informed consent was obtained prior to participation. Once participants had read the definition of reactive physical aggression, they were then instructed to read two short scenarios that described situations involving reactive physical aggression in response to perceived provocation (see Appendix F for description of scenarios). These scenarios provided commonly occurring examples of reactive physical aggression (i.e., pushing in the subway during rush hour and getting cut off by another driver during rush hour) which participants could likely relate to. Keeping these scenarios in mind, participants were asked to respond to 25 items that tapped into the constructs of the TPB model as they applied to reactive physical aggression.

\section{Data Analytic Strategy}

All analyses were performed using IBM SPSS Statistics 22.0. A reliability analysis was first conducted to ensure that each of the subscales demonstrated adequate internal consistency. 
A principal components analysis (PCA) was then conducted using an orthogonal rotation to examine the underlying latent dimensions of the data.

\section{Results}

\section{Reliability Analysis}

Reliability analyses were conducted on each of the subscales. Prior to conducting further analyses, inter-item correlations for each of the subscales were reviewed and correlations below the minimum loading cut off of .30 (as suggested by Field, 2009) were deleted. One item from the attitudes subscale (i.e., "Reactive physical aggression is pleasant/unpleasant") received a loading of .28 and was therefore deleted from the subscale, resulting in an improved Cronbach's $\alpha$ of .83 (previously .80). All remaining subscale items demonstrated inter-item correlations above .30 . The subjective norms subscale was found to have acceptable internal consistency, Cronbach's $\alpha=.72$. Each of the inter-item correlations was found to be above .30 . The reliability analysis did not suggest deletion of any of the subscale items. The PBC subscale was found to have good internal consistency, Cronbach's $\alpha=.81$. None of the inter-item correlations was below .30 and no items were suggested for deletion. Finally, the intentions subscale demonstrated very good internal consistency, Cronbach's $\alpha=.89$. Similar to the other subscales, inter-item correlations were above .30 and no items were identified for deletion.

\section{Principal Components Analysis}

A PCA was conducted on the remaining 24 items using an orthogonal (varimax) factor rotation (as one item was deleted from the initial attitudes subscale of the questionnaire). The Kaiser-Meyer-Olkin (KMO) measure of sampling adequacy was .891, which indicated that the components were suitable for factor analysis (Kaiser, 1974). In addition, the Bartlett's test of

sphericity was significant, $\chi^{2}(276)=3250.499, p<.001$, indicating that the $R$-matrix was not an 
identity matrix and therefore PCA was appropriate. Furthermore, diagonals of the anti-image correlation matrix were all over .50, supporting the inclusion of each item in the factor analysis (Field, 2009).

Kaiser's criterion indicated that four factors, accounting for $58 \%$ of the variance in the sample (eigenvalues of 7.85, 2.60, 1.86, and 1.62, respectively), should be extracted from the dataset (see Figure 3 for the scree plot). Further, when a fifth factor was extracted (eigenvalue of .93) very few items loaded on to this factor. The rotated correlation matrix was consulted to determine which items loaded on the same factors (see Table 1 for summary of factor loadings after rotation). Results indicated that Factor 1 represented the intentions construct; Factor 2 was characterized by the attitudes construct; Factor 3 represented the PBC construct; and Factor 4 represented the subjective norms construct. It is noted that two of the items each cross-loaded $>.40$ on two subscales (e.g., "Other people would expect me to engage in RPA" loaded on the intentions subscale as well as the subjective norms subscale at .43 and .45 , respectively) ${ }^{2}$. However, as each of the items was most highly loaded on the subscale to which it belonged, the researcher chose not to drop these items.

\footnotetext{
${ }^{2}$ No significant changes to overall model fit were noted when the two cross-loaded items were omitted.
} 


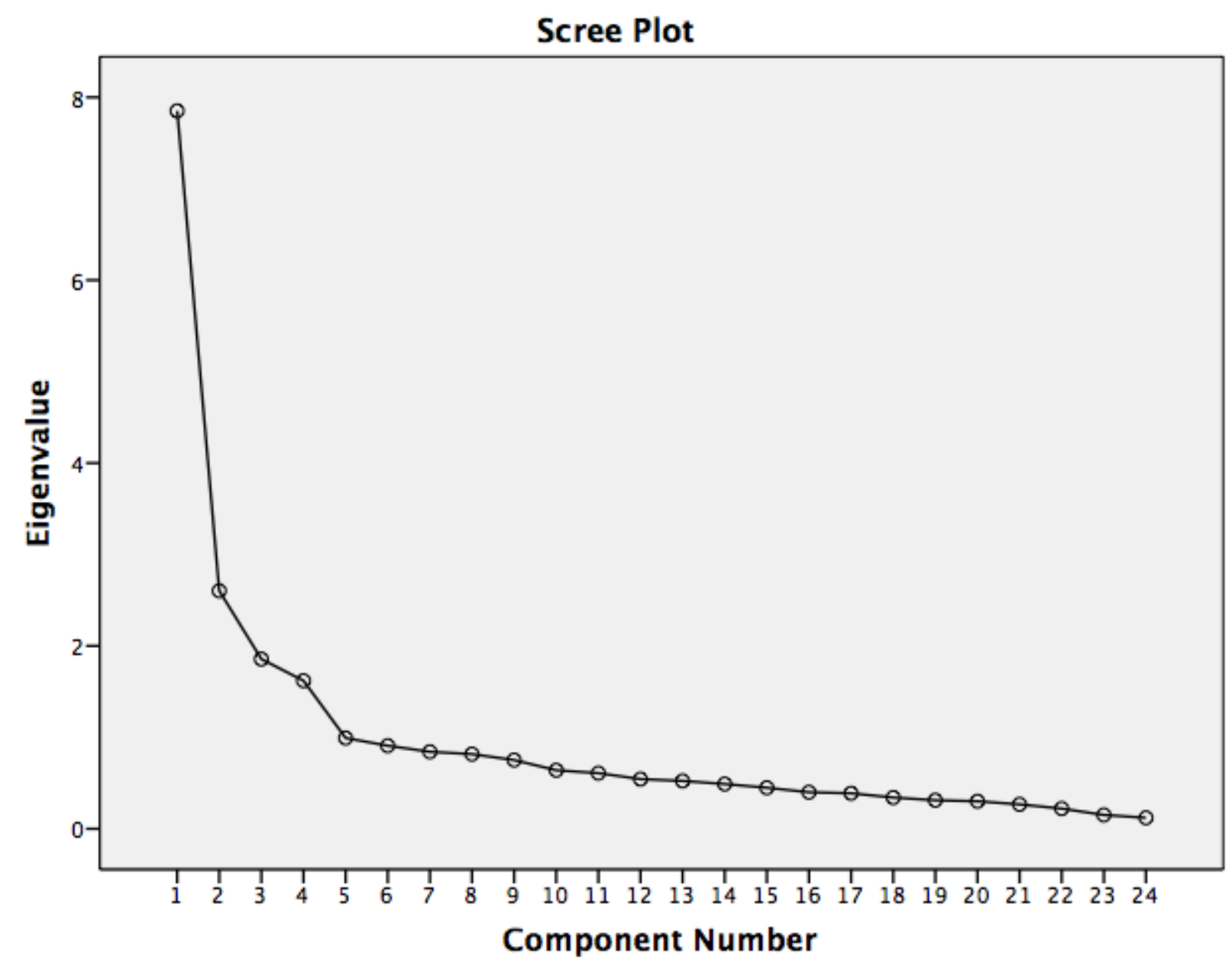

Figure 3. Principal Components Analysis: Scree plot 
Table 1

Summary of Factor Loadings after Rotation for TPB Questionnaire $(N=285)$

\begin{tabular}{|c|c|c|c|c|c|}
\hline & & \multicolumn{4}{|c|}{ Rotated Factor Loadings } \\
\hline \multicolumn{2}{|l|}{ Items } & Intentions & Attitudes & PBC & $\begin{array}{l}\text { Subjective } \\
\text { Norms }\end{array}$ \\
\hline \multirow[t]{5}{*}{ Attitudes } & RPA is harmful/beneficial & .21 & .83 & -.08 & .13 \\
\hline & RPA is wrong/right & .21 & .85 & -.09 & .24 \\
\hline & RPA is bad/good & .22 & .86 & -.06 & .21 \\
\hline & RPA is useless/useful & .18 & .72 & -.08 & .09 \\
\hline & RPA is unsatisfying/satisfying & .43 & .45 & .10 & -.06 \\
\hline \multirow[t]{6}{*}{ Subjective Norms } & $\begin{array}{l}\text { People who are important to me think that I should not } \\
\text { engage in RPA }\end{array}$ & -.09 & .39 & -.35 & .46 \\
\hline & I feel under social pressure to engage in RPA & .27 & .18 & -.15 & .35 \\
\hline & Other people would expect me to engage in RPA & .43 & .13 & -.21 & .45 \\
\hline & $\begin{array}{l}\text { People who are important to me would want me to engage in } \\
\text { RPA }\end{array}$ & .14 & .04 & -.08 & .78 \\
\hline & Most people would support me if I engaged in RPA & .26 & .18 & .07 & .65 \\
\hline & $\begin{array}{l}\text { People who are important to me think that RPA is the right } \\
\text { thing to do }\end{array}$ & .08 & .18 & -.08 & .81 \\
\hline \multirow[t]{6}{*}{ PBC } & I am confident that I could control impulses to retaliate & -.06 & -.08 & .78 & -.06 \\
\hline & Whether I engage in RPA is entirely up to me & -.02 & -.09 & .65 & -.02 \\
\hline & Avoiding RPA is easy for me & -.36 & -.02 & .70 & .01 \\
\hline & I am capable of controlling my behaviour when provoked & -.23 & -.05 & .76 & .06 \\
\hline & Avoiding RPA is difficult for me & -.35 & .04 & .51 & -.23 \\
\hline & The decision to engage in RPA is beyond my control & -.14 & -.03 & .66 & -.25 \\
\hline \multirow[t]{7}{*}{ Intentions } & I will engage in RPA if I am provoked & .61 & .32 & -.24 & .05 \\
\hline & $\begin{array}{l}\text { I intend to use physical aggression against an instigator who } \\
\text { has harmed me }\end{array}$ & .74 & .21 & -.16 & .06 \\
\hline & I expect to engage in RPA against an instigator & .69 & .19 & -.29 & .16 \\
\hline & $\begin{array}{l}\text { I do not plan to use physical aggression against someone } \\
\text { who has harmed me first }\end{array}$ & .50 & .16 & -.35 & .04 \\
\hline & I wish to engage in RPA against an instigator & .72 & .22 & -.09 & .21 \\
\hline & $\begin{array}{l}\text { I desire to engage in physical aggression against someone } \\
\text { who has harmed me first }\end{array}$ & .81 & .09 & -.12 & .14 \\
\hline & $\begin{array}{l}\text { I want to use physical aggression against someone who has } \\
\text { harmed me first }\end{array}$ & .83 & .09 & -.11 & .20 \\
\hline
\end{tabular}

Note. RPA $=$ Reactive physical aggression. $\mathrm{PBC}=$ Perceived behavioural control. Extraction Method: Principal Components Analysis. Rotation Method: Varimax with Kaiser Normalization. Items with loadings of $>.40$ are bolded. 


\section{CHAPTER THREE}

\section{STUDY 2: TEST OF THE MODIFIED TPB MODEL}

Study 2 comprised the following two aims: 1) to test the modified version of the TPB model in predicting reactive physical aggression in a sample of undergraduate students; and 2) to determine the impact of a 10 second delay between provocation and opportunity for reactive physical aggression. To recap, the modified TPB model sought to improve the prediction of reactive physical aggression by adding three novel elements to the constructs of the traditional TPB model. First, the traditional TPB model was modified through the addition of an objective assessment of reactive physical aggression, that is, the modified version of the TAP developed by Bushman and Baumeister (1998). This objective measure of aggression aimed to address issues related to potentially biased reporting of reactive physical aggression (Ogden, 2003).

Second, an implicit measure of attitudes toward reactive physical aggression was added to the modified model. It is suggested that the inclusion of an implicit measure of attitudes may address the problem of potential response biases that may be present when using explicit measures of attitudes. In order to avoid confusion between implicit and explicit attitudes, the "attitudes" construct measured via the TPB questionnaire will hereafter be referred to in this section as "explicit attitudes." Third, a measure of actual behavioural control (ABC) was added to the model. The inclusion of $\mathrm{ABC}$, measured via executive functioning, allowed the researcher to assess participants' control over their behaviour as the $\mathrm{ABC}$ score was not influenced by response bias or a lack of insight into one's behaviour.

Following the test of the modified TPB model, the researcher aimed to determine the impact of a brief delay between provocation and opportunity for reactive physical aggression. In this way, condition (i.e., no delay versus short delay) was examined as a possible moderator in the prediction of reactive physical aggression. The addition of the 10 second delay condition 
allowed the researcher to examine whether a brief delay was associated with inhibition of aggressive impulses.

\section{Hypotheses}

Hypothesis 1: It is hypothesized that more supportive intentions and lower levels of PBC will predict greater levels of reactive physical aggression.

Hypothesis 2: It is hypothesized that explicit attitudes, subjective norms, and PBC will predict intentions. More specifically, it is hypothesized that favourable attitudes toward reactive aggression, perceived social support for the behaviour, as well as lower levels of PBC will predict greater intention to engage in reactive physical aggression.

Hypothesis 3: It is hypothesized that the relations between explicit attitudes, subjective norms, and $\mathrm{PBC}$ and reactive physical aggression will be mediated by intentions.

Hypothesis 4: It is hypothesized that individuals with more supportive implicit attitudes toward aggression will display greater levels of reactive physical aggression compared to those with less supportive implicit attitudes.

Hypothesis 5: It is hypothesized that lower levels of ABC will predict higher levels of reactive physical aggression.

Hypothesis 6: It is hypothesized that condition (no delay versus short delay) will moderate the relationship between the predictors and reactive physical aggression, such that stronger relations will be observed between measures of explicit attitudes and reactive physical aggression in the short delay condition compared to the no delay condition. In contrast, stronger relations will be observed between measures of implicit attitudes and reactive physical aggression in the no delay condition compared to the short delay condition. 


\section{Method}

\section{Participants}

Sample 1. Twenty participants (75\% female) from Ryerson University were recruited through SONA, the undergraduate participant pool, for an initial manipulation check. The manipulation check was conducted in order to examine the extent to which the negative feedback condition (described in Study 2 methods section below) was experienced as ego-threatening by participants and whether participants believed they were competing against a real partner on the competitive task (i.e., the modified version of the TAP). Participants were not required to disclose additional demographic information (see Appendix $\mathrm{H}$ for methods and results related to the manipulation check).

Sample 2. Two hundred and nine participants (74\% female) from Ryerson University were recruited through SONA, the undergraduate participant pool. It is noted that all methods and results related to Study 2 pertain to this sample of participants. Seven participants were eliminated from the total number of participants in the study sample due to either high levels of suspiciousness related to the deception used in the study $(n=5)$, decision to withdraw from the study $(n=1)$, or experimenter error $(n=1)$. The final sample comprised 202 participants $(75 \%$ female) with a mean age of 20.69 years old $(S D=5.86)$. In addition, participants had completed on average 12.72 years of education $(S D=1.38)$. Using a random number generator, participants were randomly assigned to either a no delay $(n=104)$ or a delay condition $(n=98)$.

\section{Measures}

Reactive Physical Aggression. The modified version of the Taylor Aggression Paradigm (TAP; Taylor, 1967) by Bushman and Baumeister (1998) was used to measure reactive physical aggression. The TAP is disguised as a competitive reaction time task where participants compete 
against a fictitious opponent (i.e., a computer program mimics an opponent's responses).

Participants are told that they are competing against their partner to be the fastest to click the mouse when the colour of a small box on the screen changes from yellow to red. The winner of each reaction time trial is offered the option to "punish" his/her partner by blasting his/her opponent with an aversive stimulus (i.e., white noise). Participants set the duration and intensity of the white noise prior to the trial, which is then administered to the losing opponent following the trial. White noise duration ranged from 1 to 5 seconds and from $60 \mathrm{~dB}$ to $90 \mathrm{~dB}$ in intensity. TAP settings were calibrated with a decibel meter. The mean sum of the standardized score for the duration and intensity of the first noise blast was used as a measure of reactive physical aggression. The TAP has consistently shown to be a valid measure of aggression (Godlaski \& Giancola, 2009; Hoaken, Shaughnessy, \& Pihl, 2003).

Demographics. Participants were asked to provide demographic information, including age, gender, and years of education (see Sample 2 section).

Explicit Attitudes, Subjective Norms, PBC, and Intentions. The 24-item TPB questionnaire, developed and tested in Study 1, was used to measure the primary constructs of the TPB as they applied to engaging in reactive physical aggression. To recap, total scores for each of the constructs were created by summing their respective individual items. Each of the TPB questionnaire's subscales demonstrated good internal consistency (Cronbach's $\alpha$ for attitudes subscale $=.83$, subjective norms $\alpha=.72, \operatorname{PBC} \alpha=.81$, and intentions $\alpha=.89$ ).

Implicitly Measured Attitudes. A modified version of the Implicit Association Test (IAT) called the "Reactive Aggression IAT" was used to measure specific implicit attitudes toward reactive physical aggression. This measure was developed by modifying two existing versions of the IAT that had previously been used to examine general implicit attitudes toward aggression 
(Banse \& Fisher, 2002) and specific implicit attitudes toward dating violence (McCormick, 2013). The Reactive Aggression IAT measured the strength of the association between two contrasted target categories (i.e., "I like" and "I don't like") and two contrasted attribution categories (i.e., "Tolerate" and "Retaliate") via a classification task (see Table 2 for a list of stimulus items corresponding to each of the categories). The assumption underlying the Reactive Aggression IAT is that if two concepts are highly associated (e.g., "I like or Tolerate"), the classification task will be easier and the participant will be able to respond more quickly.

The Reactive Aggression IAT comprised five blocks of trials for a total of 200 trials. In the first block, participants were required to accurately classify stimulus items into the "I like" and "I don't like" target categories (e.g., "Great" into "I like" and "Bad" into "I don't like"). In the second block, participants were required to accurately classify stimulus items into the "Retaliate" and "Tolerate" attribution categories (e.g., "Revenge" into "Retaliate" and "Talk" into "Tolerate"). In the third block, the four categories that were originally presented separately now appeared together, and participants were asked to accurately classify all stimulus items into the proper combined categories (e.g., "I like and Tolerate" versus "I don't like and Retaliate"). In the fourth block, participants were again required to classify stimulus items into the target category dimensions ("I like and "I don't like"), however, the position of these categories had reversed so that they appeared on opposite sides of the computer screen. In the final block, the four categories appeared together in a new configuration (e.g., "I like and Retaliate" and "I don't like and Tolerate") and participants were required to accurately classify all stimulus words into the proper target or attribute dimension categories.

IAT scores were computed according to the procedure suggested by Greenwald, Nosek, and Banaji (2003). The mean response latency for sorting words in the incompatible block ("I 
Table 2

Reactive Aggression IAT Stimulus Items

Category Stimulus Items

I Like Great, Fantastic, Pleasant, Good, Wonderful

I Don't like Bad, Horrible, Awful, Disgusting, Terrible

Retaliate Revenge, Beat up, Punch, Slap, Avenge, Strike back, Fight, Knock-out, Attack

Tolerate Conciliation, Chat, Discuss, Understand, Talk, Agreement, Apology, Comply, Agree 
like or Retaliate" and "I don't like or Tolerate") was subtracted from the mean response latency for sorting words in the compatible block ("I like or Tolerate" and "I don't like or Retaliate"). The difference in response latency was then divided by the pooled standard deviation. According to Greenwald and colleagues (2003), trials with extreme latencies (i.e., greater than 10,000 ms or response latencies less than $400 \mathrm{~ms}$ ) are recommended for elimination from the dataset. In addition, cases with error rates higher than $40 \%$ are recommended for elimination. The IAT has been found to have strong predictive validity in the prediction of socially sensitive topics (Greenwald, Poehlman, Uhlmann, \& Banaji, 2009).

Actual Behavioural Control (ABC). The Wisconsin Card Sorting Test: Computer Version 4 Research Edition (WCST: CV4; Heaton et al., 2003) assesses executive functioning and provided a measure of ABC. A number of studies have found support for the WCST as a measure of general executive functioning (Greve, Stickle, Love, Bianchini, \& Stanford, 2005; Heaton, Chelune, Talley, Kay, \& Curtiss, 1993). The WCST: CV4 requires participants to match key cards that vary in three stimulus dimensions (i.e., colour, shape, and number) according to a changing rule. Participants were not instructed on how to sort the cards, but were provided with feedback as to whether their match was correct or incorrect. $\mathrm{ABC}$ scores were based on the number of perseverative errors.

Debriefing Questions. As part of the debriefing process, participants, as well as the researcher and her research assistants, provided ratings of participant suspiciousness. After the deception was revealed, the reasons for the use of deception were explained, and participants were asked to sign the debriefing form providing consent to use their data.

\section{Procedure}


Research Ethics Board (REB) approval was obtained prior to beginning the study. Participants were tested individually for approximately one and a half hours and were informed that the aim of the study was to learn more about university students' life goals, competitive nature, and attitudes toward aggressive behaviour. Once informed consent was obtained, participants were asked to complete an online version of the TPB questionnaire, designed to examine their explicit beliefs toward engaging in reactive physical aggression.

Following completion of the TPB questionnaire, participants were asked to complete the Reactive Aggression IAT and then the WCST: CV4. Once all computerized activities were finished, participants completed the modified version of the TAP. In line with Bushman and Baumeister's (1998) procedure, participants were first asked to write a one paragraph essay on their life goals. They were told that their essay would be evaluated by a partner of the same sex who was completing the same activities in another room. Participants were told they would receive ratings from 1 (extremely poor) to 10 (excellent) on each of the following evaluation criteria: 1) organization, 2) writing style, 3) clarity of expression, and 4) overall quality of the essay; however, the feedback was actually pre-written and did not reflect a true rating on any of the evaluation criteria. As this study aimed to examine the impact of provocation on reactive physical aggression, all study participants received only negative essay feedback from their ostensive partner. In addition to ratings, participants received the following negative comment on their essay: "This essay was poorly written. I think you would benefit from attending a writing workshop"). Prior to receiving feedback, participants also rated their ostensive partner's essay according to the same evaluation criteria and had the opportunity to provide a comment. Immediately after receiving feedback on the essay from their partner, participants completed the modified version of the TAP, presented as a computerized reaction time task. 
Participants were told that they were competing against their partner to be the fastest to react when a small box on the screen changed colours. As stated earlier, participants set the duration and intensity of the white noise prior to the trial. The white noise blast was then administered to the losing opponent following the trial. Participants were informed that their partner received the same instructions, when in actuality, the duration and intensity of the noise blasts, as well as the win/lose sequence of the trials, were predetermined by the computer program. Upon receiving the negative essay feedback, participants were randomly assigned to the "no delay" or "short delay" condition. Participants in the no delay condition received their supposed partner's negative essay feedback and were immediately asked to begin the modified version of the TAP, which was presented as a computerized reaction time task. Participants in the short delay condition were asked to wait approximately 10 seconds before beginning the TAP. During this time the experimenter appeared to check the settings on the competitive task for 10 seconds. Following the TAP, participants were probed for suspicion and were fully debriefed by the primary researcher or a research assistant.

\section{Data Analytic Strategy}

Hypotheses were evaluated through a path analysis performed using the software program, Analysis of Moment Structures (AMOS), Version 22.0, with maximum likelihood estimation (MLE). The sample size $(N=202)$ was suitable for a path analysis, based on recommended rules of thumb (Kline, 2005). The likelihood ratio test (LRT) was first conducted to determine the overall fit of the model. According to Bryne (2010), a non-significant chi-square test $\left(\chi^{2}\right)$ corresponds to an adequate model. As the LRT cannot be relied upon to test model adequacy alone, critical values associated with a number of additional goodness-of-fit measures

were analyzed. These included the relative chi-square statistic $\left(\chi^{2} / d f\right)<2$ (Tabachnick \& Fidell, 2007), as well as baseline comparison fit measures, including the comparative fit index (CFI) and 
the Tucker-Lewis index (TLI) > .95 (Garson, 2014). By common convention, the root mean square error of approximation (RMSEA), as well as its associated 95\% confidence interval and significance of closeness of fit (PCLOSE), were analyzed and reported. According to $\mathrm{Hu}$ and Bentler (1999), RMSEA values of .06 or less indicate a good fit between the data and the hypothesized model, while a non-significant PCLOSE value indicates a well-fitting model.

\section{Results}

\section{Preliminary Analyses}

The dataset was screened for missing data as well as univariate and multivariate normality prior to evaluating study hypotheses. In addition, as noted earlier, five cases with participant self-report or researcher suspicion ratings of $>5 / 10(50 \%)$ were eliminated from the

dataset. No variables appeared to have missing data. However, a number of study variables were not normally distributed, with critical ratios of skew above three and/or kurtosis above four (Kline, 2005). In addition, Mardia's (1970) normalized estimate of multivariate kurtosis was > 5.00 indicating multivariate abnormality (Bentler, 2005). As a result, bootstrapping was employed to estimate model parameters via nonparametric resampling of the data (2000 pseudosamples), along with bias corrected confidence intervals (CIs) and significance levels. An examination of first-order correlations between path variables did not yield any correlations greater than .60, indicating that multicollinearity was not a problem (Kline, 2005).

In order to screen for univariate outliers, the raw scores for each of the path variables were transformed to z-scores. All z-scores exceeding an absolute critical value of 3.29, $p<.001$ (Tabachnick \& Fidell, 2007) were considered for possible deletion from the dataset. According to this criterion, two univariate outliers were detected for both $\mathrm{ABC}$ as well as the implicit attitudes variable. As both of the outliers on the $\mathrm{ABC}$ variable and one of the outliers on the 
implicit attitudes variable were close to the cut-off score (z-scores ranging from 3.52-3.61) and did not include data that was meaningfully different from scores below the cut-off, these cases were retained in the dataset. However, the additional outlier on the implicit attitudes variable was deleted from the dataset as it was found to include an IAT response latency of less than $400 \mathrm{~ms}$.

Mahalanobis distance values greater than a cut-off value of 18.47 (based on $4 d f$; Tabachnick \& Fidell, 2007) were analyzed to identify multivariate outliers. Seven observations exceeded the cut-off value and were considered for possible deletion from the dataset. However, none of these cases was found to include data that was meaningfully different from observations under the cut-off value and were, therefore, retained by the researcher in the dataset.

In addition, the researcher and her research assistants rated their perception of the participant's level of suspicion as an additional measure of validity. A zero-order correlation between participants' self-ratings of suspicion and researcher/research assistants' ratings of suspicion was significant, $r=.69, p<.001$. However, an examination of zero-order correlations between suspicion scores and other study variables, including the reactive physical aggression score, was not significant. Therefore, suspicion ratings were not included as control variables in statistical analyses.

\section{Descriptive Statistics and Correlations}

Means, standard deviations and zero-order correlations between path variables are presented in Table 3. Mean scores for the explicitly measured TPB variables (i.e., explicit attitudes, subjective norms, PBC, and intentions) revealed high variability in scores. To recall, higher scores on the TPB variables indicate a greater intention to engage in reactive physical aggression, with the exception of PBC. In contrast, greater scores on PBC were thought to indicate lower intention to engage in physically aggressive behaviour. A wide range in scores 
Table 3

Descriptive Statistics and Pearson Correlation Matrix for Path Variables $(N=202)$

\begin{tabular}{lllllllcrcr}
\hline Variable & 1 & 2 & 3 & 4 & 5 & 6 & 7 & $M$ & $S D$ & Range \\
\hline 1. Implicit attitudes & - & & & & & & & -1.20 & .45 & $-3.14-.47$ \\
2. Explicit attitudes & .06 & - & & & & & & 11.93 & 5.93 & $5.00-28.00$ \\
3. Subjective norms & .04 & $.56^{* *}$ & - & & & & & 13.01 & 5.87 & $6.00-32.00$ \\
4. Perceived behavioural control & -.04 & $-.19^{* *}$ & $-.24^{* *}$ & - & & & & 35.32 & 5.25 & $18.00-42.00$ \\
5. Actual behavioural control & .01 & -.02 & -.01 & -.10 & - & & & 15.61 & 12.54 & $4.00-77.00$ \\
6. Intentions & .11 & $.60^{* *}$ & $.60^{* *}$ & $-.40^{* *}$ & -.01 & - & & 19.79 & 8.82 & $7.00-48.00$ \\
7. Reactive physical aggression & .10 & $.28^{* *}$ & $.14^{*}$ & $-.15^{*}$ & .02 & $.30^{* *}$ & - & 5.23 & 2.83 & $0.00-10.00$ \\
\hline
\end{tabular}

Note. ${ }^{*}$ Correlation is significant at $p<.05 .{ }^{* * *}$ Correlation is significant at $p<.01$. 
(range $=4.00$ to 77.00 ) on the $\mathrm{ABC}$ variable indicated variability in the number of perseverative errors made on the WCST: CV4. The average number of perseverative errors in the current sample $(M=15.61)$ was similar to the average number reported by MacTavish (2011) in a demographically similar sample of undergraduate students $(M=17.30)$. The mean implicit attitudes score $(M=-1.20)$ indicates that, on average, participants were lower in their implicit attitudes toward aggression. To recap, the implicit attitudes score is based on the $D$ statistic, which is calculated by subtracting the mean response latency of the incongruent category pairing (i.e., "I like or Retaliate" versus "I don't like or Tolerate") from the congruent category pairing (i.e., "I like or Tolerate" versus "I don't like or Retaliate") and dividing this total by the pooled standard deviation. A negative score indicates faster response latency for congruent category pairings than incongruent pairings.

A number of significant correlations were found between path variables (see Table 3). An examination of the correlation matrix reveals that the four variables in the traditional TPB model (i.e., explicit attitudes, subjective norms, PBC, and intentions) were significantly correlated with one another. In addition, reactive physical aggression was found to correlate with each of the four main constructs from the TPB model. Consistent with previous research (e.g., Hofmann et al., 2005), implicit and explicit attitudes were not significantly correlated. Furthermore, neither implicit attitudes nor ABC were significantly correlated with other study variables. Correlations between variables by condition (i.e., no delay versus short delay) are reported in Appendix G.

\section{Evaluation of Hypotheses}

Path analyses in AMOS were conducted in order to test the study hypotheses (see Figure 4 for path figure including regression weights). An advantage of AMOS is its ability to assess the significance of direct and indirect effects via bootstrapping confidence limits when there is a 


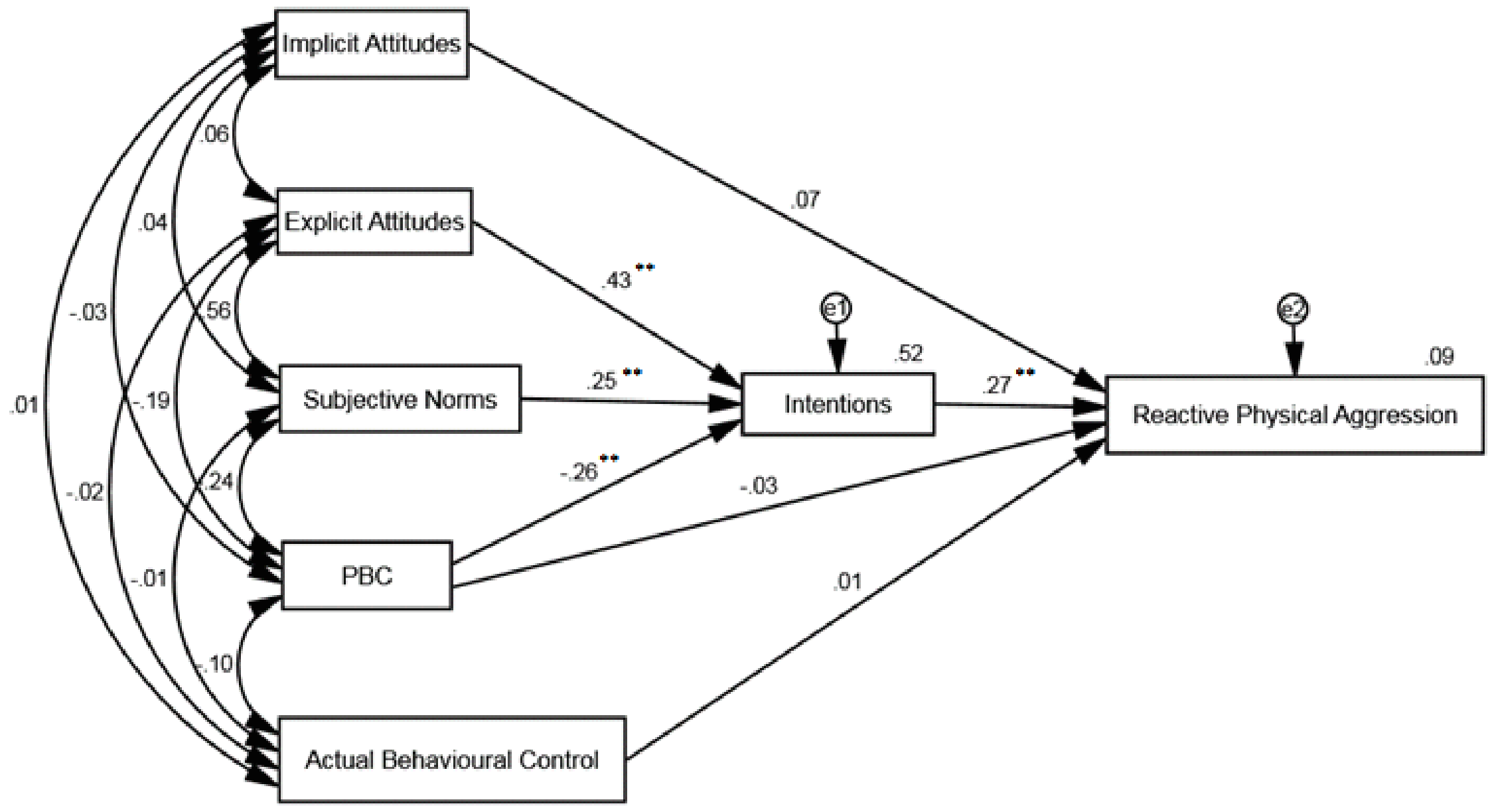

Figure 4. Modified version of the TPB model including pathway regression weights. $\mathrm{PBC}=$ Perceived behavioural control. ${ }^{* *}$ Pathway is significant at $p<.01$. 
deviation from the assumption of normality, as is the case in the current sample (Preacher \& Hayes, 2008). A summary of the standardized direct and indirect effects of the model can be found in Table 4. Prior to evaluating study hypotheses, the overall fit of the model was examined. The model demonstrated a good fit to the data, $\chi^{2}(4)=6.675, p=.154, \chi^{2} / d f=1.67$, $\mathrm{CFI}=1.00, \mathrm{TLI}=1.01, \mathrm{RMSEA}<0.05,95 \% \mathrm{CI}=[0.00,0.13], \mathrm{PCLOSE}=.36$. Notably, this model accounted for $52 \%$ of the variance in intentions and $9 \%$ of the variance in reactive physical aggression. The researcher elected not to trim nonsignificant pathways from the model as the default model proved to be a good fit to the data and the loss of nonsignificant pathways would prevent the evaluation of proposed study hypotheses.

\section{Hypothesis 1}

In order to evaluate the first hypothesis, the direct predictive pathways between intentions and reactive physical aggression, as well as $\mathrm{PBC}$ and reactive physical aggression were examined. Results of the analyses revealed that while there was a significant direct effect between intentions and reactive physical aggression $(p=.003,95 \%$ CI $[.11, .41])$, the pathway between PBC and reactive physical aggression was nonsignificant ( $p=.614,95 \%$ CI $[-.19, .10])$.

\section{Hypothesis 2}

To test whether explicit attitudes, subjective norms, and PBC would predict intentions, direct effects between these variables were examined within the model. The findings of this analysis provided support for the hypothesis with significant direct pathways found between explicit attitudes to intentions $(p=.001,95 \% \mathrm{CI}=[.31, .56])$, subjective norms to intentions $(p=$ $.003,95 \% \mathrm{CI}=[.12, .37])$, and $\mathrm{PBC}$ to intentions $(p=.002,95 \% \mathrm{CI}[-.40,-.14])$. 
Table 4

Standardized Direct and Indirect Effects of Predictors on Reactive Physical Aggression $(N=$ 202)

\section{Criteria}

\begin{tabular}{llcl}
\hline Predictors & Effect & Intentions & RPA \\
\hline Implicit Attitudes & Direct & $.43^{* *}(.06)$ & $.07(.07)$ \\
Explicit Attitudes & Direct & & $.12^{*}(.04)$ \\
Subjective Norms & Indirect & $.25^{* *}(.07)$ & \\
& Direct & & $.07^{*}(.03)$ \\
PBC & Indirect & $-.26^{* *}(.07)$ & $-.03(.08)$ \\
& Direct & & $-.07^{*}(.03)$ \\
ABC & Indirect & & $.02(.08)$ \\
Intentions & Direct & & $.27^{* *}(.08)$ \\
$R^{2}$ & Direct & & .09
\end{tabular}

Note. Standard errors are presented in parentheses. $\mathrm{PBC}=$ Perceived behavioural control. $\mathrm{ABC}=$ Actual behavioural control. RPA $=$ Reactive physical aggression. ${ }^{*} p<.05,{ }^{* *} p<.001$. 


\section{Hypothesis 3}

To test whether relations between the TPB constructs would be significantly mediated by intentions, indirect effects between these variables were analysed. Results revealed the significant mediating effect of intentions between explicit attitudes and reactive physical aggression $(p=.002,95 \%$ CI $[.05, .20])$, subjective norms and reactive physical aggression ( $p=$ $.002,95 \% \mathrm{CI}[.02, .13])$, and PBC and reactive physical aggression $(p=.001,95 \% \mathrm{CI}[-.14,-$ $.03])$. These results provide support for the application of the TPB model in the prediction of reactive physical aggression.

\section{Hypothesis 4}

In order to determine the relation between implicit attitudes toward aggression and reactive physical aggression, the direct effect between these variables was examined. A nonsignificant direct effect for this pathway $(p=.343,95 \%$ CI $[-.07, .20])$ suggested a lack of support for this hypothesis.

\section{Hypothesis 5}

In order to examine whether lower levels of $\mathrm{ABC}$ predicted greater levels of reactive physical aggression, the direct effect between these variables was examined. The model revealed a nonsignificant direct effect between $\mathrm{ABC}$ and reactive physical aggression $(p=.845,95 \% \mathrm{CI}[-$ $.14, .17])$, and therefore this hypothesis was not supported.

\section{Hypothesis 6}

In order to determine whether the model was modulated by condition (no delay versus short delay), a multiple-groups analysis was conducted in AMOS. It is noted that multi-groups analysis is a well-established analytic strategy for testing condition effects (e.g., Choma, Hodson \& Costello, 2012) and is especially applicable for evaluating interactions when the moderator is 
categorical (see e.g., Sidanius, Pratto, \& Bobo, 1996). The multiple-groups analysis used in the current study simultaneously assessed: a) the relationship between the model predictors and reactive physical aggression within each condition, and b) whether the nature or strength of those relations significantly differed between conditions. Critical ratios of differences between parameters (i.e., z-scores) were examined to assess the hypothesis that condition modulates the relations between the model predictors and reactive physical aggression. The critical ratios of differences between parameters as well as standardized estimates for each of the pathways can be found in Table 5. According to Arbuckle (2009), a critical ratio of $+/-1.96(p<.05)$ indicates that pathways are significantly different between conditions. As is shown in Table 5, no significant differences were found between model parameters. The results of this analysis did reveal, however, that the standardized estimates for the pathways in the short delay condition appeared to be stronger for the most part overall than those in the no delay condition, although these results were not statistically significant.

In summary, findings of the path analysis revealed a significant indirect effect between the traditional TPB predictors (explicit attitudes, subjective norms, and $\mathrm{PBC}$ ) and reactive physical aggression via intentions. Implicitly measured attitudes toward aggression as well as $\mathrm{ABC}$ did not significantly contribute to the prediction of reactive physical aggression. Furthermore, the inclusion of a 10 second delay between provocation and opportunity to engage in reactive physical aggression was not found to significantly reduce aggression levels. Therefore, results of the study provide support for the constructs associated with the traditional TPB model in the prediction of reactive physical aggression. 
Table 5

Standardized Direct and Indirect Effects of Predictors on Reactive Physical Aggression as

Moderated by Condition $(N=202)$

Condition 1: No Delay/Condition 2: Short Delay

\begin{tabular}{|c|c|c|c|c|}
\hline Predictors & Effect & Intentions & RPA & Z-score \\
\hline Implicit Attitudes & Direct & & $.10 / .03$ & -.50 \\
\hline \multirow[t]{2}{*}{ Explicit Attitudes } & Direct & $.40^{* *} / .47^{* *}$ & & 1.06 \\
\hline & Indirect & & $.05 \% / .10^{*}$ & \\
\hline \multirow[t]{2}{*}{ Subjective Norms } & Direct & $.29^{*} / .25^{*}$ & & -.11 \\
\hline & Indirect & & $.11 \% / .12^{* *}$ & \\
\hline \multirow[t]{2}{*}{$\mathrm{PBC}$} & Direct & $-.18^{*} /-.31^{* *}$ & $-.05 /-.01$ & $-1.34^{\mathrm{a}}$ \\
\hline & Indirect & & $.05 \% .11^{* *}$ & $.34^{\mathrm{b}}$ \\
\hline $\mathrm{ABC}$ & Direct & & $.00 / .03$ & .18 \\
\hline Intentions & Direct & & $.25 \% .31^{*}$ & -.12 \\
\hline$R^{2}$ & & $.49 / .55$ & $.09 / .10$ & \\
\hline
\end{tabular}

Note PBC $=$ Perceived behavioural control. $\mathrm{ABC}=$ Actual behavioural control. $\mathrm{RPA}=$ Reactive physical aggression. ${ }^{a}$ denotes the pairwise parameter comparison for the PBC-intentions pathway. ${ }^{\mathrm{b}}$ denotes the pairwise parameter comparison for the PBC-RPA pathway. ${ }^{*} p<.05,{ }^{* *} p<$ .01 . 


\section{CHAPTER FOUR}

\section{$\underline{\text { DISCUSSION }}$}

The present dissertation tested a modified version of the TPB to predict reactive physical aggression between undergraduate students. A review of the literature revealed that the majority of research studies using the TPB to predict aggressive or violent behaviours has focused primarily on youth and adolescents (Brown, 2007; Finigan-Carr et al., 2015; Kirkiakidis, 2010; Roberto et al., 2003) and adult offender populations (Kernsmith, 2005; Tolman, Edleson, \& Fendrich, 1996), while fewer studies (Betts et al., 2011; Thompson et al., 2011) have used the TPB to predict physical aggression between university students. As well, research on physical aggression in university students, more broadly, appears to have focused on sexual harassment or sexual violence perpetrated by students in stranger, acquaintance, or dating relationships (e.g., Aosved \& Long, 2005; Humphrey \& White, 2000). Considerably less research has examined less serious forms of physically aggressive behaviour between university students in non-romantic relationships.

The modified version of the TPB developed in this dissertation extended the traditional model by examining the impact of implicit attitudes toward aggression as well as executive functioning [(i.e., actual behavioural control $(\mathrm{ABC})]$ in the prediction of reactive physical aggression. Furthermore, the traditional model was modified to include an objective assessment of reactive physical aggression. A discussion of the findings as they relate to study hypotheses is summarized below, beginning with an examination of intentions and PBC in the prediction of reactive physical aggression.

Hypothesis 1: More supportive intentions as well as lower levels of PBC will predict greater levels of reactive physical aggression. 
Findings of the present study offered partial support for this hypothesis. First, intentions were found to significantly predict reactive physical aggression, which implies that this behaviour may be a deliberate and intentional response to perceived provocation (i.e., an ego threat). These findings are congruent with the TPB model and suggest that one's intentions are the direct antecedent of their behaviour (Ajzen, 1991). With regard to the broader literature, these findings are in accordance with Brown (2007) who found that intention to engage in reactive aggression significantly predicted aggressive behaviour within an adolescent sample. Brown's findings, as well as those reported in the present study, may be surprising as reactive aggression is typically conceptualized as a thoughtless and impulsive act (Barratt, 1999) and is associated with an inability to control one's emotions (Dodge et al., 1997). The findings of the present study suggest that reactive aggression is not a thoughtless act but is an act that requires some foresight and consideration of possible consequences. As a result, individuals in the current sample may have had some preconceived notion of how they would behave if provoked.

The finding that reactive aggression may be under one's volitional control may help to explain why the PBC construct did not directly predict reactive physical aggression in the current sample. According to Ajzen (1991), the PBC construct should directly predict one's behaviour when the behaviour in question is not under one's total control. For example, an individual may wish to obtain a new employment position but may not be in charge of the hiring process (Ajzen, 2002). In this scenario, PBC may directly predict the behaviour (i.e., securing the job position) as the individual is not in total control of whether they will be hired or not. In this way, PBC serves as a proxy for the actual control the person has in a given situation. As reactive physical aggression was found to be a controllable behaviour, it is argued that the PBC construct was not relevant as a direct predictor of reactive aggression in the present study. 
Hypothesis 2: Explicit attitudes, subjective norms, and PBC will significantly predict intentions.

As hypothesized, explicit attitudes, subjective norms, and PBC all significantly predicted intention to engage in reactive physical aggression. Pearson product moment correlations between the determinants of intentions (i.e., explicit attitudes, subjective norms, and PBC) and the intentions construct itself were similar to correlations reported in meta-analyses conducted by Armitage and Conner (2011), and more recently by McEachan and colleagues (2011). However, it is noted that the correlation between $\mathrm{PBC}$ and intentions was negative, indicating that greater PBC was associated with lower intention to engage in aggressive behaviour. This association is in contrast to Ajzen's (1985) conceptualization that the greater the PBC, the greater the intention to engage in a given behaviour. It is suggested that the negative association between PBC and intention may actually be more intuitive in this context as reactive physical aggression is typically conceptualized as an emotionally charged act that is characterized by a loss of behavioural control (Ramirez \& Andreu, 2006). In this way, it is perhaps unsurprising that participants who reported difficulty controlling their behaviour intended to engage in reactive physical aggression and vice versa.

Although results of the current study suggest that reactive aggression is a deliberate and intentional act, these findings suggest that undergraduate students are more likely to intend to be aggressive if they believe they are not able to control their behaviour if provoked. These findings are congruent with Finigan-Carr and colleagues (2015) who found that greater control over one's behaviour was associated with lower odds of engaging in aggressive behaviour in their sample of adolescent youth.

Hypothesis 3: The relationship between explicit attitudes, subjective norms, and PBC and reactive physical aggression will be significantly mediated by intentions. 
In support of this hypothesis, the relationships between attitudes, subjective norms, and PBC and reactive physical aggression were all significantly mediated by intentions. These findings offer strong support for Ajzen's (1991) TPB model and highlight the important role of intentions in the engagement of reactive physical aggression. To the writer's knowledge, this is the first study that has used the TPB model to predict an objective measure of actual reactive physical aggression. Therefore, the present study provides a novel contribution to the literature as it demonstrates that the TPB can be used to successfully predict both objective as well as selfreported aggression (e.g., Brown, 2007).

Hypothesis 4: Individuals with more supportive implicit attitudes toward aggression will display greater levels of reactive physical aggression compared to those with less supportive implicit attitudes.

Findings of the path analysis indicated that the implicit measure of attitudes toward aggression did not significantly predict reactive physical aggression, and therefore the fourth hypothesis was not supported. The limited research examining the relation between implicit attitudes and aggressive behaviour has produced mixed findings, with some studies offering support for this relationship (e.g., Robertson \& Murachver, 2007), whereas others argue that explicit attitudes tend to be stronger predictors of aggression (e.g., Maimone, 2014; Nunes, Ennis, Hermann, Maimone, \& Choy, 2014). It is possible that mixed results may be due to methodological differences among studies, such as discrepancies in IAT structure as well as differences in stimulus items and category labels used to evaluate research questions. It may also be possible that implicit measures of attitudes are more predictive of certain forms of aggression that are more spontaneous (e.g., intimate partner violence) than those that may require more thoughtful behaviour (e.g., engaging in a violent videogame). 
The lack of prediction found in the current study may have been a result of the methodology used to measure implicit attitudes toward reactive physical aggression. First, it may be possible that the IAT used in the current study was measuring "environmental associations" (Karpinski \& Hilton, 2001). To recall, this term refers to the possibility that participants may not be providing responses indicative of their personal attitudes, and instead may be responding to cultural stereotypes to which they have been exposed but with which they may or may not agree (Arkes \& Tetlock, 2004). The problem of environmental associations seems less likely in the present study as the researcher created a personalized IAT in which "I like" and "I don't like" were substituted for the more general concepts of "good" or "bad" which are commonly used in studies used to measure implicit attitudes toward violence and aggression (e.g., Nunes, Hermann, \& Ratcliffe, 2013; Robertson \& Murachver, 2007). This strategy aimed to increase the likelihood that participants would evaluate the concepts based on their own associations, rather than classifying concepts according to cultural stereotypes. It is possible, however, that this strategy was not powerful enough to prevent participants from responding according to cultural stereotypes toward aggressive behaviour.

Second, it is possible that not all the stimulus items (e.g., punch, slap, chat, talk) corresponding to the attribution categories (i.e., "Tolerate" and "Retaliate") accurately reflected the constructs they were intended to measure. For example, it may be argued that the stimulus item, "punch" may correspond to both reactive and instrumental physical aggression. Similarly, it is possible that "talk" may not be immediately associated with tolerating perceived provocation. As was previously stated, in order to maintain consistency, the stimulus items used to measure the attribution categories were modeled after Banse and Fischer (2002) in their study examining general implicit attitudes toward aggression. It is possible that some of these stimulus 
items were too broad and may not have been closely associated with tolerating or retaliating in response to perceived provocation.

Third, it is possible that the lack of significant findings may be due to the structure of the IAT used in the present study. As was stated earlier, the structure of the IAT was modeled after McCormick (2013) in her study examining implicit attitudes toward dating violence. Following McCormick's methodology, the Reactive Aggression IAT employed a series of practice trials before introducing the critical blocks [(i.e., the congruent ("I like or Tolerate"/ "I don't like or Retaliate") or incongruent pairings ("I like or Retaliate"/ "I do not like or Tolerate")] that were used to generate IAT scores. More specifically, participant scores were computed by examining discrepancies in response latencies between the congruent and incongruent pairings on practice and critical trials and dividing this value by the pooled standard deviation. Following this methodology, extensive practice trials were added before the second critical block, as this method has been found to reduce ordering effects (i.e., the finding that IAT effects may depend on the order in which the critical blocks are administered, e.g., Nosek, Greenwald, \& Banaji, 2005).

Nosek and colleagues (2005) explain that the addition of extra practice trials before the second critical block may not be enough to eliminate ordering effects and that the fixed order of the pairings may lead to an overestimate or underestimate of the magnitude of the effect. Therefore, the fixed order of the IAT used in the current study may have resulted in an overestimate of the effect, as the congruent pairing was always presented first to participants followed by the incongruent pairing. It is suggested that counterbalancing the presentation order of the combined pairings may have resulted in a more accurate estimate of the magnitude of the IAT effect. For example, Nunes, Hermann, and Ratcliffe (2013) counterbalanced the order in 
which "Rape or Good" and "Rape or Bad" were presented in their study examining implicit attitudes toward rape, past sexual coercion, and future likelihood of rape. Findings of the study revealed that those who reported the most past sexual coercion or likelihood to rape in the future had significantly more positive implicit attitudes toward rape than those who did not report past sexual coercion of future likelihood to rape. It is suggested that future studies using the IAT to predict reactive aggression should use counterbalancing to avoid issues associated with ordering effects.

Last, the lack of significant relation may be a result of the gender of study participants. In her study examining the mediating role of implicit and explicit attitudes in the relationship between exposure to interparental violence and dating violence, McCormick (2013) found that only explicit attitudes mediated the relationship between interparental and dating violence for females. However, both implicit and explicit attitudes were found to significantly mediate the relationship between interparental violence and dating violence for male participants. Although the present study did not find that the relationship between implicit attitudes toward aggression and reactive physical aggression varied by gender, it is possible that there was a lack of power to detect such an effect as three quarters of the sample were female.

In line with previous research (e.g., Hofmann et al., 2005), the current research did not find a significant correlation between measures of implicit and explicit attitudes toward reactive physical aggression. This finding may be attributable to moderator variables, such as variations in people's awareness of implicit representations or differences in conceptual correspondence between measures. It is possible that the IAT and self-report questionnaire measured slightly different concepts. To recap, the IAT asked participants to provide a relative preference between two target categories ("I like" or "I don't like" and "Tolerate" or "Retaliate"). In contrast, the 
explicit measure asked participants about their attitudes toward engaging in reactive physical aggression in two specific scenarios. Although it may not have been possible in this study, research demonstrates that correlations between indirect measures and self-report measures are generally higher when the two measures conceptually correspond to one another than when there are conceptual differences (e.g., Hofmann et al., 2005).

Hypothesis 5: Lower levels of $A B C$ will predict greater levels of reactive physical aggression.

Contrary to expectation and previous research (e.g., Foti et al., 2014; Godlaski, \& Giancola, 2009; MacTavish, 2011), the present study did not find that participants' ABC scores predicted reactive physical aggression. To recap, $\mathrm{ABC}$ was measured using the WCST: CV4 (Heaton et al., 2003), a commonly used measure of executive functioning (Rabin, Barr, \& Burton, 2005). Although these findings were unexpected, an examination of the literature revealed some debate regarding the specificity of the WCST to detect frontal lobe (the area of the brain responsible for executive functioning) pathology or dysfunction (e.g., Barcelo, 2001; Lezak, 1995; Nyhus \& Barcelo, 2009). In order to explore the specificity of the WCST, Nyhus and Barcelo (2009) examined functional neuroimaging of healthy participants during their performance on the WCST and found that there was widespread activation of neural networks beyond the prefrontal cortex. More specifically, the authors found evidence of neural network activation in the prefrontal, frontal, temporal, parieto-temporal, and parieto-occipital cortical regions, indicating that the WCST is not specific to frontal lobe function. These findings therefore suggest that there may be some limitations with this measure as it may be difficult to determine which aspects of the WCST are associated with activation in the frontal cortex as this task engages multiple areas of brain functioning at the same time. 
Nyhus and Barcelo (2009) reported that functional neuroimaging studies provide evidence that the delivery of negative feedback during the WCST may play a role in activating a widespread network of brain regions beyond that of just the prefrontal cortex. Therefore, the authors suggest that a more simplified version of the test, such as a straightforward taskswitching paradigm (i.e., shifting attention from one task to another), may increase specificity to detect changes in prefrontal executive functioning. When applying these findings to the current study, it is possible that the researcher was measuring a range of cognitive operations, rather than providing a specific estimate of level of executive functioning, and relatedly, ABC. If this was the case, it may be reasonable that the WCST was not predictive of reactive physical aggression in the present study.

In addition to issues related to specificity of the WCST, it is possible that null findings were due to the fact that a number of participants reported that they had recently learned about this measure in their undergraduate psychology course. If this was the case, it is likely that several students knew how to correctly sort the cords according to a shifting rule prior to their participation in the study. Unfortunately, the number of students who mentioned that they knew how to complete the task was not recorded and, therefore, their data were not deleted from the analyses. As a result, the measure of executive functioning used in the current study may not be an accurate indicator of participants' level of $\mathrm{ABC}$ and its association with reactive physical aggression must be interpreted with caution.

Hypothesis 6: The relations between model predictors and reactive physical aggression will be moderated by condition (no delay versus short delay).

Condition (no delay versus short delay) did not significantly moderate the relationship between model predictors and reactive physical aggression. As was previously explained, the 
modified model examined the impact of a 10 second delay between provocation and opportunity for reactive physical aggression. The brief delay condition examined whether a short delay between provocation and opportunity to retaliate was associated with inhibition of aggressive impulses. If such a delay were associated with lower levels of aggressive responding, this may suggest that briefly postponing an opportunity to retaliate may allow participants to engage in more deliberate and thoughtful behaviour than if they had the chance to immediately retaliate. This strategy is often referred to as the "cool down" approach and has been adopted by wellestablished treatment programs, such as the "STOP method" described by Nay (2014).

Although condition was not a significant moderator, the standardized estimates for the pathways involving two of the constructs of the TPB model (i.e., explicit attitudes and PBC) were larger in the short delay condition than in the no delay condition. This may suggest that the explicit belief measures for these constructs were stronger predictors of intention to engage in reactive physical aggression when participants experienced a short delay prior to engaging in the aggression task. With regard to implicit attitudes, the standardized estimate between implicit attitudes and reactive physical aggression was larger in the no delay condition. This suggests that the implicit measure of attitudes toward aggression was a stronger predictor of reactive physical aggression when participants did not have any time to think about their behaviour or possibly inhibit urges to retaliate. Although not statistically significant, these patterns are supportive of the Reflective-Impulsive System (Strack \& Deutsch, 2004). As was previously mentioned, this system refers to the finding that automatic or impulsive processes and deliberative or reflective processes may play different roles in the execution of aggressive behaviour (Fazio, 1990; Gawronski \& Bodenhausen, 2006; Strack \& Deutsch, 2004). It should be noted, however, that the explicit measures continued to be stronger predictors of intention to engage in reactive 
physical aggression regardless of whether participants experienced a delay or not. This provides further evidence that engaging in reactive physical aggression involved some rational choice for participants in the current sample, even with limited time to make a decision.

\section{Limitations}

A number of limitations of the current dissertation should be considered. First, the present study did not explore gender as a moderator of the relationships between model predictors and reactive physical aggression. Although research has consistently found that males are more physically aggressive than females (e.g., Archer, 2004; Bettencourt \& Miller, 1996), additional research has demonstrated that this difference is markedly attenuated when provocation is taken into consideration (e.g., Bettencourt \& Miller, 1996). As the manipulation check in the current study demonstrated that receiving negative essay feedback was highly provoking and resulted in increased levels of reactive physical aggression for both males and females (see Appendix H), significant sex differences in reactive physical aggression in the test of the modified TPB model were not anticipated. Although gender was not included as a moderating variable in the test of the modified TPB model, additional gender analyses (i.e., model differences for men and women and correlations for path variables by gender) can be found in Appendices I and J, respectively. Results of these analyses should be interpreted with caution as the small male sample size lacks power to make meaningful comparisons by gender. With this caution in mind, an examination of the critical ratios of the differences between model parameters did not reveal significant differences in pathways according to gender.

Second, the TPB model accounted for $52 \%$ of the variance in intentions, but only $9 \%$ of the variance in reactive physical aggression. This suggests that other variables not accounted for in the modified TPB model still affected participants' behaviour. For example, previous research 
suggests that individual factors, such as negative affect (Berkowitz, 1993) pain and discomfort (Anderson et al., 2001), as well as the influence of alcohol and caffeine (Bushman, 1997) may be associated with increases in aggressive behaviour. As the present study only examined variables involved in the TPB model, it is unclear as to how much these factors may have impacted participants' performance on the aggression task.

Third, the provocation scenarios used in the TPB questionnaire to measure attitudes toward reactive aggression were quite different from the type of provocation (i.e., negative essay feedback) participants actually encountered in the present study (i.e., with the TAP). To review, participants were provided with two scenarios that described commonly occurring examples of reactive aggression in response to perceived provocation (i.e., pushing in the subway during rush hour/road rage) and were then asked to keep these scenarios in mind while responding to questions regarding their attitudes, subjective norms, $\mathrm{PBC}$, and intentions as they applied to reactive physical aggression. However, the test of the modified TPB model examined the impact of an ego threat (i.e., negative essay feedback) in provoking reactive physical aggression. As a result, it is difficult to determine how conceptually similar the provocation described in the two scenarios were to that of negative essay feedback and whether they would result in similar levels of reactive physical aggression in the real world. In this way, it is quite possible that the intention variable on the TPB questionnaire may actually be measuring one's likelihood of engaging in reactive physical aggression if they were to be pushed in the subway or cut off on a busy highway, rather than if they were provoked by negative essay feedback.

Fourth, and relatedly, the present study was low in ecological validity. This characteristic of the present study would pose a limitation as to the generalizability of the findings to the real world. It is unlikely that individuals would find themselves in a real-world situation in which 
they were able to remain anonymous while engaging in reactive physical aggression against an instigator. Therefore, it is difficult to determine how closely the modified version of the TAP approximates reactive physical aggression in the real world. It should be noted, however, that this study is high in experimental realism, as the form of provocation used in the present study has consistently resulted in increased levels of reactive physical aggression, as demonstrated by a number of studies, including Foti and colleagues (2014) and MacTavish (2011). Furthermore, it is important to note that the present dissertation may only speak to the impact of negative essay feedback on reactive physical aggression between university students in a laboratory setting. The ability of the TPB model to predict reactive physical aggression using the modified version of the TAP remains unknown among other populations.

Fifth, limitations associated with methodological issues involving the IAT as well as the WCST may have contributed to null findings. Failure to include the counterbalancing strategy in the measure of implicit attitudes may have resulted in an overestimate of the effect as the congruent pairing was always presented first to participants followed by the incongruent pairing. It is possible that counterbalancing may have eliminated such an effect and may have resulted in a different association between IAT scores and reactive physical aggression. Furthermore, it is possible that the stimulus words corresponding to the attribution categories (e.g., punch, slap, chat, talk) were too broad and may not have been specific to reactive physical aggression or tolerating perceived provocation. In addition, as was mentioned above, it is possible that limitations associated with the WCST may have influenced the results.

Finally, it is possible that the cross-sectional nature of this study may have influenced results as all measures were completed during the same appointment. For example, it is possible that participating in the TAP shortly after reflecting on personal beliefs toward aggression on the 
TPB questionnaire may have influenced participants' behaviour on the aggression task. Indeed, Manning (2009) found that relations between intentions and behaviour were significantly stronger for studies measuring concurrent behaviour compared to those measuring prospective behaviours.

\section{Future Directions}

Findings of the current research suggest that reactive physical aggression is an intentional and deliberate behaviour. Furthermore, results revealed that one's intention to engage in reactive physical aggression is significantly influenced by three factors: attitudes toward the behaviour, perceived social pressure, and perceived control over their behaviour. A particular strength of the TPB is that it examines the influence of multiple factors in the prediction of reactive physical aggression and, therefore, offers a number of potential treatment targets that may effectively reduce aggressive behaviour.

Given that attitudes, subjective norms, and PBC significantly predicted intention to engage in reactive physical aggression, which predicted actual behaviour, it is suggested that future research could develop and explore the impact of treatment programs that modify attitudes in favour of reactive aggression, and, ultimately, one's intention to engage in this behaviour. In order to identify relevant treatment targets, it may be helpful to first obtain a more in-depth understanding of participants' beliefs toward reactive physical aggression. This may be accomplished through what Fishbein and Ajzen (1980) refer to as an elicitation study. According to Fishbein and Ajzen (2003), an elicitation study is designed to elicit a population's salient beliefs toward a given behaviour. Salient beliefs are those that first come to mind when asked an open-ended question about a specific behaviour, such as, "What do you think would be the advantages of using physical aggression against someone who has provoked you?" According to 
Sutton and colleagues (2003), it is the combination of salient beliefs that comprise one's overall belief about a given behaviour. For example, an individual who intends to engage in reactive physical aggression may hold the following salient beliefs: reactive physical aggression allows me to release my anger and makes me feel powerful.

Once the researcher has obtained a range of salient beliefs, she or he may begin to look for themes in participants' beliefs, which inform relevant treatment targets. For example, if several participants report that engaging in reactive physical aggression is desirable as it allows them to release their anger, one intervention strategy may focus on providing methods of releasing anger in a nonaggressive manner (e.g., breathing deeply or visualizing relaxing scenery). Another strategy may be to modify cognitive biases, such as the hostile attribution bias (i.e., the tendency to perceive others' intent as hostile or malicious in response to ambiguous provocation situations; Crick \& Dodge, 1996), by encouraging participants to consider alternative possibilities in ambiguous provocation scenarios. For example, the researcher would encourage participants to consider the possibility that an individual bumped into them on the subway because they were rushing or not looking, rather than intentionally trying to harm them. In order to examine the impact of such an intervention program, it is suggested that the constructs in the TPB model are measured pre- and post-intervention.

In addition, future research may aim to test the modified TPB model used in the current study with populations at risk for endorsing antisocial attitudes and engaging in aggressive behaviour (e.g., offender populations). It is suggested that the TPB may be a particularly useful model in predicting violent behaviour within an offender population, as pro-criminal attitudes are consistently found to be one of the strongest predictors of future violent behaviour and criminal recidivism (Helmus, Hanson, Babchishin, \& Mann, 2013). Prior to applying the modified model 
to another population of participants, it is suggested that the measure of implicit attitudes be revised to adopt a counterbalancing strategy and that executive functioning be measured using a more simplistic task-switching paradigm than is used in the current study. Further research is required to determine whether modifications made to the TPB model in the current study may be more or less predictive of aggression for individuals at higher risk for aggressive behaviour. Gaining a better understanding of the constructs most predictive of aggressive behaviour within a more aggression prone population may be instrumental to informing prevention strategies.

The current research suggests that the TPB offers a useful theoretical framework for the prediction of reactive physical aggression between undergraduate students. It would be interesting to determine whether the results of the current dissertation could be replicated with other types (e.g., relational) and forms (e.g., proactive) of aggressive behaviour. As the majority of research on aggression has been conducted on youth (e.g., Finigan-Carr et al., 2015) and adult offender populations (e.g., Kernsmith, 2005), the predictors of various types and forms of aggressive behaviour among adults warrants further attention.

Additionally, future research may wish to explore the moderating role of gender on reactive physical aggression. Although research suggests that sex differences in physical aggression are significantly reduced under provoking conditions (Bettencourt \& Miller, 1996), the current study was unable to provide a meaningful comparison of models by gender due to the limited sample size of male participants. It is suggested that future research should aim to recruit a larger sample of male participants in order to have an adequate level of power to detect significant effects and further clarify the role of gender in reactive physical aggression.

Lastly, it is suggested that future studies could examine whether the age, gender, or ethnicity of the ostensive partner in the modified version of the TAP may moderate the level of 
expressed reactive physical aggression. In the current study, participants were told that their partner was a member of the same sex and that they were also enrolled in a first year undergraduate psychology course. As the mean age of the study participants was 20.69 years old, it may be that participants were imagining that their partner was similar in age and gender. It would be of interest to examine whether level of reactive physical aggression varied depending on whether participants were told that their partner was similar or different to them on a range of demographic variables. Differences in levels of aggression toward partners who are demographically dissimilar may reveal underlying biased attitudes toward members of outgroups that may not be readily admitted to on measures of explicit attitudes. In support of this possibility, research examining implicit attitudes toward age and race, has found automatic preferences for young over old people (Perdue \& Gurtman, 1990) and white over black people (Cunningham, Preacher, \& Banaji, 2001). However, the ways in which these automatic preferences relate to aggression towards certain groups is unknown.

\section{Conclusions}

The current dissertation tested a modified version of the TPB to predict reactive physical aggression in undergraduate students. More specifically, the dissertation made a novel contribution to the literature by considering the influence of explicit and implicit attitudes as well as executive functioning in the prediction of actual reactive physically aggressive behaviour. Findings of the study offered support for the traditional TPB model and suggested that reactive physical aggression is a deliberate and intentional behaviour. More specifically, findings revealed that the relationships between attitudes, subjective norms, PBC and reactive physical aggression were significantly mediated by intentions. The fact that intentions appear to be the immediate antecedent of aggressive behaviour is an important observation as it suggests that 
university students may have a preconceived notion of how they will behave if provoked. These results offer a range of implications, such as the role of future research in designing intervention programs aimed at modifying aggressive intentions and attitudes. As previous research has demonstrated that even mild aggressive behaviours may be precursors to engagement in more serious physically aggressive behaviour (De Wall, Anderson, \& Bushman, 2011), the investigation of less serious forms of physical aggression among university students is an important area of inquiry. 


\section{Appendix A: Questionnaire Development}

In order to develop the TPB questionnaire, the researcher followed the (frequently cited) manual on constructing questionnaires based on the TPB by Francis et al. (2004). This manual provides a detailed step-by-step procedure for constructing valid and reliable items designed to effectively measure each of the primary constructs of the TPB. Prior to designing the TPB items, Francis et al. suggest that the behaviour to be evaluated must first be defined. In the current study, reactive physical aggression was defined as "an injurious act where the intention is to cause physical harm to an individual who has previously harmed or threatened to harm the aggressor." Francis et al. recommend that each of the primary constructs should consist of approximately six items in order to adequately measure the construct. When designing the attitudes construct, Francis et al. suggest that the researcher include both instrumental items (i.e., whether the behaviour achieves something, e.g., useless - useful) as well as experiential items (i.e., how the person feels when performing the behaviour, e.g., pleasant - unpleasant). Measurement of the attitudes construct in the current questionnaire involved the use of six bipolar adjectives (e.g., "good or bad") that included both instrumental and experiential items and followed a single "stem" item (i.e., "I think that reactive physical aggression is..."). It is noted that the final questionnaire included only five items as one item was eliminated in the reliability analysis described in Study 1 . Each of the responses was recorded on a 7-point Likert scale with the bipolar adjectives functioning as the endpoints of the scale. For example, "I think reactive physical aggression is: (1) Harmful to (7) Beneficial.”

In order to measure the subjective norms construct, Francis et al. (2004) suggest the use of questions referring to the opinions of people that are important to the respondent. The researcher developed six items to measure the subjective norms construct, including items such 
as "Other people would expect me to engage in reactive physical aggression" as well as, "Most people would support me if I engaged in reactive physical aggression." Each of the responses was recorded on a 7-point Likert scale ranging from (1) Strongly Disagree to (7) Strongly Agree.

Francis et al. (2004) explain that items measuring the PBC construct should reflect the level of confidence the individual has that they are capable of performing the target behaviour. Therefore, Francis et al. proposed that the PBC construct be made up of items assessing both one's self-efficacy as it applies to performing a behaviour (i.e., how difficult or easy it would be for them to perform the behaviour) as well as the controllability of the behaviour (i.e., whether performing the behaviour is entirely up to them or is under their control). The questionnaire used in this dissertation aimed to address factors related to self-efficacy as well as controllability by including items such as, "Avoiding reactive physical aggression is difficult for me" as well as "The decision to engage in reactive physical aggression is beyond my control." The PBC construct comprised six items and required participants to rate their responses on a 7-point Likert scale ranging from (1) Strongly Disagree to (7) Strongly Agree. In contrast to how the relation between PBC and intentions has been conceptualized by Ajzen (1985) (i.e., the greater the PBC, the greater the intention to engage in the behaviour), higher scores on PBC items in the current study were thought to indicate lower intention to engage in physically aggressive behaviour. The researcher chose to conceptualize the PBC-intentions association in this way as reactive physical aggression is a direct response to provocation and may occur as a result of a lack of control over angry impulses to retaliate. In this way, it may be assumed that an individual who reports having greater perceived control over their behaviour (e.g., "Avoiding reactive physical aggression is easy for me") would be more likely to report a lower intention to engage in reactive physical aggression if the opportunity arises. 
Last, Francis et al. (2004) stated that a number of intention-related items must be included in order to adequately measure one's "generalized intention" to engage in a particular behaviour. Therefore, the researcher asked respondents about their intention to engage in reactive physical aggression in a number of ways. For example, "I expect to engage in reactive physical aggression against an instigator" and "I will engage in reactive physical aggression if I am provoked." The intentions construct comprised seven items and was measured using a 7-point Likert scale ranging from (1) Strongly Disagree to (7) Strongly Agree.

In total, the questionnaire consisted of 24 items measuring each of the constructs of the TPB model (see Appendices B - E for questionnaire items). Total scores for each variable were created by summing individual items. With the exception of $\mathrm{PBC}$, higher scores on each of the variables indicated that overall, the respondent was in favour of engaging in reactive physical aggression. Higher scores on the PBC construct indicated that the respondent was more in control of their behaviour, and was therefore hypothesized to express a lower intention of engaging in reactive physical aggression. All items on the attitudes, subjective norms, and intentions subscales with negatively keyed items were re-coded so higher scores reflected a more positive view of reactive physical aggression. Items on the PBC subscale with negatively-keyed items were re-coded so higher scores reflected more perceived control. For example, a participant who responded with "Strongly Disagree" (1) for the item, "I DO NOT plan to use physical aggression if someone has physically harmed me first" would receive a score of 7 for this item. Furthermore, a participant who responded with "Strongly Disagree" (1) for the item, "Avoiding reactive physical aggression is difficult for me" would receive a score of 7 for this item. 


\section{Appendix B: Explicit Attitudes Items}

Overall, I think that reactive physical aggression is

$\begin{array}{lllllllll}\text { 1. Harmful } & 1 & 2 & 3 & 4 & 5 & 6 & 7 & \text { Beneficial }\end{array}$

2. The wrong thing to do $\quad \begin{array}{lllllllll}1 & 2 & 3 & 4 & 5 & 6 & 7 & \text { The right thing to do }\end{array}$

3. $\begin{array}{lllllllll}\mathrm{Bad} & 1 & 2 & 3 & 4 & 5 & 6 & 7 & \text { Good }\end{array}$

$\begin{array}{llllllllll}\text { 4. Useless } & 1 & 2 & 3 & 4 & 5 & 6 & 7 & \text { Useful }\end{array}$

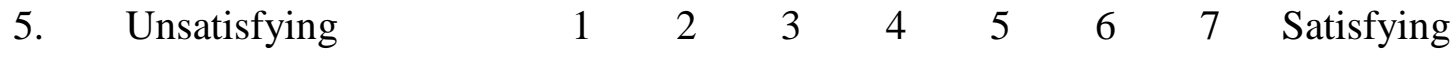




\section{Appendix C: Subjective Norms Items}

1. People who are important

to me think that I should

NOT engage in reactive

physical aggression

2. I feel under social pressure

to engage in reactive

physical aggression

3. Other people would expect

me to engage in reactive

physical aggression

4. People who are important

to me would want me to

engage in reactive physical

aggression

5. Most people would support me if I engaged in reactive physical aggression

6. People who are important to me think that reactive physical aggression is the right thing to do

$\begin{array}{lllllllll}\begin{array}{l}\text { Strongly } \\ \text { Disagree }\end{array} & 1 & 2 & 3 & 4 & 5 & 6 & 7 & \begin{array}{l}\text { Strongly } \\ \text { Agree }\end{array}\end{array}$

Strongly

Disagree

1234

56

7 Strongly

Agree

Strongly

Disagree

$\begin{array}{llll}1 & 2 & 3 & 4\end{array}$

45

7 Strongly
Agree

Strongly

Disagree
$\begin{array}{llllllll}1 & 2 & 3 & 4 & 5 & 6 & 7 & \text { Strongly }\end{array}$
Agree
$\begin{array}{llllllll}1 & 2 & 3 & 4 & 5 & 6 & 7 & \text { Strongly }\end{array}$
Agree

Disagree

Strongly

Disagree

12

34

45

6
67 Strongly
Agree




\section{Appendix D: PBC Items}

1. I am confident that I could control angry impulses to retaliate if I wanted to

2. Whether I engage in reactive physical aggression is entirely up to me

3. Avoiding reactive physical Strongly aggression is easy for me Disagree

4. I am capable of controlling my behaviour when I am provoked

5. Avoiding reactive physical aggression is difficult for me

6. The decision to engage in reactive physical aggression is beyond my control

\section{Strongly \\ Disagree}

Strongly

Disagree

Strongly

Disagree

Strongly

Disagree

Strongly

Disagree

12

234

56

7 Strongly

Agree
12
4
56
7
Strongly
Agree
$\begin{array}{llllllll}1 & 2 & 3 & 4 & 5 & 6 & 7 & \text { Strongly }\end{array}$ Agree
$\begin{array}{llllllll}1 & 2 & 3 & 4 & 5 & 6 & 7 & \text { Strongly }\end{array}$ Agree

\section{Agree}

$\begin{array}{llllllll}1 & 2 & 3 & 4 & 5 & 6 & 7 & \begin{array}{l}\text { Strongly } \\ \text { Agree }\end{array}\end{array}$




\section{Appendix E: Intentions Items}

1. I will engage in reactive physical aggression if I am provoked

2. I intend to use physical aggression against an instigator who has harmed me first

3. I expect to engage in reactive physical aggression against an instigator

4. I DO NOT plan to use physical aggression if someone has physically harmed me first

5. I wish to engage in reactive physical aggression against an instigator

6. I desire to engage in physical aggression against someone who has harmed me first

\section{I want to use physical} aggression against someone who has harmed me first

$\begin{array}{llllllllll}\begin{array}{l}\text { Strongly } \\ \text { Disagree }\end{array} & 1 & 2 & 3 & 4 & 5 & 6 & 7 & \begin{array}{l}\text { Strongly } \\ \text { Agree }\end{array}\end{array}$

Strongly

Disagree
12
4
6
Strongly
Agree

Strongly

Disagree

1234

45

6

Strongly
Agree

Strongly

12

23

4

56

7 Strongly

Agree

Strongly

$\begin{array}{llllll}1 & 2 & 3 & 4 & 5 & 6\end{array}$

7 Strongly

Agree

Disagree

Strongly

Disagree

1

2

4

56

7
Strongly
Agree

Strongly

Disagree

12

2

4

56

7

Strongly 


\section{Appendix F: Scenarios}

Reactive physical aggression refers to an injurious act where the intention is to cause physical harm to an individual who has previously harmed or threatened to harm the aggressor.

The following scenarios provide two examples of reactive physical aggression:

1. You are taking the subway during morning rush hour service on a weekday. When the subway car opens its doors for boarding, someone behind you pushes you into the crowded subway car and says, "Watch where you 're going!" You then retaliate by pushing them back in the subway car.

2. You are driving on the highway during morning rush hour on a weekday. You are about to merge into the next lane when the driver beside you cuts you off, rolls down their window and yells, "Learn how to drive!" You retaliate by honking your horn very loudly and purposely following the driver too closely. 


\section{Appendix G}

Pearson Correlation Matrix for Path Variables by Condition (No Delay/Short Delay)

\begin{tabular}{|c|c|c|c|c|c|c|c|}
\hline Variable & 1 & 2 & 3 & 4 & 5 & 6 & 7 \\
\hline 1. Implicit attitudes & - & & & & & & \\
\hline 2. Explicit attitudes & $.07 / .20^{*}$ & - & & & & & \\
\hline 3. Subjective norms & $.03 / .04$ & $.60^{* *} / .53^{* *}$ & - & & & & \\
\hline 4. Perceived behavioural control & $-.09 /-.03$ & $-.23 * /-.15$ & $-.38^{* *} /-.11$ & - & & & \\
\hline 5. Actual behavioural control & $.00 / .03$ & $-.01 /-.03$ & $.00 /-.02$ & $-.04 /-.15$ & - & & \\
\hline 6. Intentions & $.07 / 14$ & $.59^{* *} / .62^{* *}$ & $.60^{* *} / .53 * *$ & $-.38^{* *} /-.41 * *$ & $.04 /-.03$ & - & \\
\hline 7. Reactive physical aggression & $.12 / .08$ & $.28^{* *} / .28^{* *}$ & $.12 / .17$ & $-.16 /-.14$ & $.01 / .03$ & $.28^{* *} / .32^{* *}$ & - \\
\hline
\end{tabular}

Note. ${ }^{*}$ Correlation is significant at $p<.05$. ${ }^{* * *}$ Correlation is significant at $p<.01$. 


\section{Appendix H: Manipulation Check Study}

The purpose of the manipulation check study was to: a) examine the extent to which the negative essay feedback was experienced as ego-threatening by participants and b) determine whether participants believed they were competing against a real partner on the competitive reaction time task [i.e., the modified version of the TAP). The manipulation check study was conducted following the procedure outlined by Bushman and Baumeister (1998) in their study examining the effects of a perceived ego-threat on aggressive behaviour. In their study, Bushman and Baumeister randomly assigned participants to receive either negative or positive essay feedback, followed by participation in a modified version of the TAP, which was disguised as a competitive reaction time task. The researcher then determined the provoking effect of essay feedback on participants' emotions (i.e., degree of anger, offence, and insult) as well as levels of reactive physical aggression as measured by the TAP.

\section{Hypotheses}

Hypothesis 1: Participants in the negative feedback condition will report greater levels of anger, offence, and insult compared to those assigned to the positive feedback condition.

Hypothesis 2: Participants in the negative feedback condition will demonstrate higher levels of reactive physical aggression compared to those assigned to the positive feedback condition.

\section{Method}

\section{Participants}

Twenty participants (75\% female) from Ryerson University were recruited through SONA, the undergraduate participant pool, in exchange for one course credit. Participants were 
required to be enrolled in a first year undergraduate psychology course in order to participate. Participants were not required to disclose additional demographic information.

\section{Measures}

Reactive Physical Aggression. The modified version of the TAP by Bushman and Baumeister (1998) was used to measure reactive physical aggression. Please see Study 2 for full description of this measure.

Debriefing Questions. As part of the debriefing process, participants completed a brief questionnaire about how angry, insulted, and offended they were, rated on a scale from 1 (not at all) to 10 (extremely). This was done to assess the validity of the experimental manipulation. Once the deception was revealed, participants were additionally asked to rate how suspicious they were that they did not really have a partner in the study on a scale from 1 to 10 . As an additional measure of validity, the researcher and her research assistants rate their perception of the participant's level of suspicion. After the deception was revealed, the reasons for the use of deception were explained, and participants were asked to sign the debriefing form providing consent to use their data.

\section{Procedure}

Research Ethics Board (REB) approval was obtained prior to beginning the study. All participants were tested individually and were informed that the aim of the study was to learn more about university students' life goals and the impact of essay feedback on performance on a competitive reaction time task. Using a random number generator, participants were randomly assigned to either a positive feedback $(n=10)$ or a negative feedback condition $(n=10)$. Participants were first asked to write a one paragraph essay on their life goals. They were told that their essay would be evaluated by a partner of the same sex who was completing the same 
activities in another room. Participants were told they would receive ratings from 1 (extremely poor) to 10 (excellent) on each of the following evaluation criteria: 1) organization, 2) writing style, 3) clarity of expression, and 4) overall quality of the essay; however, the feedback for both conditions was actually pre-written and did not reflect a true rating on any of the evaluation criteria. Indeed, all participants in the positive feedback condition received a score of $10 / 10$ on each of the evaluation criteria, whereas participants in the negative feedback condition received scores of 5/10 and 6/10 across the evaluation areas. In addition, the feedback included either a positive comment ("No suggestions! This is a great essay!"), or a negative comment (“This essay was poorly written. I think you would benefit from a writing workshop"). Participants were also asked to provide feedback on their partner's work according to the same evaluation criteria.

Immediately after receiving feedback on the essay from their partner, participants completed the modified version of the TAP, presented as a computerized reaction time task. Finally, in the debriefing process, participants were asked to rate on a 10-point scale how angry, insulted, and offended they were after they had received the feedback on the essay. This was done to assess the validity of the experimental manipulation. Participants were also probed for suspicion and were fully debriefed by the primary researcher or a research assistant.

\section{Results}

In order to compare group means across conditions, independent-samples $t$-tests were performed using IBM SPSS Statistics 22.0. In line with previous findings (Bushman \& Baumeister, 1998; Foti et al., 2014; MacTavish, 2011), participants in the negative feedback condition experienced significantly greater feelings of offence $(M=7.80, S D=3.04), t(9)=-$ $8.09, p<.001, d=3.61$, insult $(M=7.7, S D=3.09), t(9)=-7.87, p<.001, d=3.52$, and anger $(M$ $=7.50, S D=2.91), t(9)=-8.14, p<.001, d=3.62$, than those in the positive feedback condition 
$(M=0.00, S D=0.00$ for offence, insult, and anger, respectively). Furthermore, findings revealed that participants in the negative feedback condition engaged in higher levels of reactive physical aggression $(M=7.05, S D=2.95)$ compared to those in the positive condition $(M=1.75, S D=$ $0.92), t(10.70)=-5.36, p<.001, d=2.40$. With regard to the validity of the deception used in this study, a zero-order correlation between participants' self-ratings of suspicion and researcher/research assistants' ratings of suspicion was significant, $r=.79, p<.001$.

In summary, the manipulation check was successful and confirmed both of the study's hypotheses. First, the manipulation check revealed that the form of provocation used in the current study, that is, negative essay feedback, caused participants to feel significantly more offended, insulted, and angry compared to participants in the positive feedback condition. Second, participants who experienced an ego-threat engaged in greater levels of reactive physical aggression than those who did not experience an ego-threat. As the manipulation check demonstrated the provoking effect of receiving negative essay feedback on reactive physical aggression, all participants in the test of the modified TPB model (i.e., Study 2) were assigned only to the negative feedback condition. 


\section{Appendix I}

Standardized Direct and Indirect Effects of Predictors on Reactive Physical Aggression as Moderated by Gender $(N=202)$

\begin{tabular}{|c|c|c|c|c|}
\hline \multirow[b]{2}{*}{ Predictors } & \multirow[b]{2}{*}{ Effect } & \multicolumn{3}{|c|}{ Male/Female } \\
\hline & & Intentions & RPA & z-score \\
\hline Implicit Attitudes & Direct & & $.21 / .00$ & -1.16 \\
\hline \multirow[t]{2}{*}{ Explicit Attitudes } & Direct & $.48^{* * *} / .37^{* *}$ & & -.78 \\
\hline & Indirect & & $.09 / .12^{* *}$ & \\
\hline \multirow[t]{2}{*}{ Subjective Norms } & Direct & $.32 \% / .17^{*}$ & & -.79 \\
\hline & Indirect & & $.06 / .06^{*}$ & \\
\hline \multirow[t]{2}{*}{ PBC } & Direct & $-.16 /-.35^{* *}$ & $-.09 / .02$ & $-.95^{\mathrm{a}}$ \\
\hline & Indirect & & $.03 /-.11^{* *}$ & $.64^{\mathrm{b}}$ \\
\hline $\mathrm{ABC}$ & Direct & & $.03 / .00$ & -.22 \\
\hline Intentions & Direct & & $.19 / .32^{* *}$ & .93 \\
\hline$R^{2}$ & & $.54 / .45$ & $.11 / .10$ & \\
\hline
\end{tabular}




\section{Appendix J}

Pearson Correlation Matrix for Path Variables by Gender (Male/Female)

\begin{tabular}{|c|c|c|c|c|c|c|c|}
\hline Variable & 1 & 2 & 3 & 4 & 5 & 6 & 7 \\
\hline 1. Implicit attitudes & - & & & & & & \\
\hline 2. Explicit attitudes & $.18 /-.01$ & - & & & & & \\
\hline 3. Subjective norms & $.15 /-.05$ & $.63^{* * *} / .48^{* * *}$ & - & & & & \\
\hline 4. Perceived behavioural control & $-.16 / .02$ & $.05 /-.25^{* *}$ & $-.00 /-.32^{* *}$ & - & & & \\
\hline 5. Actual behavioural control & $.06 / .02$ & $-.16 / .04$ & $-.08 / .02$ & $-.11 /-.10$ & - & & \\
\hline 6. Intentions & $.24 / .04$ & $.67^{* *} / .54^{* *}$ & $.63^{* *} / .46^{* *}$ & $-.13 /-.50^{* *}$ & $-.17 / .06$ & - & \\
\hline 7. Reactive physical aggression & $.27 / .20$ & $.19 / .31^{* *}$ & $.19 / .11$ & $-.15 /-.14$ & $.02 / .02$ & $.24 / .31^{* *}$ & - \\
\hline
\end{tabular}

Note. ${ }^{*}$ Correlation is significant at $p<.05$. ${ }^{* * *}$ Correlation is significant at $p<.01$. 


\section{References}

Abbey, A. (2011). Alcohol's role in sexual violence perpetration: Theoretical explanations, existing evidence and future directions. Drug and Alcohol Review, 30, 481-489. doi: 10.1111/j.1465-3362.2011.00296.x

Abbey, A., \& McAuslan, P. (2004). A longitudinal examination of male college students' perpetration of sexual assault. Journal of Consulting and Clinical Psychology, 72, 747756. doi: 10.1037/0022-006X.72.5.747

Ahern, A. L., \& Hetherington, M. M. (2006). The thin ideal and body image: an experimental study of implicit attitudes. Psychology of Addictive Behaviors, 20, 338-342. doi: 10.1037/0893-164X.20.3.338

Ajzen, I. (1985). From intentions to actions: A theory of planned behavior. In J. Kuhl \& J. Beckmann (Eds.), Action-control: From cognition to behavior (pp. 11-39). Heidelberg, Germany: Springer.

Ajzen, I. (1991). The theory of planned behavior. Organizational Behavior and Human Decision Processes, 50, 179-211. doi: 10.1016/0749-5978(91)90020-T

Ajzen, I. (2002). Perceived behavioral control, self-efficacy, locus of control, and the theory of planned behavior. Journal of Applied Social Psychology, 32, 665-683. doi: 10.1111/j.1559-1816.2002.tb00236.x

Ajzen, I., \& Dasgupta, N. (2015). Explicit and implicit beliefs, attitudes, and intentions: The role of conscious and unconscious processes in human behavior. In P. Haggard \& B. Eitam (Eds.), The sense of agency (pp. 115-144). New York: Oxford University Press.

Ajzen, I., \& Driver, B. L. (1991). Prediction of leisure participation from behavioral, normative, 
and control beliefs: An application of the theory of planned behavior. Leisure Sciences, 13, 185-204. doi: 10.1080/01490409109513137

Ajzen, I., \& Fishbein, M. (1980). Understanding attitudes and predicting social behavior. Englewood-Cliffs, NJ: Prentice-Hall.

Ajzen, I., \& Madden, T. J. (1986). Prediction of goal-directed behavior: attitudes, intentions, and perceived behavioral control. Journal of Experimental Social Psychology. 22, 453-474. doi: 10.1016/0022-1031(86)90045-4

Albarracin, D., Johnson, B. T., Fishbein, M., \& Muellerleile, P. A. (2001). Theories of reasoned action and planned behavior as models of condom use: A meta-analysis. Psychological Bulletin, 127, 142-161. doi 10.1037/0033-2909.127.1.142

Alvarez, J. A., \& Emory, E. (2006). Executive function and the frontal lobes: A meta-analytic review. Neuropsychology Review, 16, 17-42. doi: 10.1007/s11065-006-9002-x

Anderson, V. A., Anderson, P., Northam, E., Jocobs, R., \& Catroppa, C. (2001). Development of executive functions through late childhood and adolescence in an Australian sample. Developmental Neuropsychology, 20, 385-406. doi: 10.1207/S15326942DN2001_5

Anderson, C. A., \& Bushman, B. J. (1997). External validity of" trivial" experiments: The case of laboratory aggression. Review of General Psychology, 1, 19-41. doi: 10.1037/10892680.1.1.19

Anderson, C. A., Deuser, W. E., \& DeNeve, K. M. (1995). Hot temperatures, hostile affect, hostile cognition, and arousal: Tests of a general model of affective aggression. Personality and Social Psychology Bulletin, 21, 434-448. doi: $10.1177 / 0146167295215002$

Anderson, C. A., \& Huesmann, L. R. (2003). Human aggression: A social-cognitive view. In M. 
A. Hogg \& J Cooper (Eds.), The sage handbook of social psychology (pp. 296-323). Thousand Oaks, CA: Sage Publications, Inc.

Aosved, A. C., \& Long, P. J. (2005). College women's experiences of psychological maltreatment and sexual assault. Violence and Victims, 20, 577-587. doi: 10.1891/08866708.2005.20.5.577

Archer, J. (2004). Sex differences in aggression in real-world settings: A meta analytic review. Review of General Psychology, 8, 291-322. doi: 10.1037/1089-2680.8.4.291

Arcuri, L., Castelli, L., Galdi, S., Zogmaister, C., \& Amadori, A. (2008). Predicting the vote: Implicit attitudes as predictors of the future behavior of decided and undecided voters. Political Psychology, 29, 369-387. doi: 10.1111/j.1467-9221.2008.00635.x

Arkes, H. R., \& Tetlock, P. E. (2004). Attributions of implicit prejudice, or "would Jesse Jackson 'fail' the implicit association test?" Psychological Inquiry, 15, 257-278. doi: 10.1207/s15327965pli1504_01

Armitage, C. J., \& Conner, M. (2001). Efficacy of the theory of planned behaviour: A metaanalytic review. British Journal of Social Psychology, 40, 471-499. doi: $10.1348 / 014466601164939$

Asendorpf, J. B., Banse, R., \& Mücke, D. (2002). Double dissociation between implicit and explicit personality self-concept: The case of shy behavior. Journal of Personality and Social Psychology, 83, 380-393. doi: 10.1037/0022-3514.83.2.380

Banfield, J. F., Wyland, C. L., Macrae, C. N., Munte, T. F., \& Heatherton, T. F. (2004). The cognitive neuroscience of self-regulation. New York, NY: The Guilford Press.

Banse, R., \& Fischer, I. (2002, July). Implicit and explicit aggressiveness and the prediction of aggressive behavior. Poster presented at the 11th European Conference on Personality 
of the European Society for Personality Psychology, Jena, Germany.

Barceló, F. (2001). Does the Wisconsin Card Sorting Test measure prefrontal function? The Spanish Journal of Psychology, 4, 79-100. doi: 10.1017/S1138741600005680

Barker, E. D., Tremblay, R. E., Nagin, D. S., Vitaro, F., \& Lacourse, E. (2006). Development of male proactive and reactive physical aggression during adolescence. Journal of Child Psychology and Psychiatry, 47, 783-790. doi: 10.1111/j.1469-7610.2005.01585.x

Baron, R. A., \& Eggleston, R. J. (1972). Performance on the "aggression machine": Motivation to help or harm? Psychonomic Science, 26, 321-322. doi: 10.3758/BF03328631

Basen-Engquist, K., \& Parcel, G. S. (1992). Attitudes, norms, and self-efficacy: A model of adolescents' HIV-related sexual risk behavior. Health Education \& Behavior, 19, $263-$ 277. doi: $10.1177 / 109019819201900209$

Baumeister, R. F., \& Boden, J. M. (1998). Aggression and the self: High self-esteem, low selfcontrol, and ego threat. In R. Geen \& E. Donnerstein (Eds.), Human aggression: theories, research, and implications for social policy, (pp. 111-137). CA: Academic, San Diego.

Baumeister, R. F., \& Vohs, K. D. (2003). Self-regulation and the executive function of the self. In M. R. Leary \& J. P. Tangney (Eds.), Handbook of self and identity, (pp.197-217). New York, NY: The Guilford Press.

Bechara, A., Damasio, A. R., Damasio, H., Anderson, S. W. (1994). Insensitivity to future consequences following damage to human prefrontal cortex. Cognition, 50, 7-15. doi: $10.1016 / 0010-0277(94) 90018-3$

Berkowitz, L. (1990). On the formation and regulation of anger and aggression: A cognitiveneoassociationistic analysis. American Psychologist, 45, 494-503. doi: 10.1037/0003066X.45.4.494 
Bettencourt, A. A., \& Miller, N. (1996). Gender differences in aggression as a function of provocation: A meta-analysis. Psychological Bulletin, 119, 422-447. doi: 10.1037/00332909.119.3.422

Betts, K. R., Hinsz, V. B., Heimerdinger, S. R. (2011). Predicting intentions of romantic partner abuse with the theory of planned behavior. Current Psychology: A Journal for Diverse Perspectives on Diverse Psychological Issues, 30, 130-147. doi: 10.1007/s12144-011$9105-2$

Bledsoe, L. K. (2006). Smoking cessation: An application of theory of planned behavior to understanding progress through stages of change. Addictive Behaviors, 31, 1271-1276. doi: 10.1016/j.addbeh.2005.08.012

Bogers, R. P., Brug, J., Van Assema, P., \& Dagnelie, P. C. (2004). Explaining fruit and vegetable consumption: the theory of planned behaviour and misconception of personal intake levels. Appetite, 42, 157-166. doi: 10.1016/j.appet.2003.08.015

Brown, J. E. (2007). Intending to be aggressive: Applying the theory of planned behaviour to reactive and instrumental adolescent aggression. University of Saskatchewan Electronic Theses and Dissertations.

Bushman, B. J., \& Baumeister, R. F. (1998). Threatened egotism, narcissism, self-esteem, and direct and displaced aggression: Does self-love or self-hate lead to violence? Journal of Personality and Social Psychology, 75, 219-229. doi: 10.1037/0022-3514.75.1.219

Buss, A. H. (1961). The psychology of aggression. New York, NY: Wiley.

Campbell, J. C., Messing, J. T., Kub, J., Agnew, J., Fitzgerald, S., Fowler, B., \& ..., Bolyard, R. (2011). Workplace violence: Prevalence and risk factors in the safe at work study. 
Journal of Occupational and Environmental Medicine, 53, 82-89. doi:

10.1097/JOM.0b013e3182028d55

Card, N. A., \& Little, T. D. (2006). Proactive and reactive aggression in childhood and adolescence: A meta-analysis of differential relations with psychosocial adjustment. International Journal of Behavioral Development, 30, 466-480. doi: $10.1177 / 0165025406071904$

Casper, E. (2007). The theory of planned behavior applied to continuing education for mental health professionals. Psychiatric Services, 58, 1324-1329. doi:

10.1176/appi.ps.58.10.1324

Choma, B. L., \& Hafer, C. L. (2009). Understanding the relation between explicitly and implicitly measured political orientation: The moderating role of political sophistication. Personality and Individual Differences, 47, 964-967. doi: 10.1016/j.paid.2009.07.024

Choma, B. L., Hodson, G., \& Costello, K. (2012). Intergroup disgust sensitivity as a predictor of islamophobia: The modulating effect of fear. Journal of Experimental Social Psychology, 48, 499-506. doi: 10.1016/j.jesp.2011.10.014

Conner, M., Norman, P., \& Bell, R. (2002). The theory of planned behavior and healthy eating. Health Psychology, 21, 194. doi: 10.1037/0278-6133.21.2.194

Crick, N. R., \& Dodge, K. A. (1996). Social information-processing mechanisms in reactive and proactive aggression. Child Development, 67, 993-1002. doi: 10.1111/j.14678624.1996.tb01778.x

Dal Cin, S., Gibson, B., Zanna, M. P., Schumate, R., \& Fong, G. T. (2007). Smoking in movies, implicit associations of smoking with the self, and intentions to smoke. Psychological Science, 18, 559-563.doi: 10.1111/j.1467-9280.2007.01939.x 
Davis, L. E., Ajzen, I., Saunders, J., \& Williams, T. (2002). The decision of African American students to complete high school: An application of the theory of planned behavior. Journal of Educational Psychology, 94, 810- 819. doi: 10.1037//0022-0663.94.4.810

Denson, T. F., Pedersen, W. C., Ronquillo, J., \& Nandy, A. S. (2009). The angry brain: Neural correlates of anger, angry rumination, and aggressive personality. Journal of Cognitive Neuroscience, 21, 734-744. doi: 10.1162/jocn.2009.21051

DeWall, C. N., Anderson, C. A., \& Bushman, B. J. (2011). The general aggression model: Theoretical extensions to violence. Psychology of Violence, 1, 245-258. doi: $10.1037 / \mathrm{a} 0023842$

Dodge, K. A. (1980). Social cognition and children's aggressive behavior. Child Development, $51,162-170$.

Dodge, K. A., \& Coie, J. D. (1987). Social-information-processing factors in reactive and proactive aggression in children's peer groups. Journal of Personality and Social Psychology, 53, 1146-1158. doi: 10.1037/0022-3514.53.6.1146

Dodge, K. A., Lochman, J. E., Harnish, J. D., Bates, J. E., \& Pettit, G. S. (1997). Reactive and proactive aggression in school children and psychiatrically impaired chronically assaultive youth. Journal of Abnormal Psychology, 106, 37-51. doi: 10.1037/0021843X.106.1.37

Eckhardt, C. I., Samper, R., Suhr, L., \& Holtzworth-Munroe, A. (2012). Implicit attitudes toward violence among male perpetrators of intimate partner violence: A preliminary investigation. Journal of Interpersonal Violence, 27, 471-491. doi: $10.1177 / 0886260511421677$

Evans, J. P., \& Taylor, J. (1995). Understanding violence in contemporary and earlier gangs: An 
exploratory application of the theory of reasoned action. Journal of Black Psychology, 21, 71-81. doi: 10.1177/00957984950211006

Fazio, R. H. (1990). Multiple processes by which attitudes guide behavior: The MODE model as an integrative framework. In M. P. Zanna (Ed.), Advances in experimental social psychology (pp. 75-109). San Diego, CA: Academic Press.

Fazio, R. H., \& Olson, M. A. (2003). Implicit measures in social cognition research: Their meaning and use. Annual Review of Psychology, 54, 297-327. doi: 10.1146/annurev.psych.54.101601.145225

Feshbach, S. (1964). The function of aggression and the regulation of aggressive drive. Psychological Review, 71, 257-272. doi: 10.1037/h0043041

Field, A. (2009). Discovering statistics using SPSS (3rd ed.). London, UK: SAGE Publications Ltd.

Fila, S. A., \& Smith, C. (2006). Applying the theory of planned behavior to healthy eating behaviors in urban Native American youth. International Journal of Behavioral Nutrition and Physical Activity, 3, 1-10. doi: 10.1186/1479-5868-3-11

Finigan-Carr, N. M., Cheng, T. L., Gielen, A., Haynie, D. L., \& Simons-Morton, B. (2015). Using the theory of planned behavior to predict aggression and weapons carrying in urban African American early adolescent youth. Health Education \& Behavior, 42, 220230. doi: $10.1177 / 1090198114548479$

Fishbein, M. (2008). A reasoned action approach to health promotion. Medical Decision Making, 28, 834-844. doi: 10.1177/0272989X08326092

Fiske, S. T. (2009). Social beings: Core motives in social psychology (2nd ed.). New York, NY: Wiley. 
Foti, G., Hennig, K., \& Hoaken, P. (2014). An investigation of narcissism and executive functioning as predictors of aggression: A comparison of models. Manuscript under review.

Fox, J. A., \& Savage, J. (2009). Mass murder goes to college: An examination of changes on college campuses following Virginia Tech. American Behavioral Scientist, 52, 12861308. doi: $10.1177 / 0002764209332558$

Francis, J. J., Eccles, M. P., Johnston, M., Walker, A., Grimshaw, J., Foy, R., \& ..., Bonetti, D. (2004). Constructing questionnaires based on the theory of planned behaviour. A Manual for Health Services Researchers, 2010, 2-12.

Gawronski, B., \& Bodenhausen, G. V. (2006). Associative and propositional processes in evaluation: an integrative review of implicit and explicit attitude change. Psychological Bulletin, 132, 692-731. doi: 10.1037/0033-2909.132.5.692

Gawronski, B., \& Bodenhausen, G. V. (2011). The associative-propositional evaluation model: Theory, evidence, and open questions. Advances in Experimental Social Psychology, 44, 59-127. doi: 10.1016/B978-0-12-385522-0.00002-0

Gawronski, B., LeBel, E. P., \& Peters, K. R. (2007). What do implicit measures tell us?: Scrutinizing the validity of three common assumptions. Perspectives on Psychological Science, 2, 181-193. doi : 10.1111/j.1745-6916.2007.00036.x

Gawronski, B., \& Payne, B. K. (Eds.). (2010). Handbook of implicit social cognition: Measurement, theory, and applications. New York, NY: Guilford Press.

Giancola, P. R., \& Mezzich, A. C. (2000). Executive functioning mediates the relation between language competence and antisocial behavior in conduct-disordered adolescent females. Aggressive Behavior, 26, 359-375. doi: 10.1002/1098-2337 
Giancola, P. R., \& Parrott, D. J. (2008). Further evidence for the validity of the Taylor aggression paradigm. Aggressive Behavior, 34, 214-229. doi: 10.1002/ab.20235

Giancola, P.R., \& Zeichner, A. (1995). Construct validity of a competitive reaction-time aggression paradigm. Aggressive Behavior, 21, 199-204. doi: 10.1002/1098-2337

Godin, G., \& Kok, G. (1996). The theory of planned behavior: a review of its applications to health-related behaviors. American Journal of Health Promotion, 11, 87-98. doi: $10.4278 / 0890-1171-11.2 .87$

Godlaski, A. J., \& Giancola, P. R. (2009). Executive functioning, irritability, and alcohol-related aggression. Psychology of Addictive Behaviors, 23, 391-403. doi: 10.1037/a0016582

Goldberg, E. (2001). The executive brain: Frontal lobes and the civilized mind. Oxford: Oxford University Press.

Gordon, M. S. (2008). Extending the theory of planned behavior in the exercise domain: A study of community college students in an urban multicultural setting. FIU Electronic Theses and Dissertations. Paper 205.

Grant, D. A., \& Berg, E. (1948). A behavioral analysis of degree of reinforcement and ease of shifting to new responses in Weigl-type card-sorting problem. Journal of Experimental Psychology, 38, 404-411. doi: 10.1037/h0059831

Greenwald, A. G., \& Farnham, S. D. (2000). Using the implicit association test to measure selfesteem and self-concept. Journal of Personality and Social Psychology, 79, 1022-1038. doi: 10.1037/0022-3514.79.6.1022

Greenwald, A. G., McGhee, D. E., \& Schwartz, J. L. K. (1998). Measuring individual differences in implicit cognition: The implicit association test. Journal of Personality and Social Psychology, 74, 1464-1480. doi: 10.1037/0022-3514.74.6.1464 
Greenwald, A. G., Nosek, B. A., \& Banaji, M. R. (2003). Understanding and using the implicit association test: I. An improved scoring algorithm. Journal of Personality and Social Psychology, 85, 197-216. doi: 10.1037/0022-3514.85.2.197

Greenwald, A. G., Poehlman, T. A., Uhlmann, E. L., \& Banaji, M. R. (2009). Understanding and using the Implicit Association Test: III. Meta-analysis of predictive validity. Journal of Personality and Social Psychology, 97, 17-41. doi: 10.1037/a0015575

Gross, A. M., Winslett, A., Roberts, M., \& Gohm, C. L. (2006). An examination of sexual violence against college women. Violence Against Women, 12, 288-300. doi: $10.1177 / 107780120527738$

Gudjonsson, G. H., \& Moore, E. (2001). Self-deception and other-deception among admissions to a maximum security hospital and a medium secure unit. Psychology Crime and Law, 7, 25-31. doi: 10.1080/10683160108401780

Hammock, G., \& Richardson, D. (1992). Predictors of aggressive behavior. Aggressive Behavior, 18, 219-229. doi: 10.1002/1098-2337

Hansen, T., \& Jensen, J. M. (2007). Understanding voters' decisions: A theory of planned behaviour approach. Innovative Marketing, 3, 87-94.

Harrell, A. (1991). Evaluation of court-ordered treatment for domestic violence offenders: Summary and recommendations. Unpublished report prepared for the State Justice Institute.

Harris, K., Halpern, C., Whitsel, E., Hussey, J., Tabor, J., Entzel, P., .. \& Udry, J. (2009). The national longitudinal study of adolescent health: Research design. Retrieved from http://www.cpc.unc.edu/projects/addhealth/design

Heaton, R. K., Chelune, G. J., Talley, J. L., Kay, G. G., \& Curtiss, G. (1993). Wisconsin Card 
Sorting Test manual: Revised and expanded. Odessa, FL: Psychological Assessment Resources.

Heaton, R. K., PAR Staff, \& Goldin, J. N. (2003). WCST: CV4 Wisconsin Card Sorting Test: Computer Version 4 research edition user's manual. Lutz, FL: Psychological Assessment Resources, Inc.

Helmers, K. F., Young, S. N., \& Pihl, R. O. (1995). Assessment of measures of impulsivity in healthy male volunteers. Personality and Individual Differences, 19, 927-935. doi:10.1016/S0191-8869(95)00107-7

Hines, D. A., \& Straus, M. A. (2007). Binge drinking and violence against dating partners: the mediating effect of antisocial traits and behaviors in a multinational perspective. Aggressive Behavior, 33, 441-457. doi: 10.1002/ab.20196

Hoaken, P. N., Shaughnessy, V. K., \& Pihl, R. O. (2003). Executive cognitive functioning and aggression: Is it an issue of impulsivity? Aggressive Behavior, 29, 15-30. doi: 10.1002/ab.10023

Hoffmeister, K., Teige-Mocigemba, S., Blechert, J., Klauer, K. C., \& Tuschen-Caffier, B. (2010). Is implicit self-esteem linked to shape and weight concerns in restrained and unrestrained eaters? Journal of Behavior Therapy and Experimental Psychiatry, 41, 3138. doi: 10.1016/j.jbtep.2009.08.009

Hofmann, W., Gawronski, B., Gschwendner, T., Le, H., \& Schmitt, M. (2005). A meta-analysis on the correlation between the Implicit Association Test and explicit self-report measures. Personality and Social Psychology Bulletin, 31, 1369-1385. doi: $10.1177 / 0146167205275613$

Huesmann, L. R. (1988). An information processing model for the development of aggression. 
Aggressive Behaviour, 14, 13-24.

Humphrey, J. A., \& White, J. W. (2000). Women's vulnerability to sexual assault from adolescence to young adulthood. Journal of Adolescent Health, 27, 419-424. doi: 10.1016/S1054-139X(00)00168-3

Jones, D. N., \& Paulhus, D. L. (2010). Different provocations trigger aggression in narcissists and psychopaths. Social Psychological and Personality Science, 1, 12-18. doi:

\section{$10.1177 / 1948550609347591$}

Jong, J., Halberstadt, J., \& Bluemke, M. (2012). Foxhole atheism, revisited: The effects of mortality salience on explicit and implicit religious belief. Journal of Experimental Social Psychology, 48, 983-989. doi: 10.1016/j.jesp.2012.03.005

Juvonen, J., Wang, Y., \& Espinoza, G. (2013). Physical aggression, spreading rumors, and social prominence in early adolescence: Recriprocal effects supporting gender similarities? Journal of Youth and Adolescence, 42, 1801-1810. doi: 10.1007/s10964-012-9894-0

Kalichman, S. C., \& Rompa, D. (2001). The sexual compulsivity scale: Further development and use with HIV-positive persons. Journal of Personality Assessment, 76, 379-395. doi: 10.1207/S15327752JPA7603_02

Kaminski, R. J., Koons-Witt, B. A., Stewart Thompson, N. S., \& Weiss, D. (2010). The impacts of the Viginia Tech and Northern Illinois University shootings on fear of crime on campus. Journal of Criminal Justice, 38, 88-98. doi: 10.1016/j.jcrimjus.2009.11.011

Karpinski, A., \& Hilton, J. L. (2001). Attitudes and the implicit association test. Journal of Personality and Social Psychology, 81, 774-788. doi: 10.1037/0022-3514.81.5.774

Kaukinen, C. (2014-online). Dating violence among college students: The risk and protective factors. Trauma Violence Abuse. doi: 10.1177/1524838014521321 
Kendall, P., \& Wilcox, L. (1979). Self-control in children: Development of a rating scale. Journal of Consulting and Clinical Psychology, 47, 1020-1029. doi: 10.1037/0022006X.47.6.1020

Kernsmith, P. (2005). Treating perpetrators of domestic violence: Gender differences in the applicability of the theory of planned behavior. Sex Roles, 52, 757-770. doi: 10.1007/s11199-005-4197-5

Kochanska, G., Murray, K. T., \& Harlan, E. T. (2000). Effortful control in early childhood: continuity and change, antecedents, and implications for social development. Developmental Psychology, 36, 220-232. doi: 10.1037/0012-1649.36.2.220

Korn, J. H. (1997). Illusions of reality: A history of deception in social psychology. Albany, NY: State University of New York Press.

Koss, M. P., Abbey, A., Campbell, R., Cook, S., Norris, J., Testa, M., ... \& White, J. (2007). Revising the SES: A collaborative process to improve assessment of sexual aggression and victimization. Psychology of Women Quarterly, 31, 357-370. doi: 10.1111/j.14716402.2007.00385.x

Leeper Piquero, N., Piquero, A. R., Craig, J. M., \& Clipper, S. J. (2013). Assessing research on workplace violence, 2000-2012. Aggression and Violent Behavior, 18, 383-394. doi: 10.1016/j.avb.2013.03.001

Lento-Zwolinski, J. (2007). College students' self-report of psychosocial factors in reactive forms of relational and physical aggression. Journal of Social and Personal Relationships, 24, 407-421. doi: 10.1177/0265407507077229

Leonard, K. E., Quigley, B. M., \& Collins, R. L. (2002). Physical aggression in the lives of 
young adults. Prevalence, location, and severity among college and community samples. Journal of Interpersonal Violence, 17, 533-550. doi: 10.1177/0886260502017005004

Lezak, M.D. (1995). Neuropsychological assessment. New York: Oxford University Press.

Lin, C. S., \& Chen, C. F. (2011). Application of theory of planned behavior on the study of workplace dishonesty. International Proceedings of Economics Development \& Research, 2, 66-69.

Lonsway, K. A., \& Fitzgerald, L. F. (1995). Attitudinal antecedents of rape myth acceptance: A theoretical and empirical reexamination. Journal of Personality and Social Psychology, 68, 704-711. doi: 10.1037/0022-3514.68.4.704

Luckey, R. H. (1999). A study of interpersonal violence among college students living on campus. Dissertation Abstracts International, 60(4-A), 1042. (UMI No. 9928064).

MacTavish, A. (2011). Executive functioning in provoked physical aggression. University of Guelph Master's Thesis.

Maimone, S. (2014). The relationship between attitudes towards violence and violent behaviour: The use of implicit and self-report measures. Carleton University Master's Thesis.

Manning, M. (2009). The effects of subjective norms on behaviour in the theory of planned behaviour: A meta-analysis. British Journal of Social Psychology, 48, 649-705. doi: $10.1348 / 014466608 X 393136$

McCloskey, M. S., \& Berman, M. E. (2003). Alcohol intoxication and self-aggressive behavior. Journal of Abnormal Psychology, 112, 306-311. doi: 10.1037/0021-843X.112.2.306

McCormick, L. C. (2013). From what they see, to what they think, to what they do: How exposure to interparental violence leads to dating violence, through implicit and explicit attitudes. University of Guelph Dissertation. 
McEachan, R. R. C., Conner, M., Taylor, N. J., \& Lawton, R. J. (2011). Prospective prediction of health-related behaviours with the theory of planned behaviour: A meta-analysis. Health Psychology Review, 5, 97-144. doi: 10.1080/17437199.2010.521684

Metcalfe, J., \& Mischel, W. (1999). A hot/cool system analysis of delay of gratification: Dynamics of willpower. Psychology Review, 106, 13-19.

Milgram, S. (1963). Behavioral study of obedience. The Journal of Abnormal and Social Psychology, 67, 371. doi: 10.1037/h0040525

Milner, B., \& Petrides, M. (1984). Behavioural effects of frontal-lobe lesions in man. Trends in Neurosciences. Special Issue: The Frontal Lobes--Uncharted Provinces of the Brain, 7, 403-407. doi: 10.1016/S0166-2236(84)80143-5

Morrison, D. M., Rogers-Gillmore, M., \& Baker, S. A. (1995). Determinants of condom use among high-risk heterosexual adults: A test of the theory of reasoned action. Journal of Applied Social Psychology, 25, 651-676. doi: 10.1111/j.1559-1816.1995.tb01767.x

Nay, W. R. (2014). The anger management workbook: Use the STOP method to replace destructive responses with constructive behavior. New York, NY: The Guilford Press.

Norman, P., \& Conner, M. (2006). The theory of planned behaviour and binge drinking: Assessing the moderating role of past behaviour within the theory of planned behaviour. British Journal of Health Psychology, 11, 55-70. doi: 10.1348/135910705X43741

Norman, P., Conner, M., \& Bell, R. (1999). The theory of planned behavior and smoking cessation. Health Psychology, 18, 89. doi: 10.1037/0278-6133.18.1.89

Norman, P., \& Cooper, Y. (2011). The theory of planned behaviour and breast self-examination: Assessing the impact of past behaviour, context stability and habit strength. Psychology \& Health, 26, 1156-1172. doi: 10.1080/08870446.2010.481718 
Nosek, B. A. (2007). Implicit-explicit relations. Current Directions in Psychological Science, 16, 65-69. doi: 10.1111/j.1467-8721.2007.00477.x

Nosek, B. A., Greenwald, A. G., \& Banaji, M. R. (2005). Understanding and using the Implicit Association Test: II. Method variables and construct validity. Personality and Social Psychology Bulletin, 31, 166-180. doi: 10.1177/0146167204271418

Nosek, B. A., \& Smyth, F. L. (2007). A multitrait-multimethod validation of the Implicit Association Test: Implicit and explicit attitudes are related but distinct constructs. Experimental Psychology, 54, 14-29. doi: 10.1027/1618-3169.54.1.14

Nunes, K. L., Ennis, L., Hermann, C. A., Maimone, S. M., \& Choy, A. L. (2014). Four approaches to measuring attitudes towards violence: Beliefs, explicit evaluation, outcome expectancies, and implicit evaluation. Manuscript submitted for publication.

Nunes, K. L., Hermann, C. A., \& Ratcliffe, K. (2013). Implicit and explicit attitudes toward rape are associated with sexual aggression. Journal of Interpersonal Violence, 28, 26572675. doi: $10.1177 / 0886260513487995$

Nyhus, E., \& Barceló, F. (2009). The Wisconsin Card Sorting Test and the cognitive assessment of prefrontal executive functions: a critical update. Brain and Cognition, 71, 437-451.doi: 10.1016/j.bandc.2009.03.005

Ogden, J. (2003). Some problems with social cognition models: a pragmatic and conceptual analysis. Health Psychology, 22, 424. doi: 10.1037/0278-6133.22.4.424

Olson, M. A., \& Fazio, R. H. (2004). Reducing the influence of extrapersonal associations on the Implicit Association Test: personalizing the IAT. Journal of Personality and Social Psychology, 86, 653-667. doi: 10.1037/0022-3514.86.5.653

Olson, J. M., \& Zanna, M. P. (1993). Attitudes and attitude change. Annual Review of 
Psychology, 44, 117-154. doi: 10.1146/annurev.psych.121208.131609.

Orpinas, P., Murray, N., \& Kelder, S. (1999). Parental influences on students' aggressive behaviors and weapon carrying. Health Education and Behavior, 37, 774-787. doi: $10.1177 / 109019819902600603$

Palmer, R. S., McMahon, T. J., Rounsaville, B. J., \& Ball, S. A. (2010). Coercive sexual experiences, protective behavioral strategies, alcohol expectancies and consumption among male and female college students. Journal of Interpersonal Violence, 25, 15631578. doi: $10.1177 / 0886260509354581$

Papadopoulos, C., Ross, J., Stewart, D., Dack, C., James, K., \& Bowers, L. (2012). The antecendents of violence and aggression within psychiatric inpatient settings. Acta Psychiatrica Scandinavica, 125, 425-439. doi: 10.1111/j.1600-0447.2012.01827.x

Parker, D., Manstead, A. S., Stradling, S. G., Reason, J. T., \& Baxter, J. S. (1992). Intention to commit driving violations: an application of the theory of planned behavior. Journal of Applied Psychology, 77, 94-101. doi: 10.1037/0021-9010.77.1.94

Phillips, J. P. (2011). Construct validity of a laboratory aggression paradigm: A multitraitmultimethod approach. University of Kentucky Doctoral Dissertations. Paper 131.

Poulin, F., \& Boivin, M. (2000). Reactive and proactive aggression: evidence of a two-factor model. Psychological Assessment, 12, 115-122. doi: 10.1037/1040-3590.12.2.115

Rabin, L. A., Barr, W. B., \& Burton, L. A. (2005). Assessment practices of clinical neuropsychologists in the United States and Canada: A survey of INS, NAN, and APA Division 40 members. Archives of Clinical Neuropsychology, 20, 33-65. doi: 10.1016/j.acn.2004.02.005

Ramirez, J. M. (2009). Some dychotomous classifications of aggression according to its 
function. Journal of Organisational Transformation \& Social Change, 6, 85-101. doi: 10.1386/jots.6.2.85_1

Reitan, R. M., \& Wolfson, D. (1995). Category test and trail making test as measures of frontal lobe functions. Clinical Neuropsychologist, 9, 50-56.doi : 10.1080/13854049508402057

Richetin, J., Richardson, D. S., \& Mason, G. D. (2010). Predictive validity of IAT aggressiveness in the context of provocation. Social Psychology, 41, 27-34. doi: $10.1027 / 1864-9335 / \mathrm{a} 000005$

Roberto, A. J., Meyer, G., Boster, F. J., \& Roberto, H. L. (2003). Adolescents' decisions about verbal and physical aggression. Human Communication Research, 29, 135-147. doi: 10.1111/j.1468-2958.2003.tb00834.x

Robertson, K., \& Murachver, T. (2007). Correlates of partner violence for incarcerated women and men. Journal of Interpersonal Violence, 22, 639-655. doi: $10.1177 / 0886260506298835$.

Robinson, M. D., Fetterman, A. K., Hopkins, K., \& Krishnakumar, S. (2013). Losing one's cool: Social competence as a novel inverse predictor of provocation-related aggression. Personality and Social Psychology Bulletin, 39, 1268-1279. doi: $10.1177 / 0146167213490642$

Robinson, M. D., Meier, B. P., Zetocha, K. J., \& McCaul, K. D. (2005). Smoking and the Implicit Association Test: When the contrast category determines the theoretical conclusions. Basic and Applied Social Psychology, 27, 201-212. doi: 10.1207/s15324834basp2703_2

Rose-Krasnor, L. (1997). The nature of social competence: A theoretical review. Social Development, 6, 111-135. doi: 10.1111/j.1467-9507.1997.tb00097.x 
Rothermund, K., \& Wentura, D. (2004). Underlying processes in the implicit association test: dissociating salience from associations. Journal of Experimental Psychology: General, 133, 139-165. doi: 10.1037/0096-3445.133.2.139

Shorey, R. C., Cornelius, T. L., \& Bell, K. M. (2008). A critical review of theoretical frameworks for dating violence: Comparing the dating and marital fields. Aggression and Violent Behavior, 13, 185-194. doi: 10.1016/j.avb.2008.03.003

Shorey, R. C., Stuart, G. L., \& Cornelius, T. L. (2011). Dating violence and substance use in college students: A review of the literature. Aggression and violent behavior, 16, 541550. doi: 10.1016/j.avb.2011.08.003

Sidanius, J., Pratto, F., \& Bobo, L. (1996). Racism, conservatism, affirmative action, and intellectual sophistication: A matter of principled conservatism or group dominance? Journal of Personality and Social Psychology, 70, 476-490. doi: 10.1037/00223514.70.3.476

Simkin, M. G., \& McLeod, A. (2010). Why do college students cheat? Journal of Business Ethics, 94, 441-453. doi: 10.1007/s10551-009-0275-x

Simons-Morton, B., Haynie, D., Crump, A., Saylor, K., Eitel, P., \& Yu, K. (1999). Expectancies and other psychosocial factors associated with alcohol use among early adolescent boys and girls. Addictive Behaviors, 24, 229-238. doi: 10.1016/S0306-4603(98)00095-1

Smithmyer, C. M., Hubbard, J. A., \& Simons, R. F. (2000). Proactive and reactive aggression in delinquent adolescents: Relations to aggression outcome expectancies. Journal of Clinical Child Psychology, 29, 86-93. doi: 10.1207/S15374424jccp2901_9

Spence, A., \& Townsend, E. (2007). Predicting behaviour towards genetically modified food using implicit and explicit attitudes. British Journal of Social Psychology, 46, 437-457. 
doi: $10.1348 / 014466606 \times 152261$

Storch, E. A., Bagner, D. M., Geffken, G. R., \& Baumeister, A. L. (2004). Association between overt and relational aggression and psychosocial adjustment in undergraduate college students. Violence and Victims, 19, 689-700. doi: 10.1891/vivi.19.6.689.66342

Strack, F., \& Deutsch, R. (2004). Reflective and impulsive determinants of social behavior. Personality and Social Psychology Review, 8, 220-247. doi:

10.1207/s15327957pspr0803_1

Straus, M. A. (2004). Prevalence of violence against dating partners by male and female university students worldwide. Violence Against Women, 10, 790-811. doi: $10.1177 / 1077801204265552$

Stueve, A., O'Donnell, L., \& Link, B. (2001). Gender differences in risk factors for violent behavior among economically disadvantaged African American and Hispanic young adolescents. International Journal of Law and Psychiatry, 24, 539-557. doi: $10.1016 / \mathrm{S} 0160-2527(01) 00083-8$

Sutton, S., French, D. P., Hennings, S. J., Mitchell, J., Wareham, N. J., Griffin, S., ... \& Kinmonth, A. L. (2003). Eliciting salient beliefs in research on the theory of planned behaviour: The effect of question wording. Current Psychology, 22, 234-251. doi: $10.1007 / \mathrm{s} 12144-003-1019-1$

Taylor, S. P. (1967). Aggressive behavior and physiological arousal as a function of provocation and the tendency to inhibit aggression. Journal of Personality, 35, 297-310. doi: 10.1111/j.1467-6494.1967.tb01430.x

Teubel, T., Asendorpf, J. B., Banse, R., \& Schnabel, K. (2011). Implicit but not explicit 
aggressiveness predicts performance outcome in basketball players. International Journal of Sport Psychology, 42, 390-400. doi:

Thompson, M. P., Koss, M. P., Kingree, J. B., Goree, J., \& Rice, J. (2011). A prospective meditational model of sexual aggression among college men. Journal of Interpersonal Violence, 26, 2716-2734. doi: 10.1177/0886260510388285

Tolman, R. M., Edleson, J. L., \& Fendrich, M. (1996). The applicability of the theory of planned behavior to abusive men's cessation of violent behavior. Violence and Victims, 11, 341354.

Tonglet, M., Phillips, P. S., \& Read, A. D. (2004). Using the Theory of Planned Behaviour to investigate the determinants of recycling behaviour: a case study from Brixworth, UK. Resources, Conservation, and Recycling, 41, 191-214. doi:

10.1016/j.resconrec.2003.11.001

Trafimow, D., Sheeran, P., Conner, M., \& Finlay, K.A. (2002). Evidence that perceived behavioural control is a multidimensional construct: Perceived control and perceived difficulty. British Journal of Social Psychology, 41, 101-121. doi:

$10.1348 / 014466602165081$

Tremblay, P. F., Graham, K., \& Wells, S. (2008a). Severity of physical aggression reported by university students: A test of the interaction between trait aggression and alcohol consumption. Personality and Individual Differences, 45, 3-9. doi:

10.1016/j.paid.2008.02.008

Tremblay, P. F., Harris, R., Berman, H., MacQuarrie, B., Hutchinson, G. E., Smith, M., ... \& Dearlove, K. (2008b). Negative social experiences of university and college students. Canadian Journal of Higher Education, 38, 57-75. 
Turchik, J. A. (2010). The prediction of sexual risk behaviors among college students using the theory of planned behavior. Proquest Dissertations \& Theses. Paper 3423540

Twenge, J. M., Baumeister, R. F., Tice, D. M., \& Stucke, T. S. (2001). If you can't join them, beat them: Effects of social exclusion on aggressive behavior. Journal of Personality and Social Psychology, 81,1058-1069.

Valliant, P. M., Gristey, C., Pottier, D., \& Kosmyna, R. (1999). Risk factors in violent and nonviolent offenders. Psychological Reports, 85, 675-680.

Vazire, S. \& Funder, D. (2006). Impulsivity and the self-defeating behavior of narcissists. Personality and Social Psychology Review, 10, 154-165. doi: $10.1207 / \mathrm{s} 15327957$ pspr1002_4

Vogt, W. P. (1993). Dictionary of statistics and methodology. Newbury Park, CA: Sage.

Wei, H., \& Jonson-Reid, M. (2011). Friends can hurt you: Examining the coexistence of friendship and bullying among early adolescents. School Psychology International, 32, 244-262. doi: 10.1177/0143034311402310

Wicker, A. W. (1969). Attitudes versus actions: The relationship of verbal and overt behavioral responses to attitude objects. Journal of Social Issues, 25, 41-78. doi: 10.1111/j.15404560.1969.tb00619.x

Wilkowski, B. M., \& Robinson, M. D. (2010). The anatomy of anger: An integrative cognitive model of trait anger and reactive aggression. Journal of Personality, 78, 9-38.

Wooldredge, J., \& Steiner, B. (2013). Violent victimization among state prison inmates. Violence and Victims, 28, 531-551. doi: 10.1891/0886-6708.11-00141

Zeichner, A., Frey, F. C., Parrott, D. J., \& Butryn, M. F. (1999). Measurement of laboratory 
aggression: A new response-choice paradigm. Psychological Reports, 85, 1229-1237. doi: 10.2466/pr0.1999.85.3f.1229

Zeichner, A., \& Pihl, R. O. (1979). Effects of alcohol and behavior contingencies on human aggression. Journal of Abnormal Psychology, 88, 153-160. doi: 10.1037/0021843X.88.2.153 